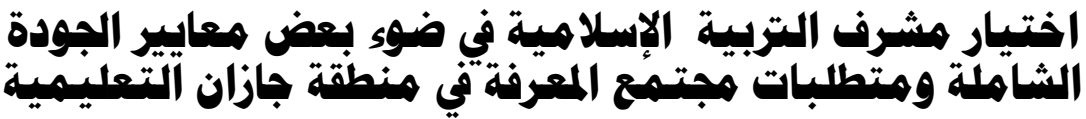

داه فوزي بن صالح بنجـــر

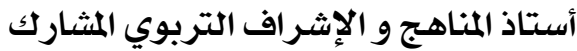

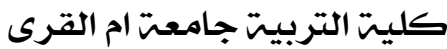

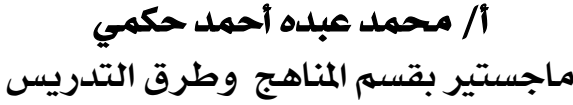

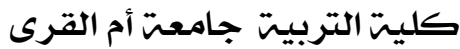

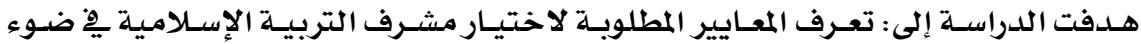

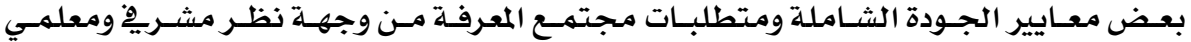

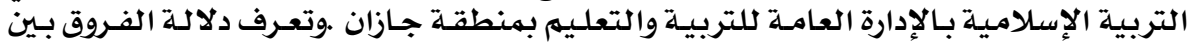

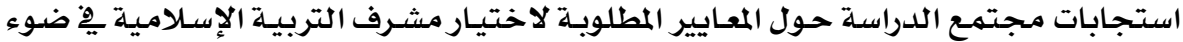

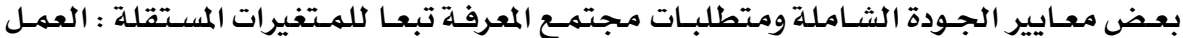

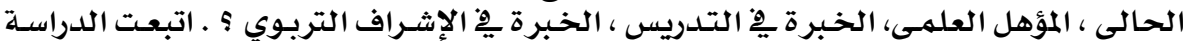

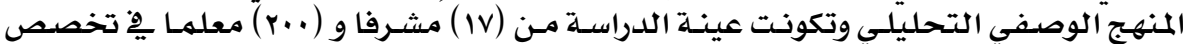

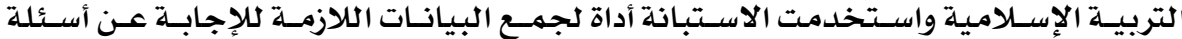

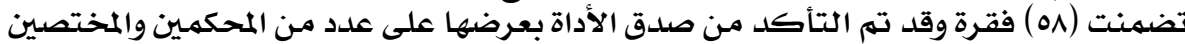

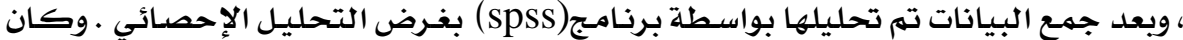

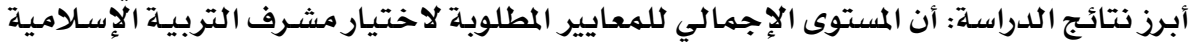

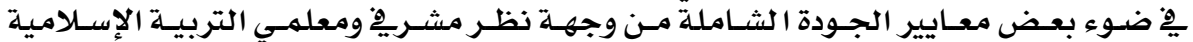

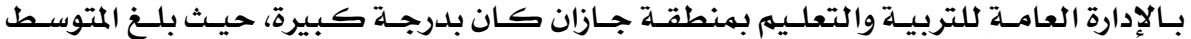

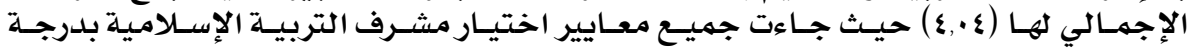

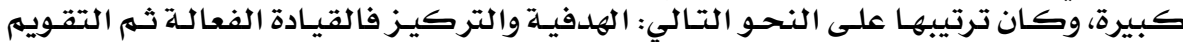

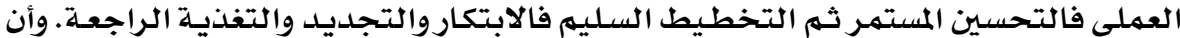

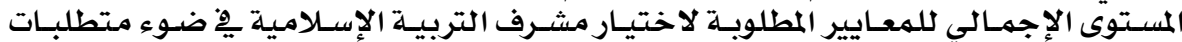

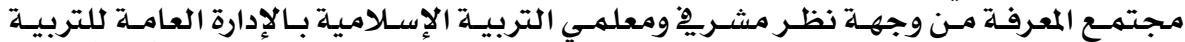

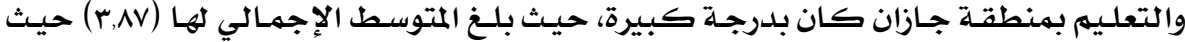

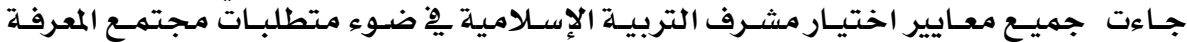

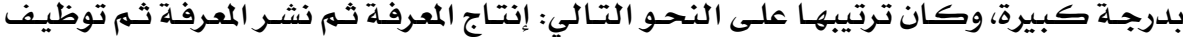
المعرفة.

الكلمات المفتاحية : مشرف التربية الإسلامية، معايير الجودة الشاملة ، مجتمع المعرفة

Choosing the Islamic Education Supervisors in Light of Some Standards of the Comprehensive Quality and Requirements of the Knowledge Community In Jazan Educational Zone

\section{Mohammad Abdo Ahmad}

Dr. Fawzi bin Saleh banjar

\section{$\underline{\text { Abstract }}$}

The study objectives as following :identification on the required standards to choose the Islamic education supervisors in light of some standards the comprehensive quality from Pont view of the Islamic education supervisors and teachers at the public directorate for education in Gazan area . identification on the required standards to choose the

\section{$\varepsilon$ Y}




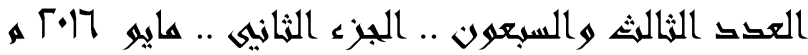

Islamic education supervisors in light of the knowledge community requirements from point view of supervisors and the Islamic education teachers ta the public directorate for education in Gazan area identification on the difference among the study community responses around the some standards to choose the Islamic education supervisor in light of some standards the comprehensive quality and knowledge community requirements according to the independent variables : the present job, the scientific qualification, the experience in teaching, the experience in the education supervision.The study has adopted analytic descriptive method and the study community consists of all Islamic education supervisors and their number (17) supervisors and sample of teachers (200) from the original community. The questionnaire has been used as tool to collect the necessary data for answering about the questions including (58) item and it has been confirmed from truth of the arbitrators and the the specialists.Rate of its content by using Corn Bach Alfa coefficient. (0, 908), so it is valid for studying and after collecting the data, it has been analyzed by (spss) program in purpose of statistical analysis and then using the following ways. The study has showed the following results The results have showed that the total level for the required standards to choose the Islamic education supervisor in light of some comprehensive quality standards from point view of the Islamic education supervisors and teachers at the public directorate for education in Gazan area and the total level was great where the total medium is $(4,04)$ by normative deviation $(0,942)$. It has been noticed that all standards have been rising to choose the Islamic education supervisor, where all standards came very great and its arranged as following.The results have showed that the total level for the required standards to choose the Islamic education supervisor in light of the knowledge community requirements from point view of the Islamic education supervisor and teachers at the public directorate for education in Gazan area, where the total level was great.The total average is $(3,87)$, by normative deviation $(1,012)$ and it has been noticed That all standards to choose the Islamic education supervisor in light of the knowledge community requirements, where all standards came very great and its arrangement as following Providing knowledge, publishing knowledge, and employing knowledge

Key Words: Islamic Education Supervisors, Standards of the Comprehensive Quality, Knowledge Community.

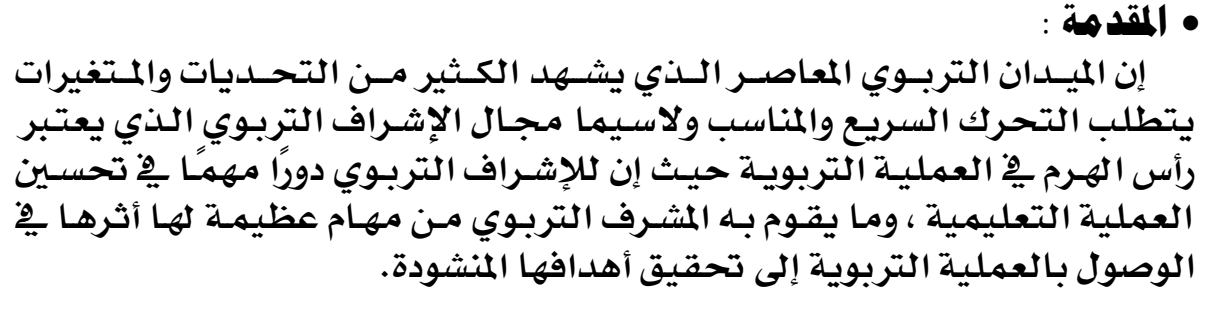

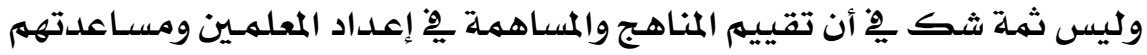

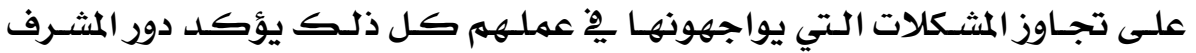

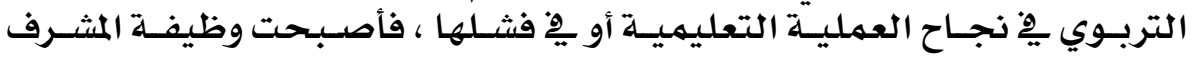




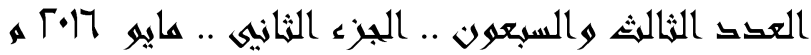

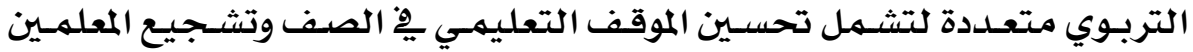

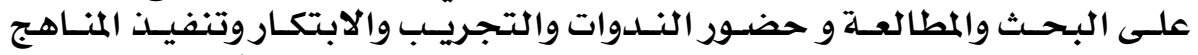

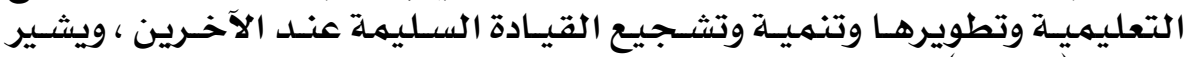

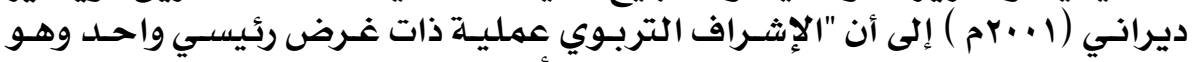

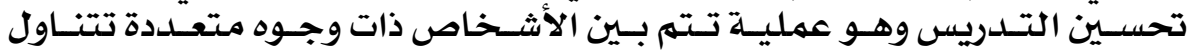

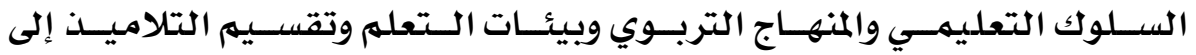

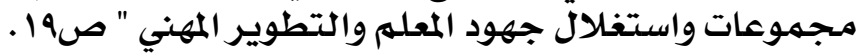

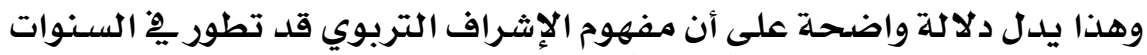

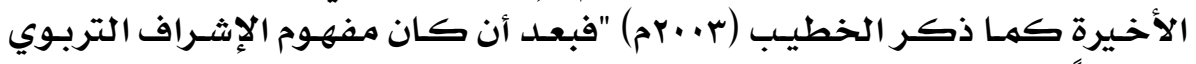

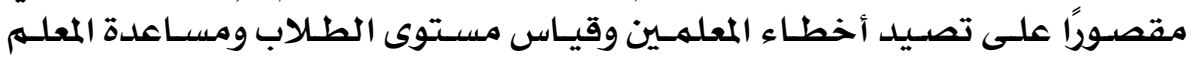

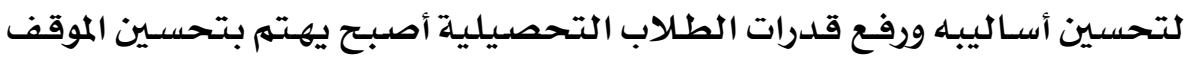

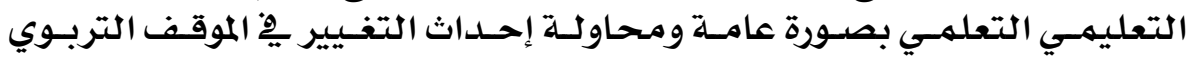

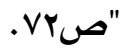

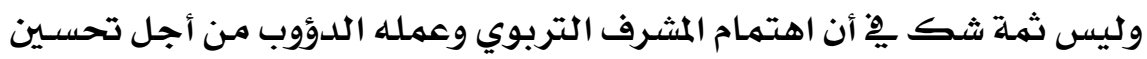

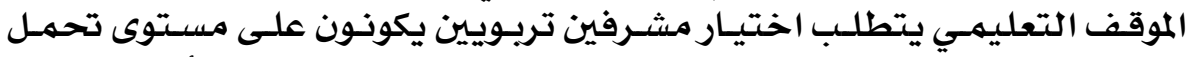

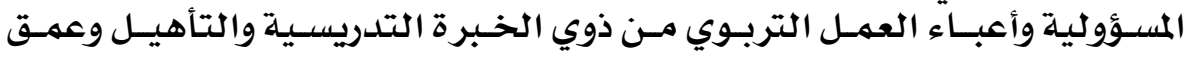

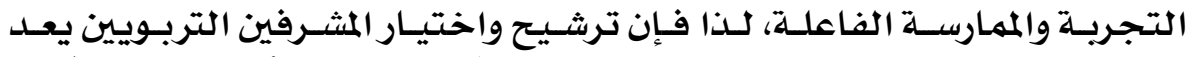

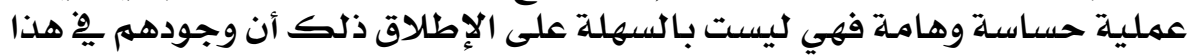

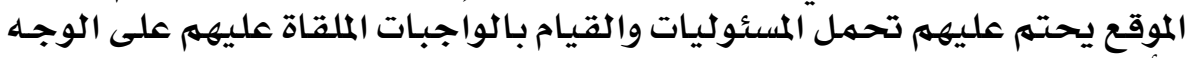

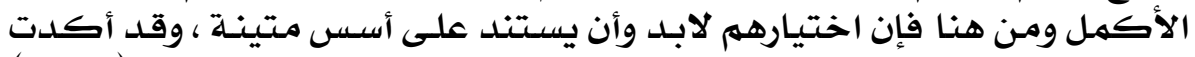

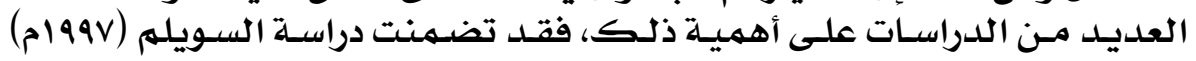

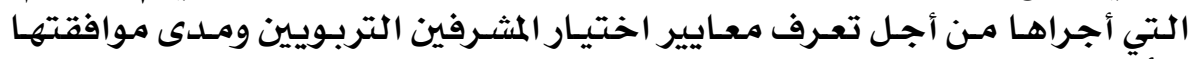

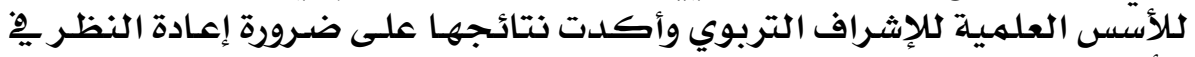

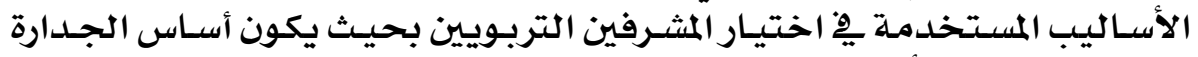

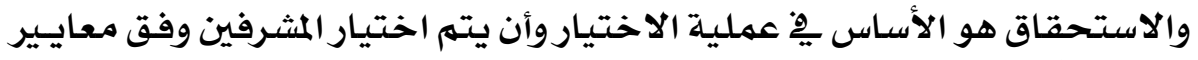
علمية وفنية وواقعيلة هو الاقياق

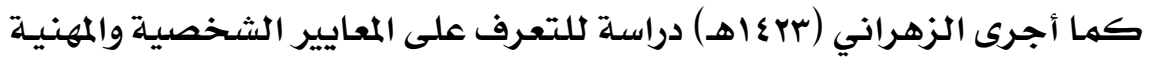

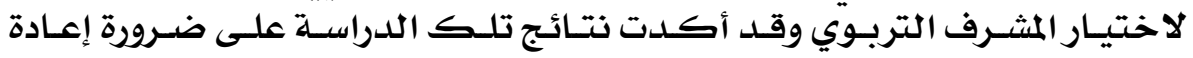

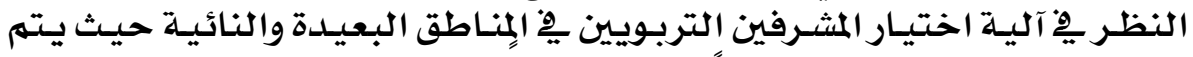

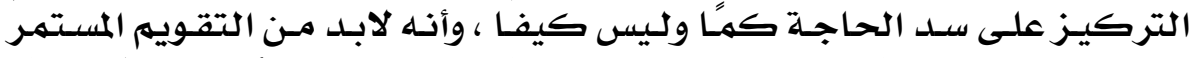

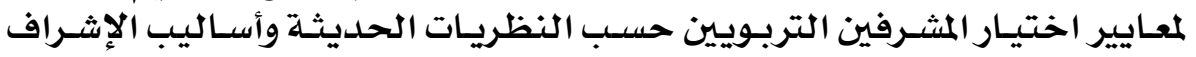

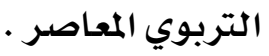

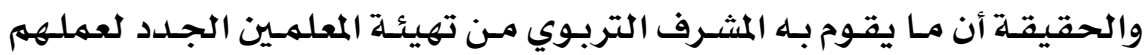

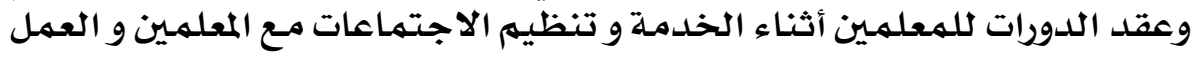

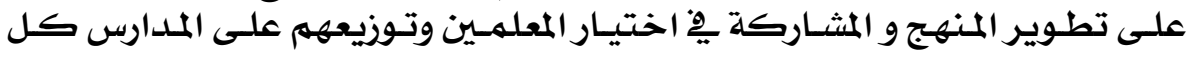

\section{$\varepsilon \varepsilon 1$}




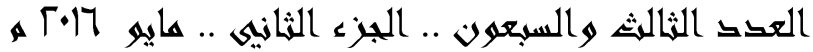

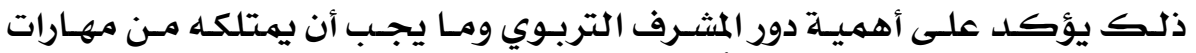

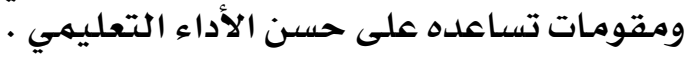

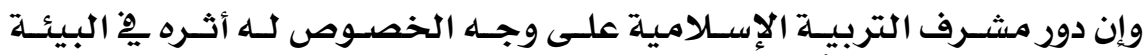

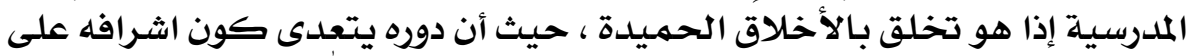

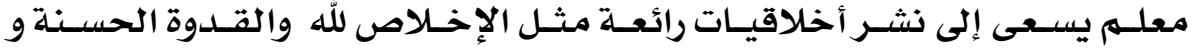

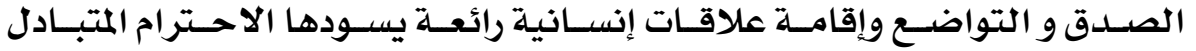

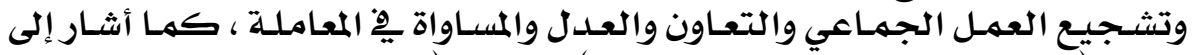

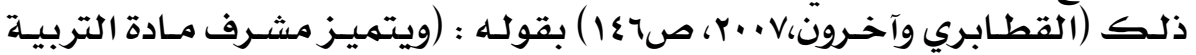

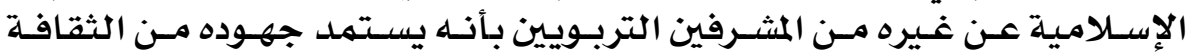

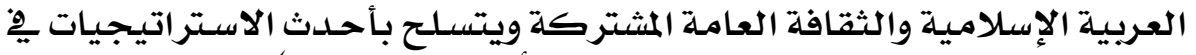

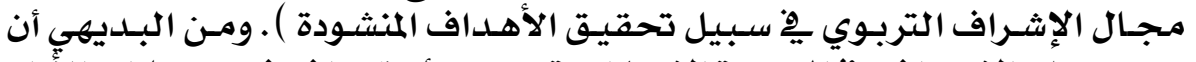

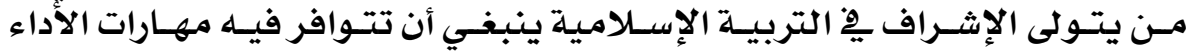

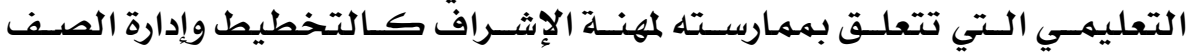

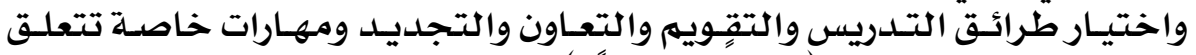

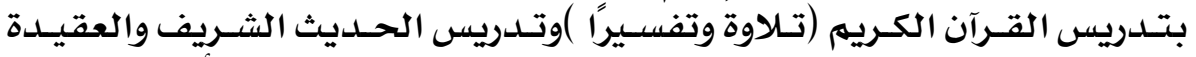

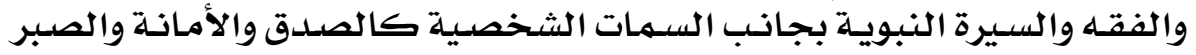

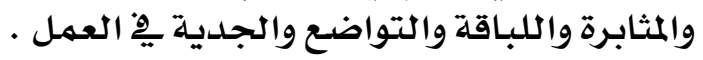

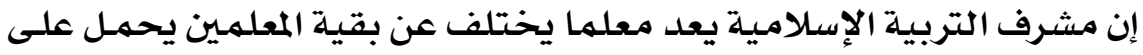

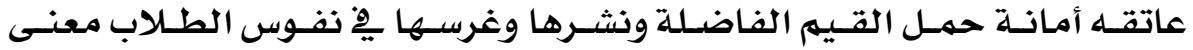

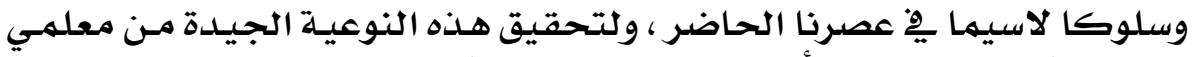

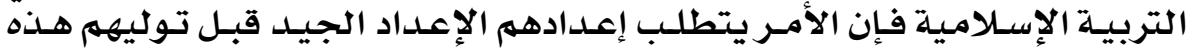

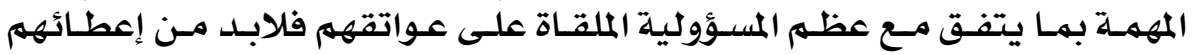

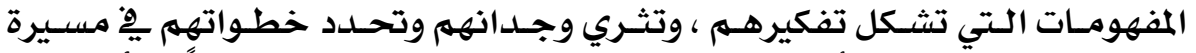

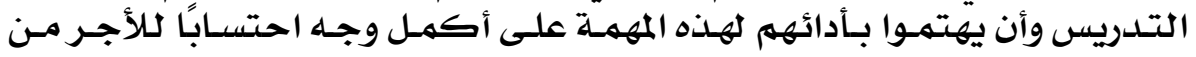

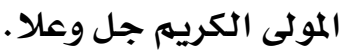

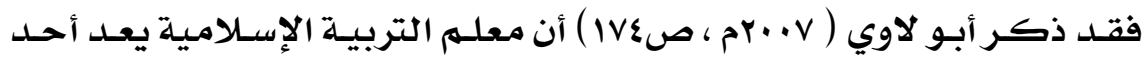

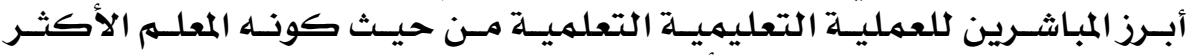

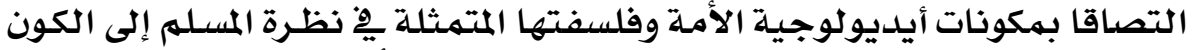

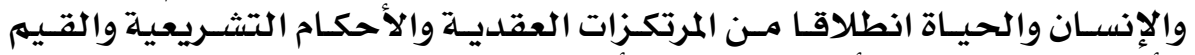

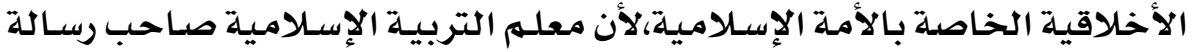

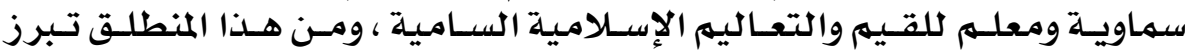

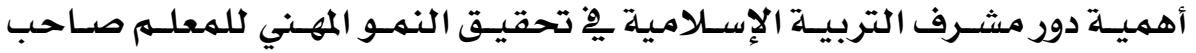

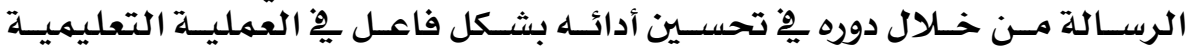

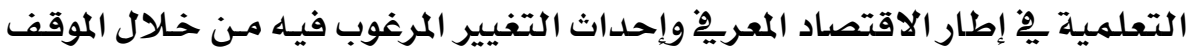

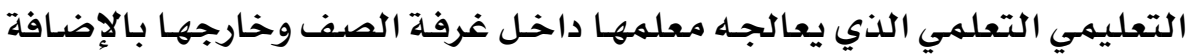

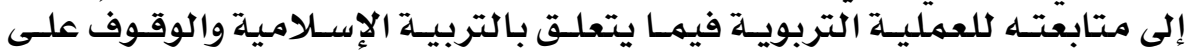

\section{$\varepsilon \varepsilon Y$}




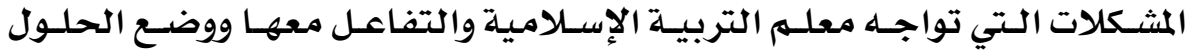

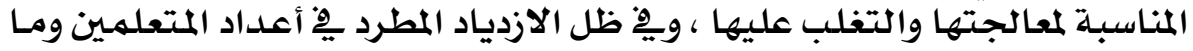

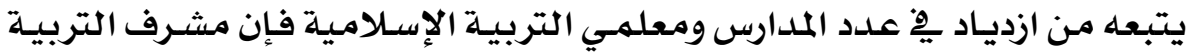

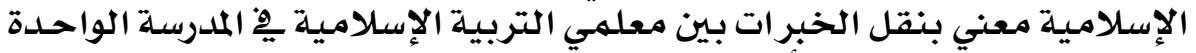

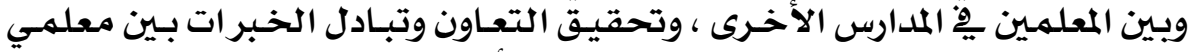

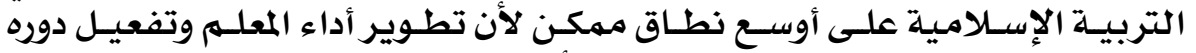

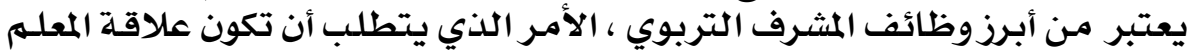

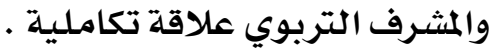

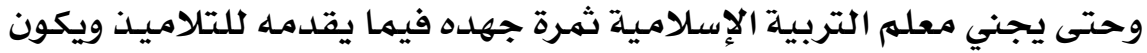

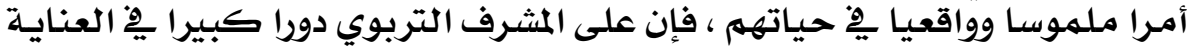

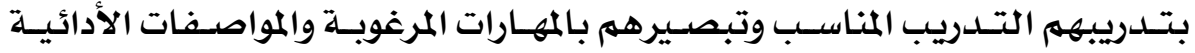

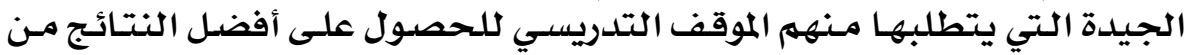

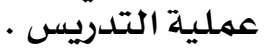

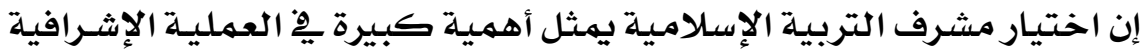

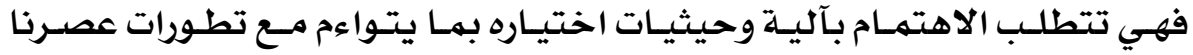

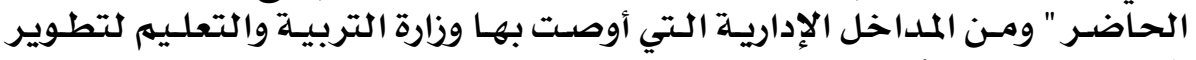

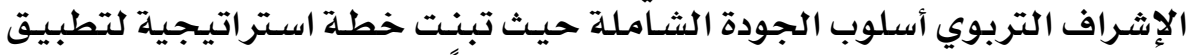

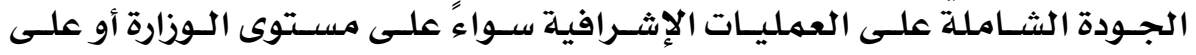

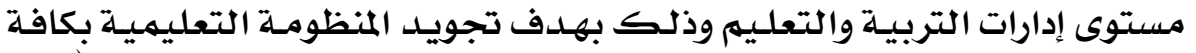

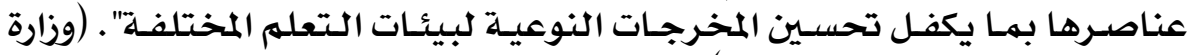

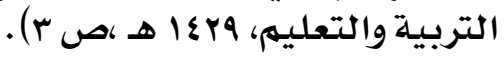

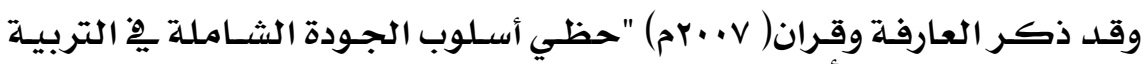

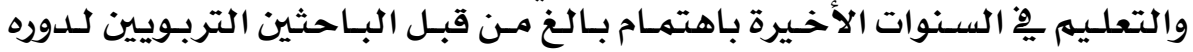

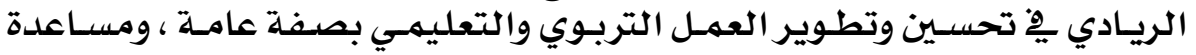

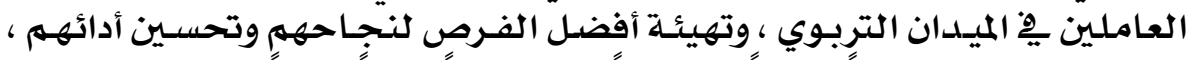

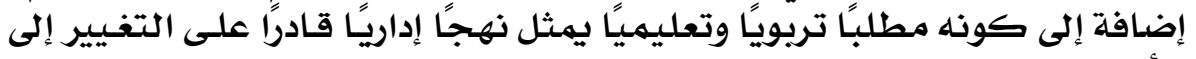

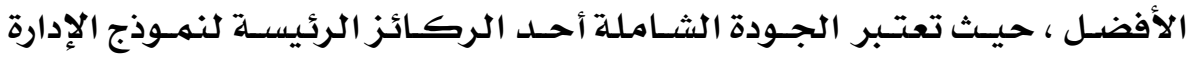

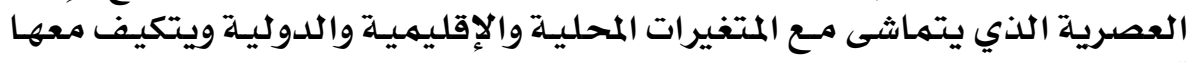

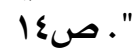

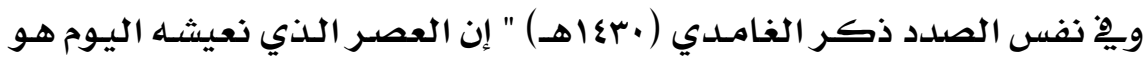

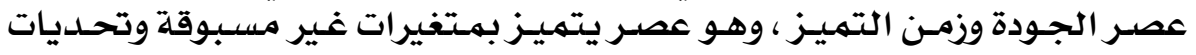

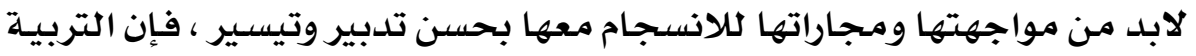

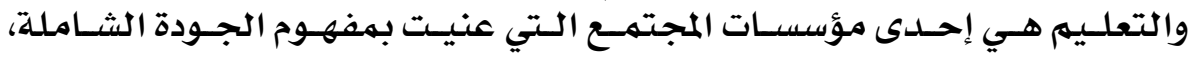

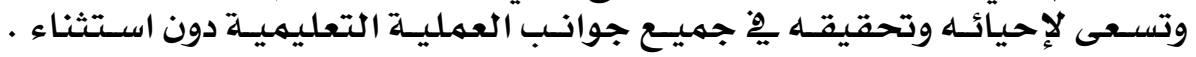

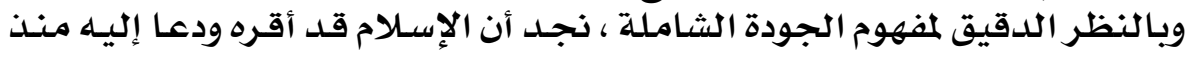

\section{$\varepsilon \varepsilon Y$}




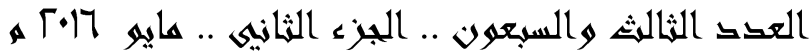

بزوغ فجره، فالإسلام دعا للعلهم وجودته وإتقانه ، مـع إتقـان العمل والإحسـان فيـه ". صع فح فره

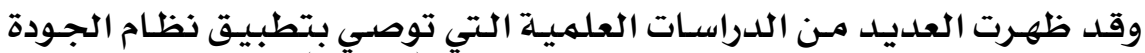

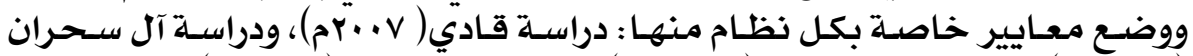

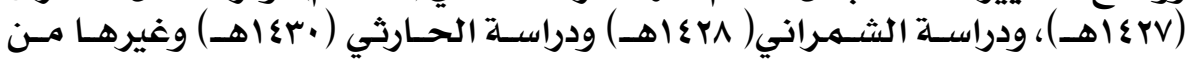
الدراسات .

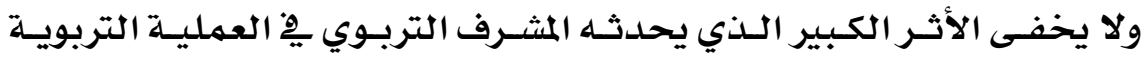

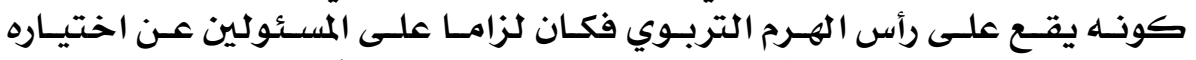

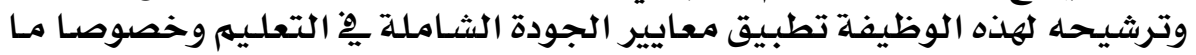

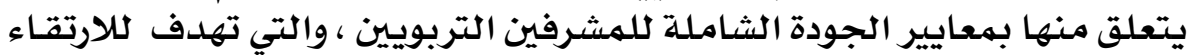

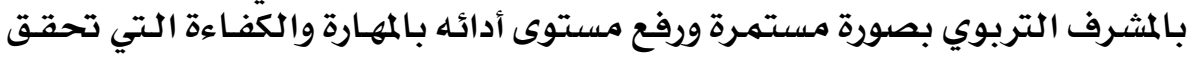

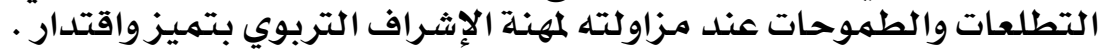

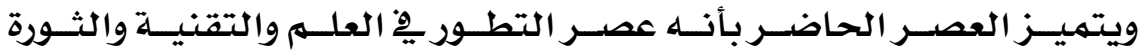

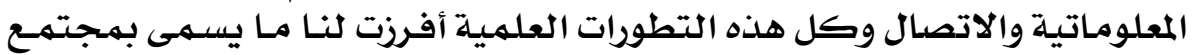

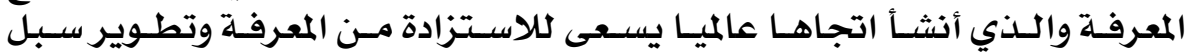

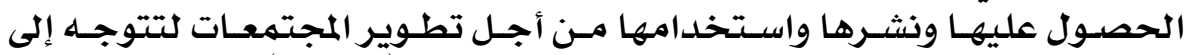

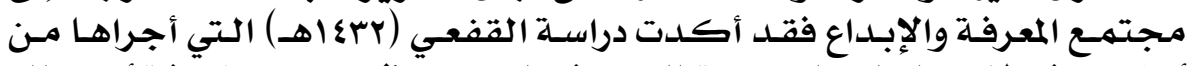

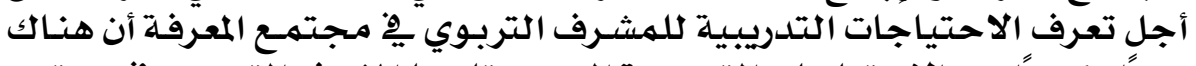

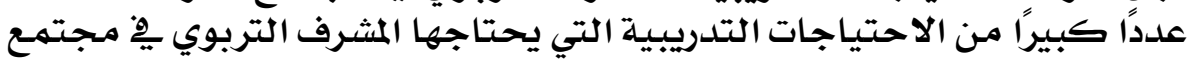

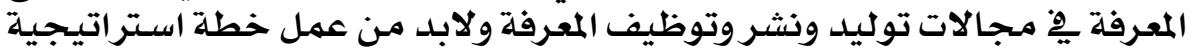

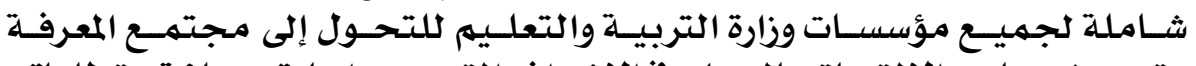

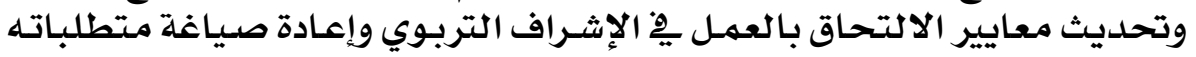

وكفاياته .

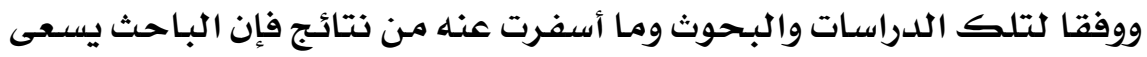

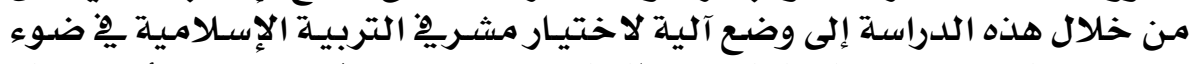

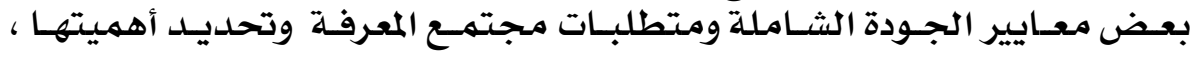

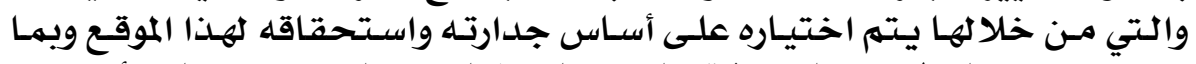

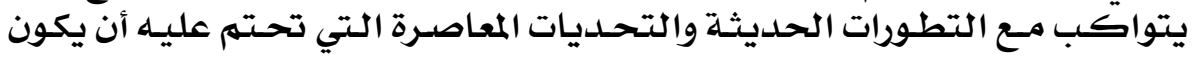

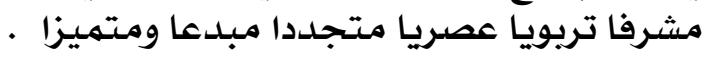

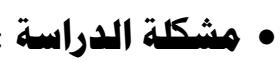

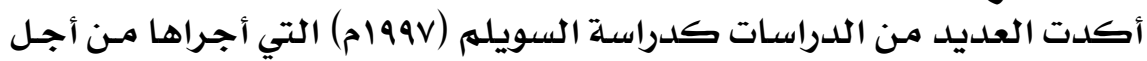

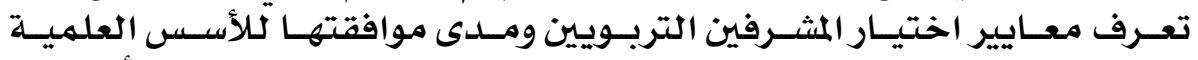

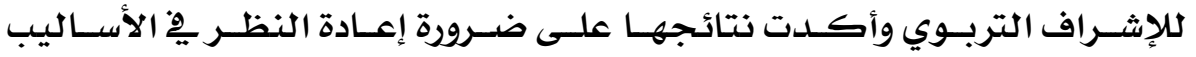

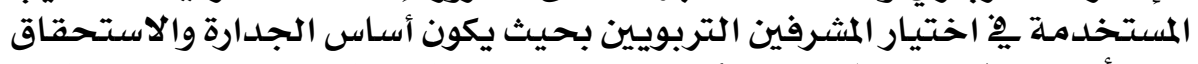

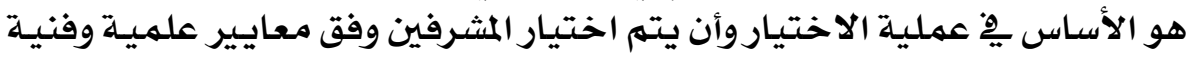

\section{$\varepsilon \varepsilon \varepsilon$}




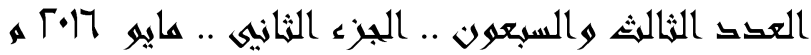

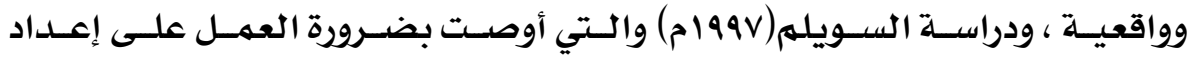

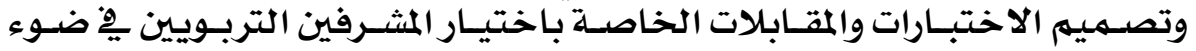

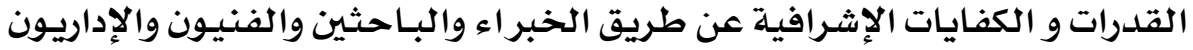

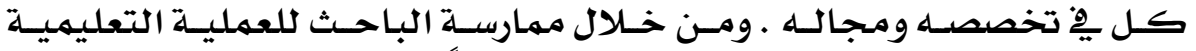

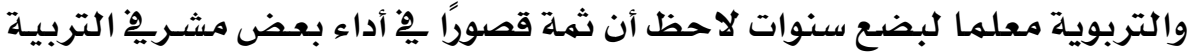

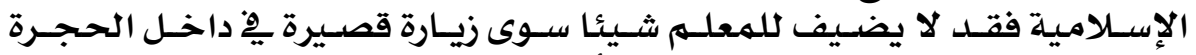

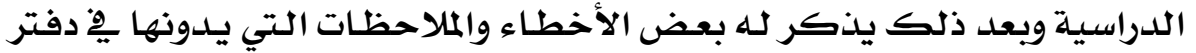

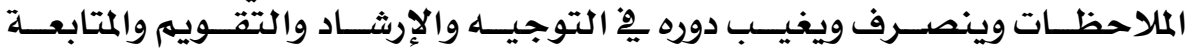

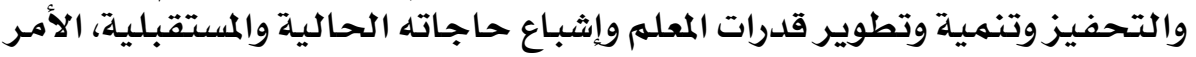

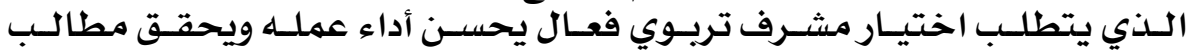

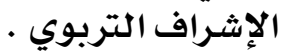

وعلى هذا تتحسد مشكلة الدراسـة يِّ السؤال الرئيس التالي: مـا معايير اختيـار

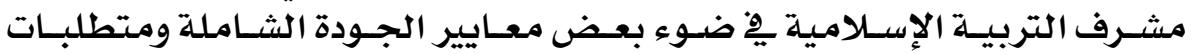

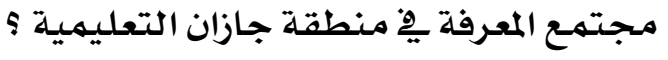
ويتفرع عن هذا السؤال الأسئلة الفرعية التالية :

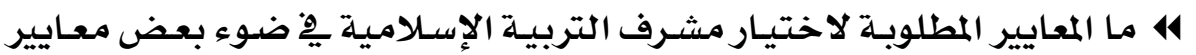

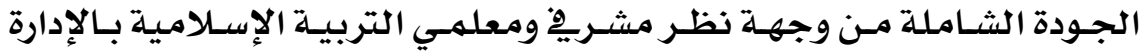

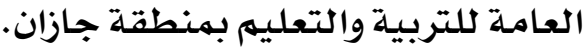

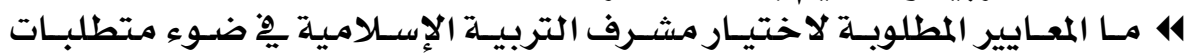

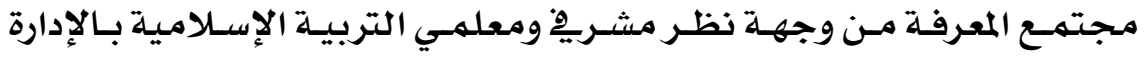

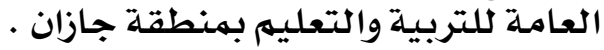

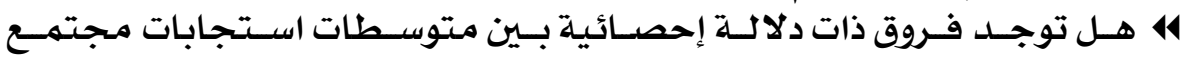

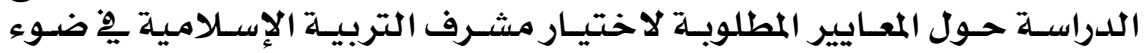

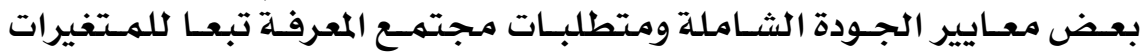

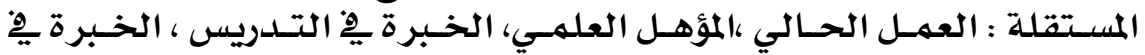

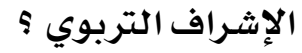

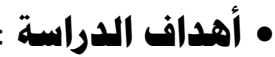

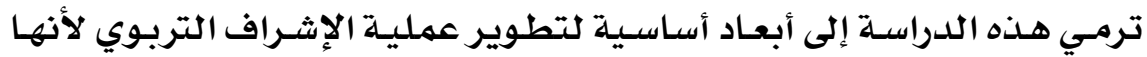

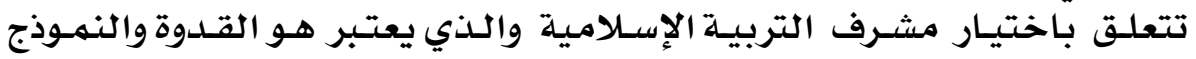

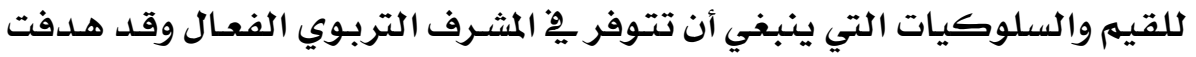
هذه الدراسة إلى : لئه

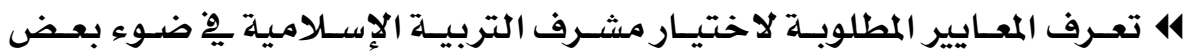

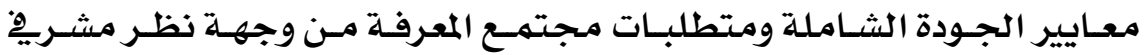

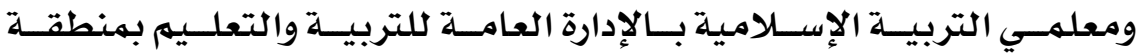

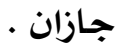

\section{$\varepsilon \leqslant 0$}




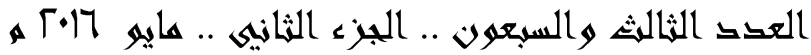

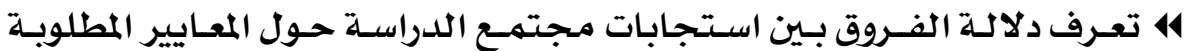

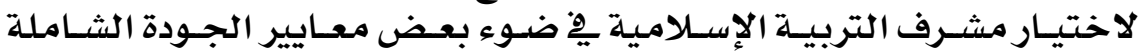

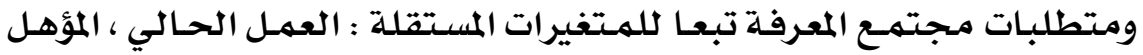

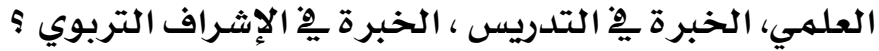

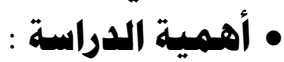

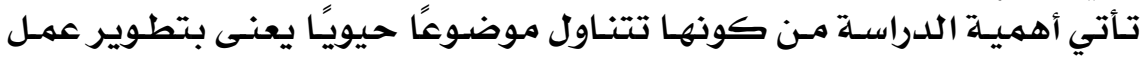

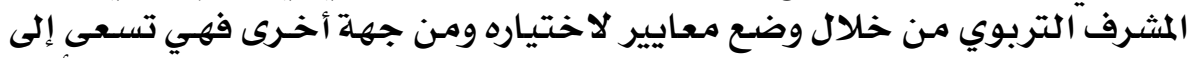

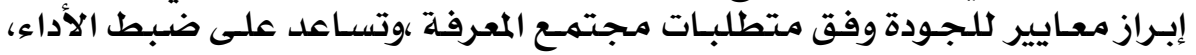

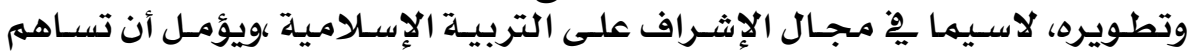
نتائج الدراسة لِية

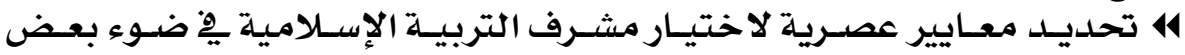

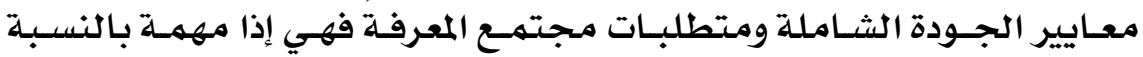

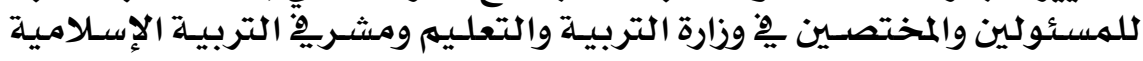

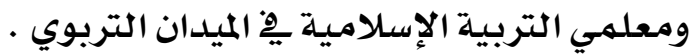

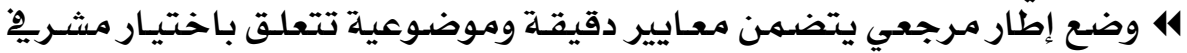

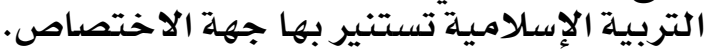

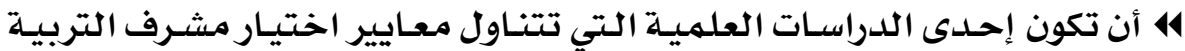

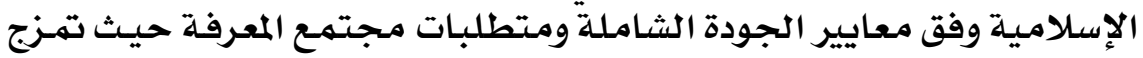

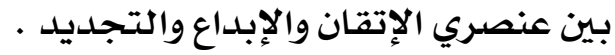

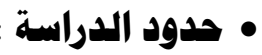
تتناول هذه الدراسة الحدة : الحدود التالية :

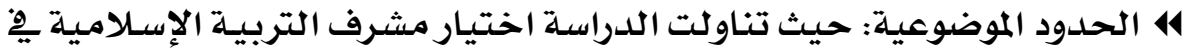

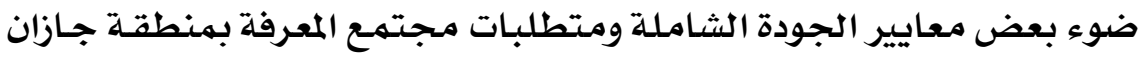
التعليمية.

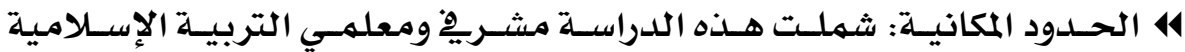

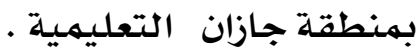

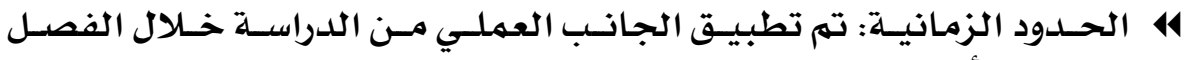

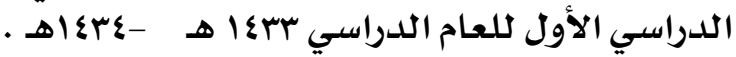

• • •

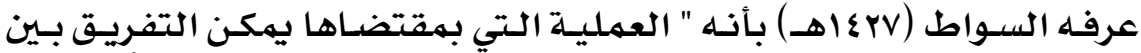

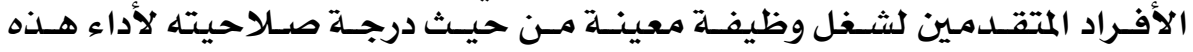

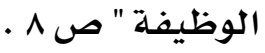

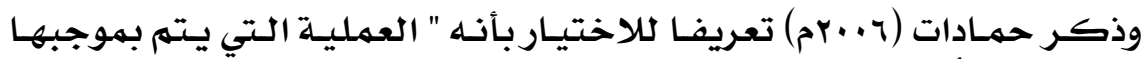

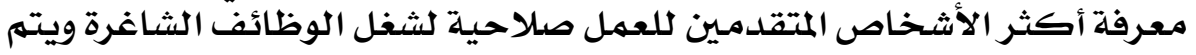

\section{$\varepsilon \varepsilon 7$}




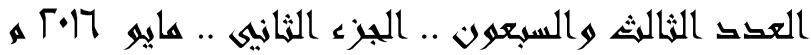

ذلكـ عـن طريـق تعـرف مهارات وقـدرات وشخصـيات طـالبي التوظيف بأسـاليب

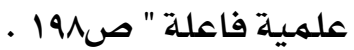

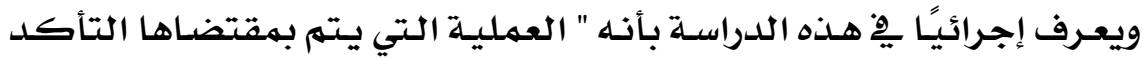

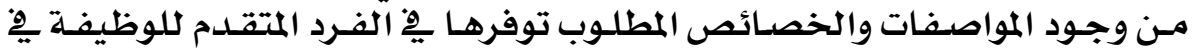

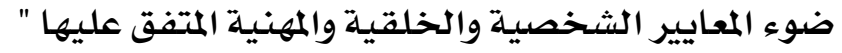

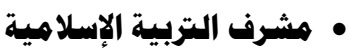

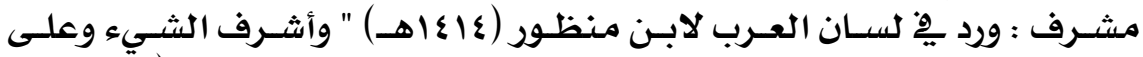

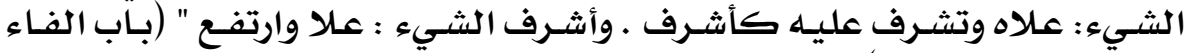

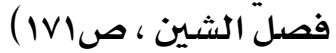

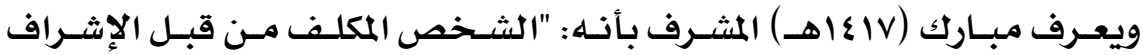

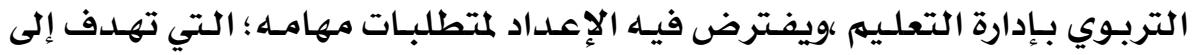

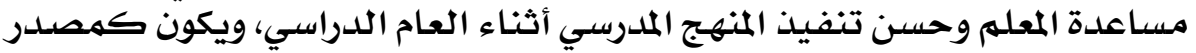

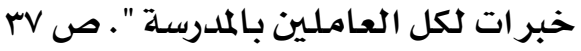

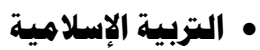

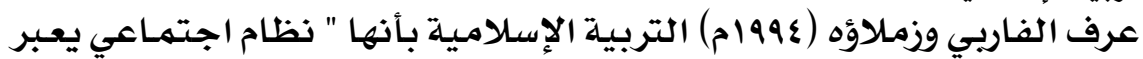

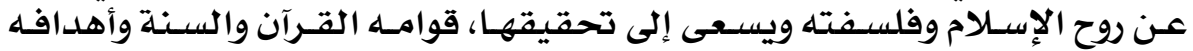

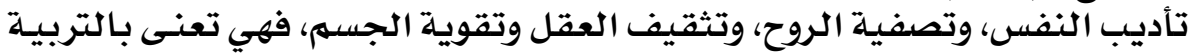

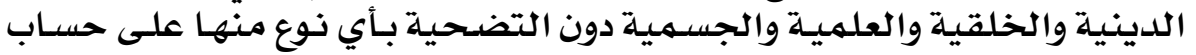

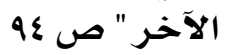

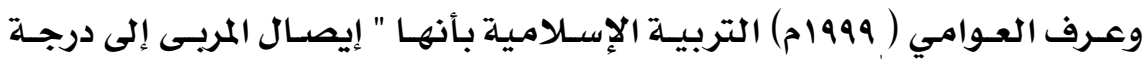

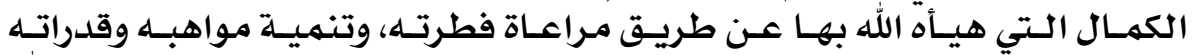

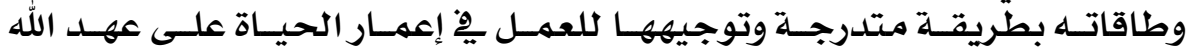

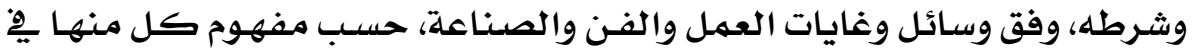

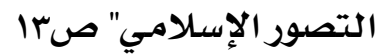

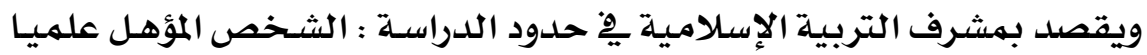

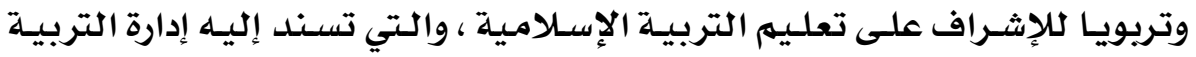

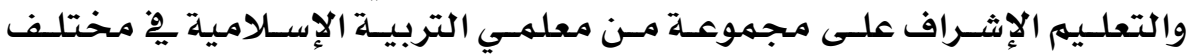

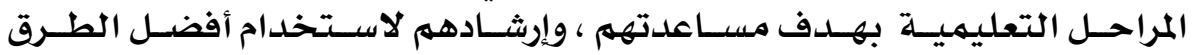

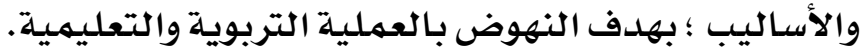

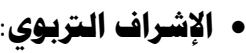

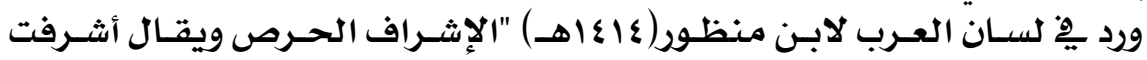

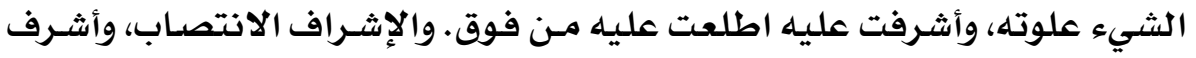

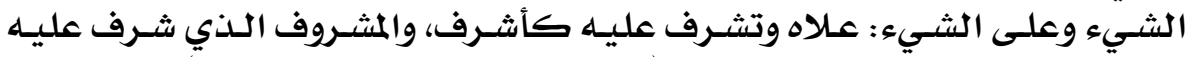

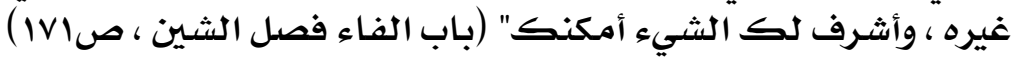

\section{$\varepsilon \varepsilon V$}




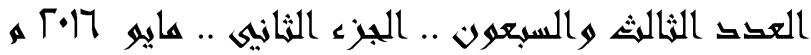

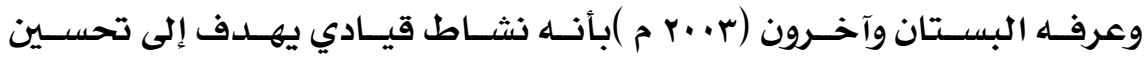

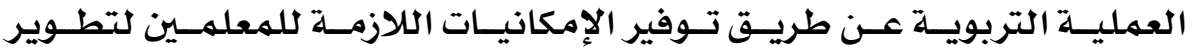

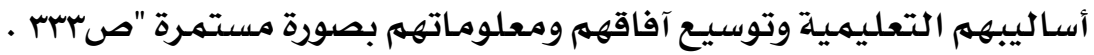

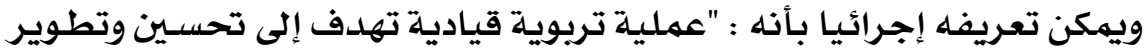

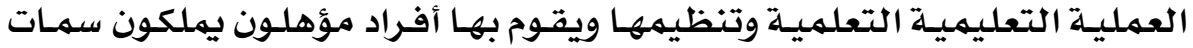

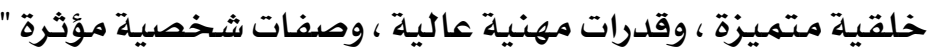

•

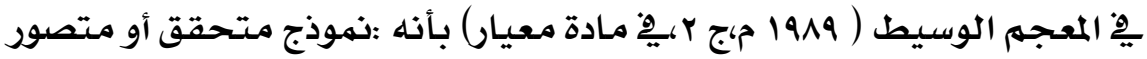

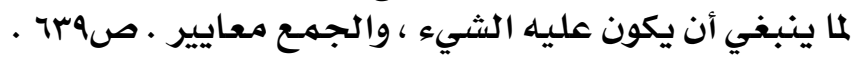

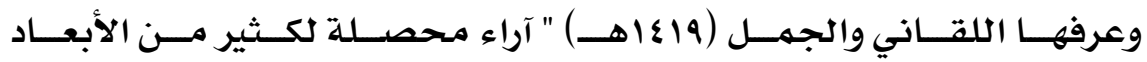

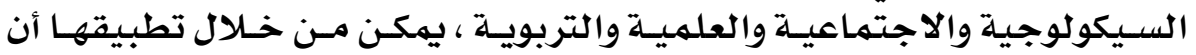

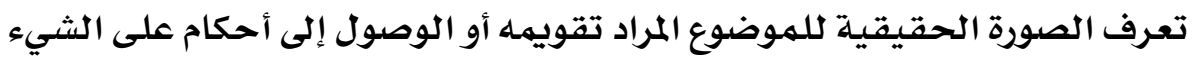

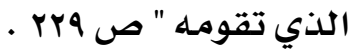

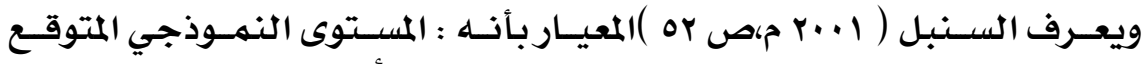

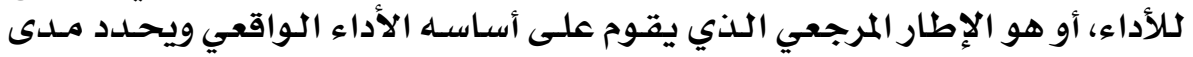
ابتعاده أو اقترابه مـن هذا الإر المرجعي المعيار.

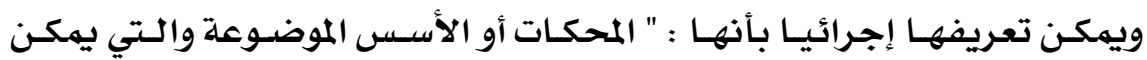

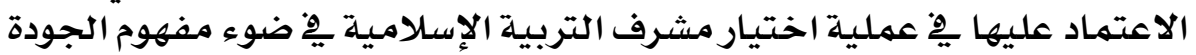

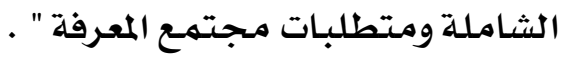

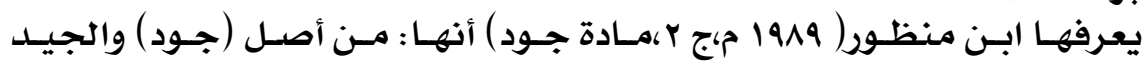

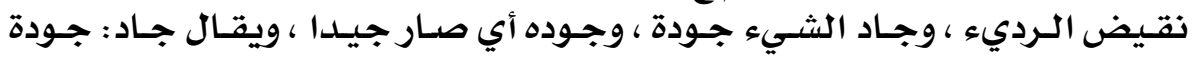

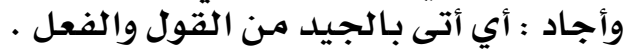

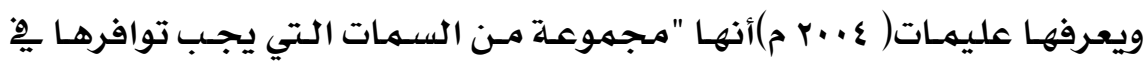

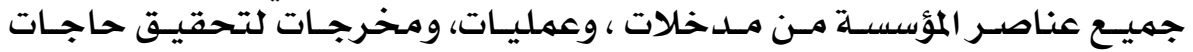

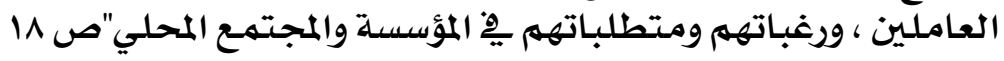

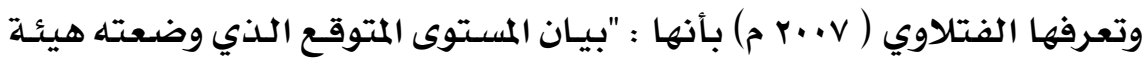

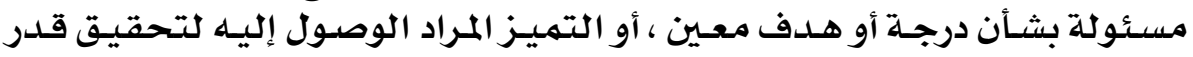

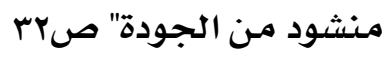

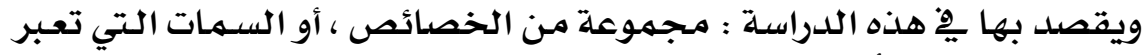

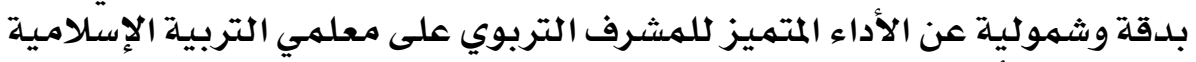

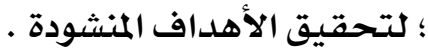

\section{$\varepsilon \varepsilon \wedge$}




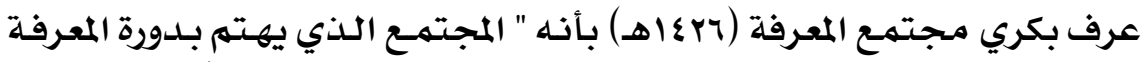

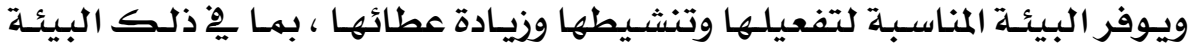

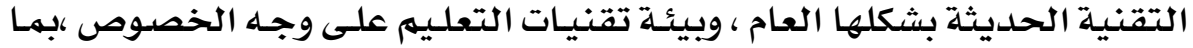

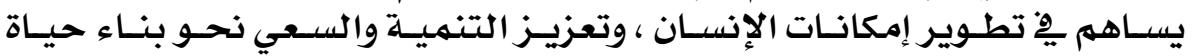

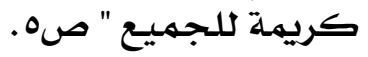

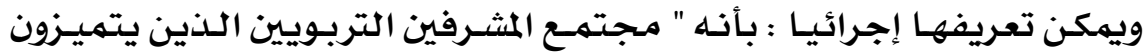

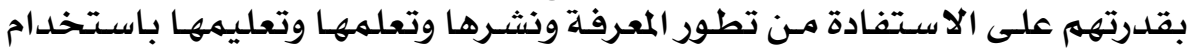

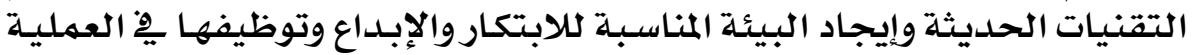

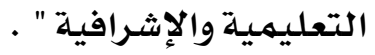

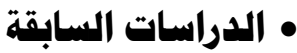

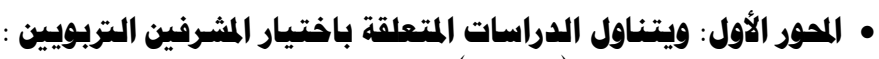

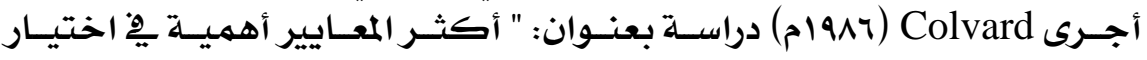

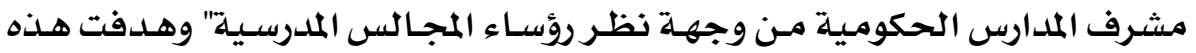

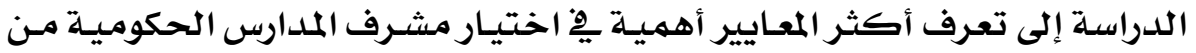

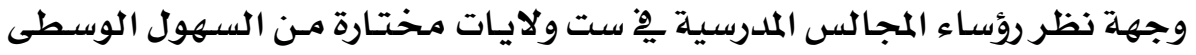

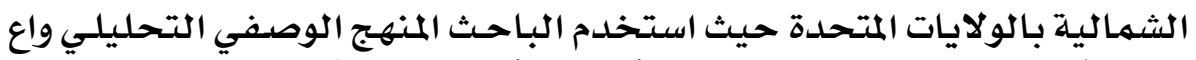

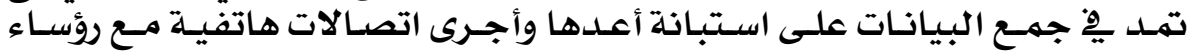
المجالس المدرسية

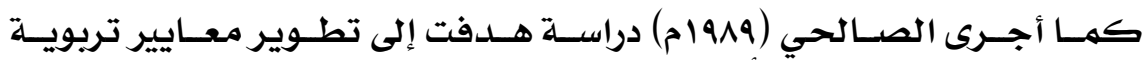

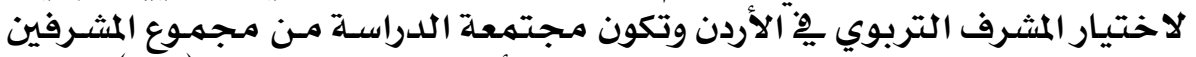

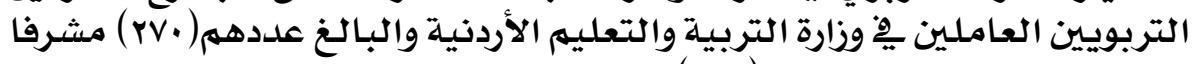

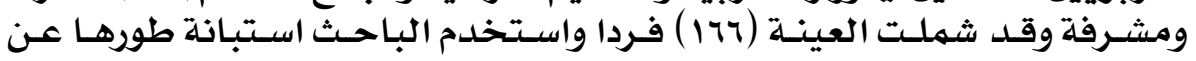

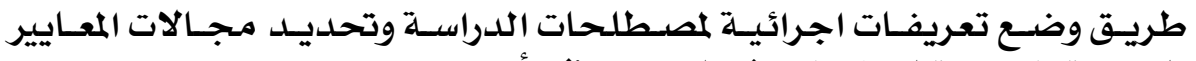

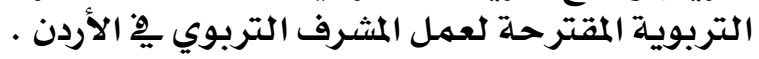

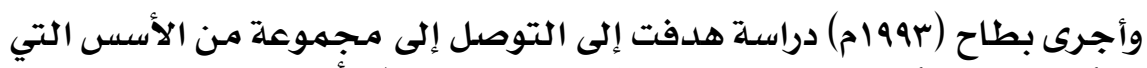

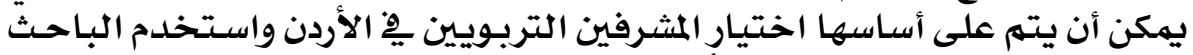

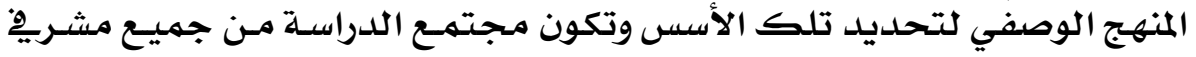

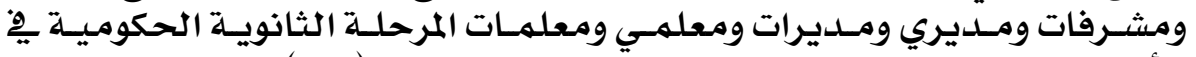

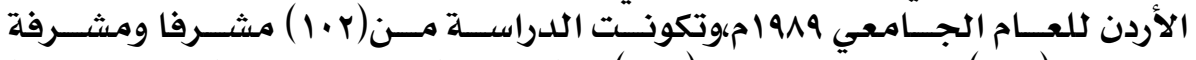

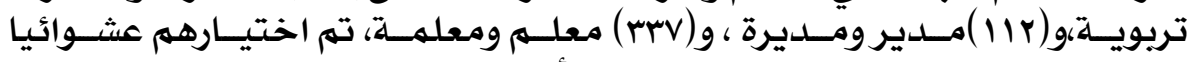

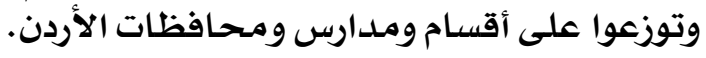

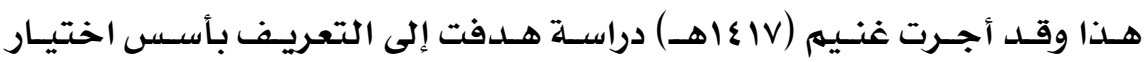

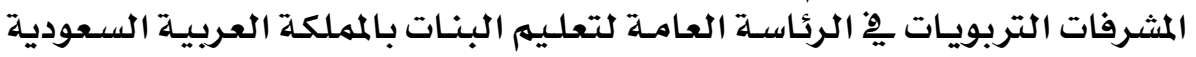

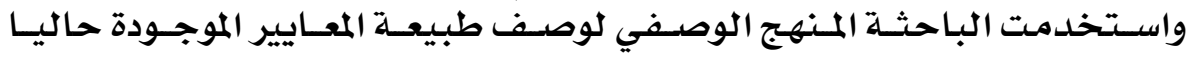

\section{$\varepsilon \varepsilon q$}




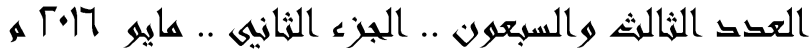

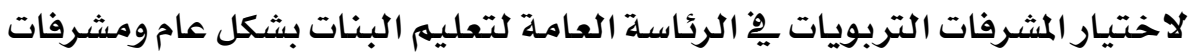

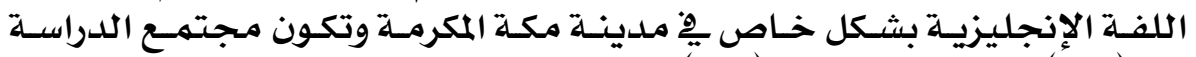

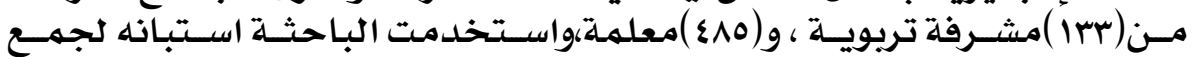

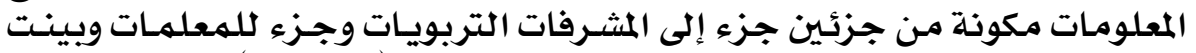

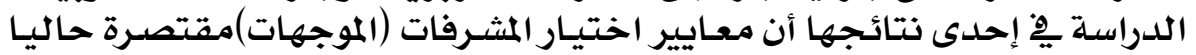

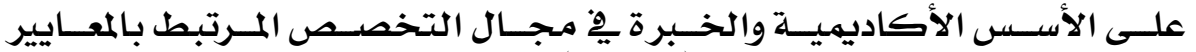

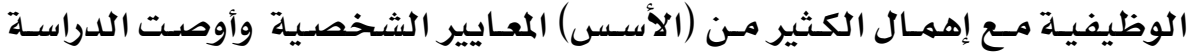

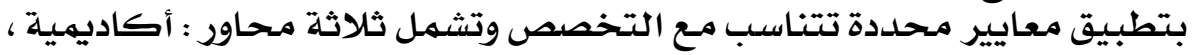

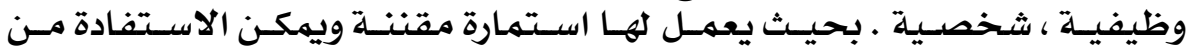

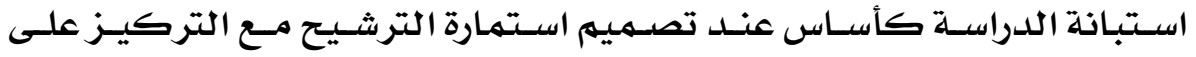

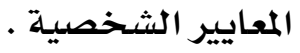

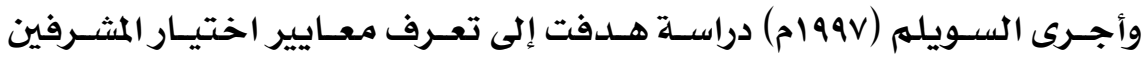

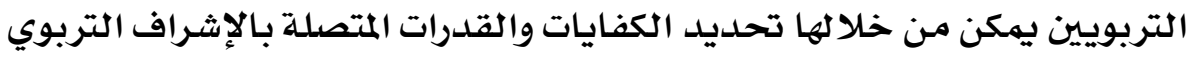

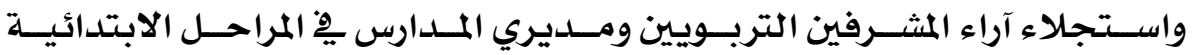

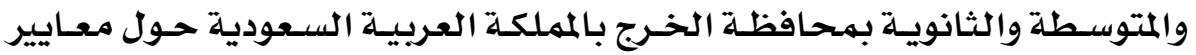

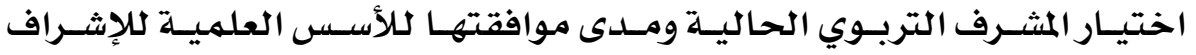

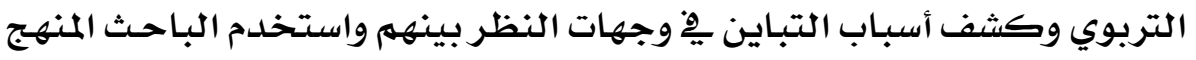

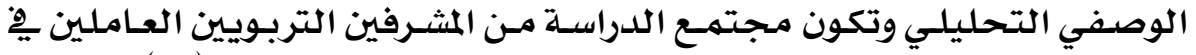

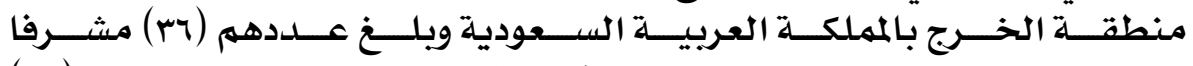

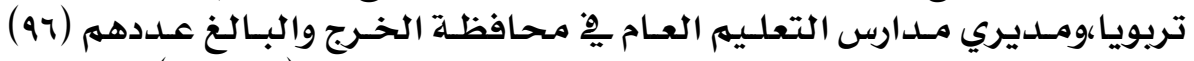

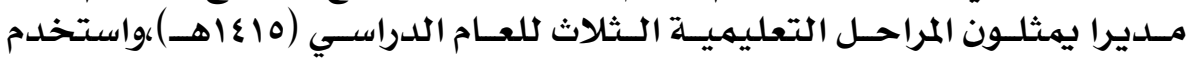

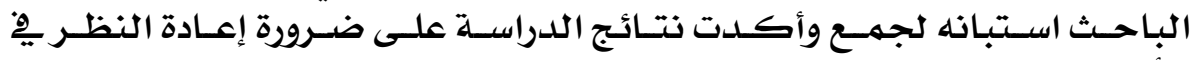

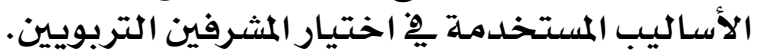

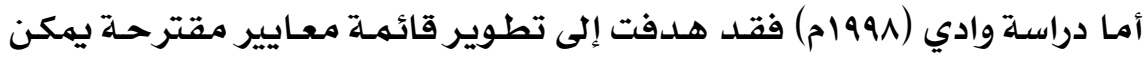

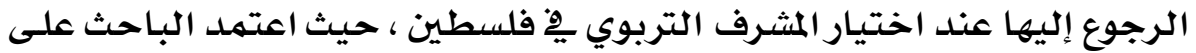

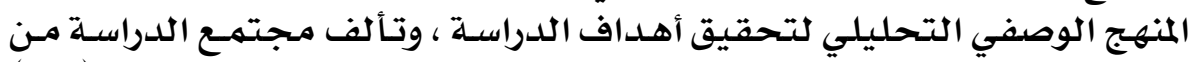

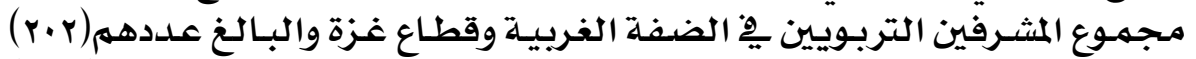

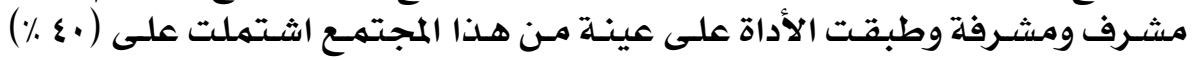

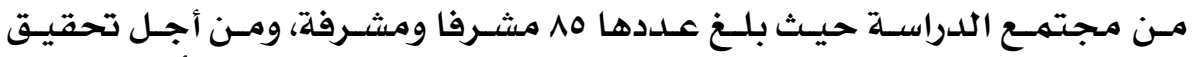

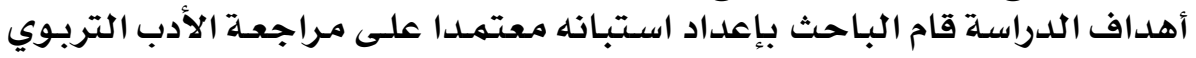

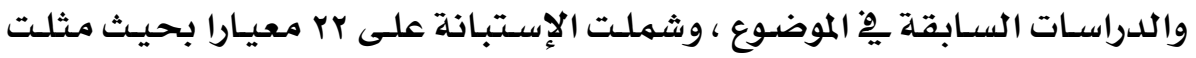

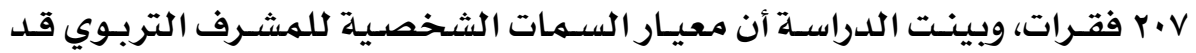

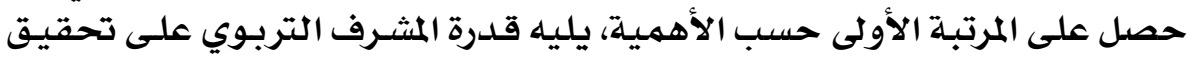

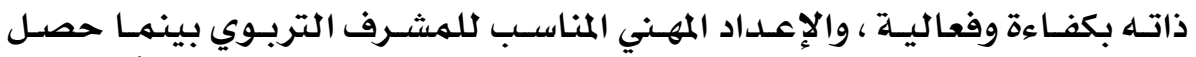

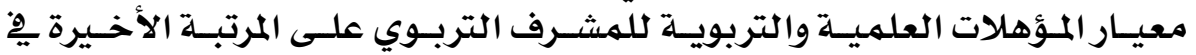

\section{\& 0 .}




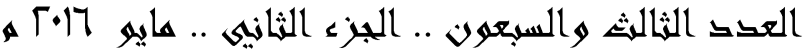

الأهمية بعـد معيـار الخبرة العلميـة ومعيـار القـدرة على تبسـيط الكتاب المدرسي والمنهاج

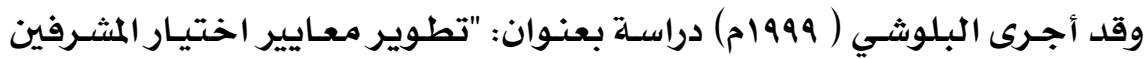

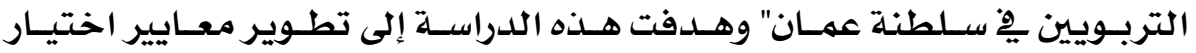

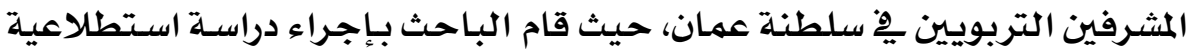

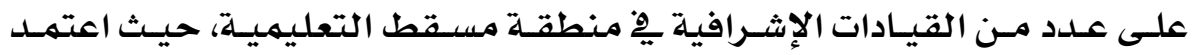

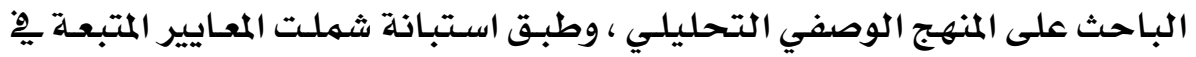

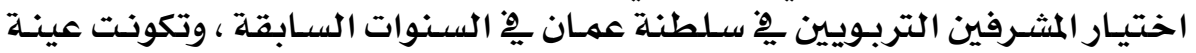

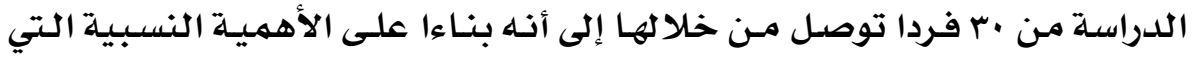

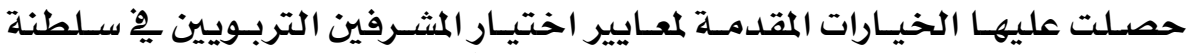

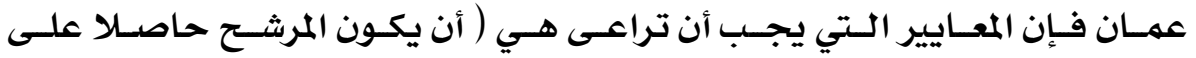

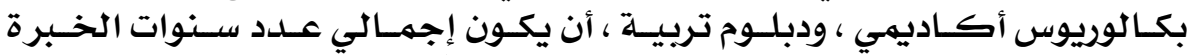

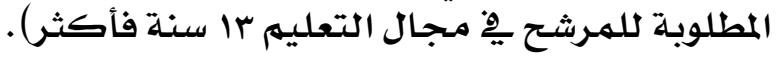

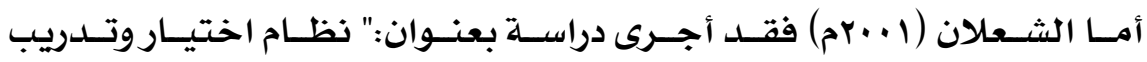

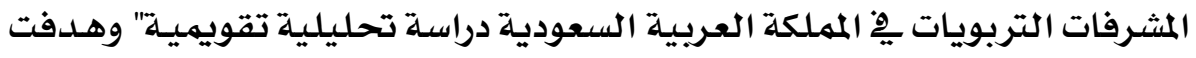

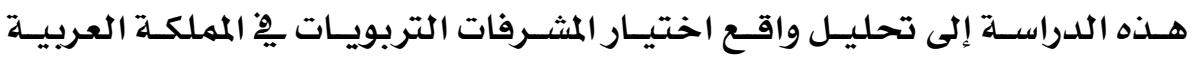

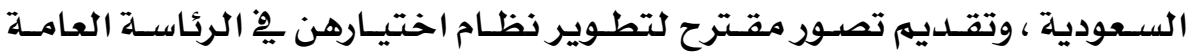

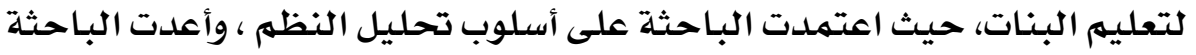

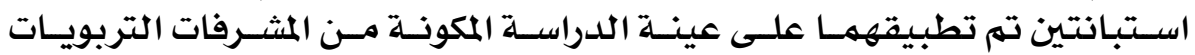

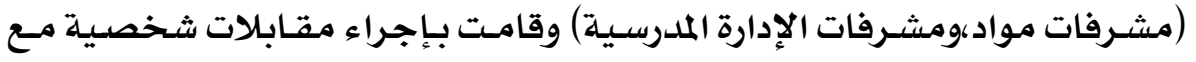

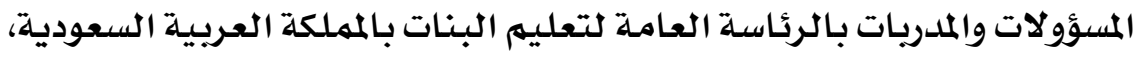

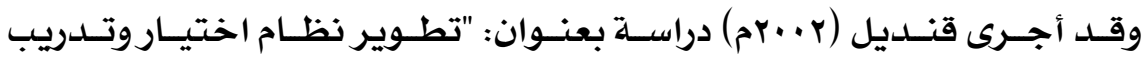

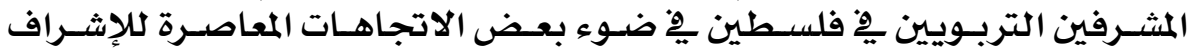

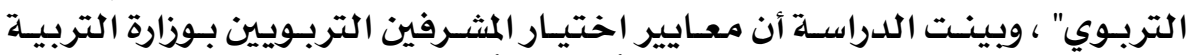

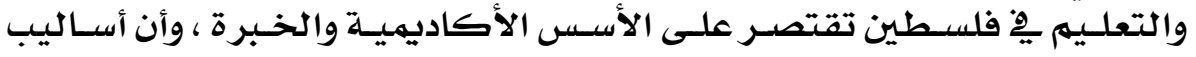

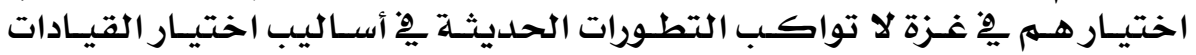

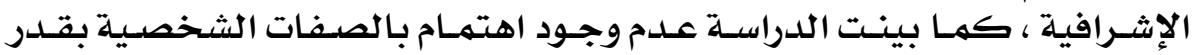

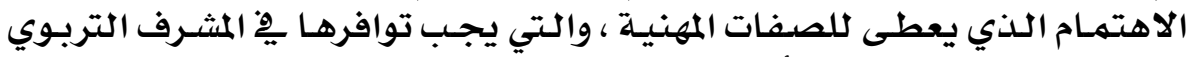

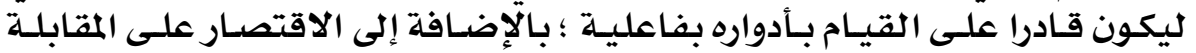
الشخصية فقط قادر عل

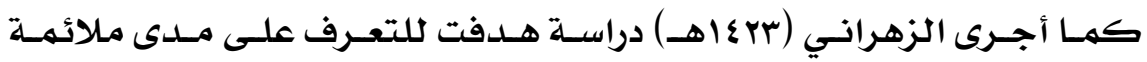

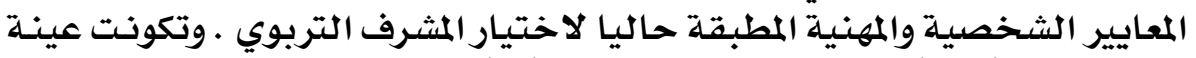

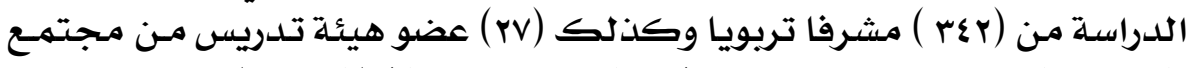

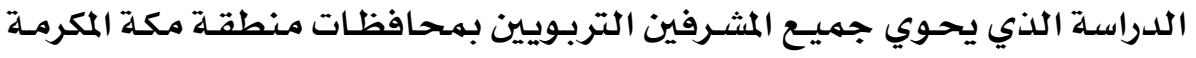

\section{\&o1}




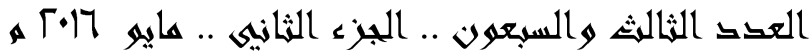

والمختصـين يِ الإثـراف التربـوي مـن الأكاديميين بكليـات التربيـة ، وكـان مـهـج

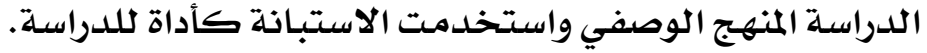

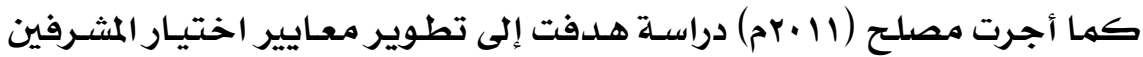

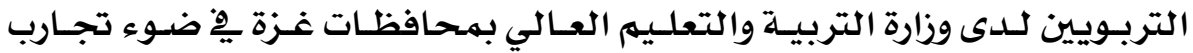

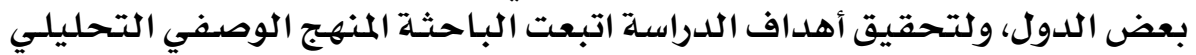

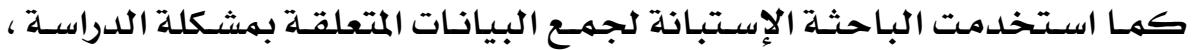

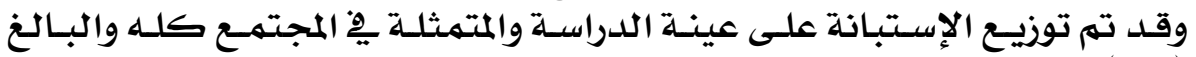

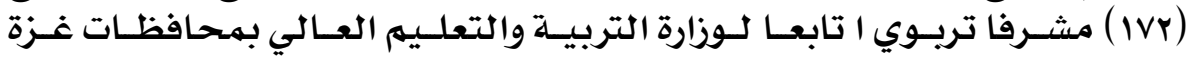

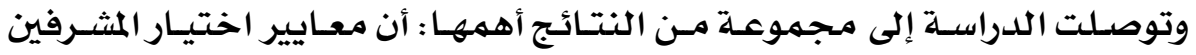

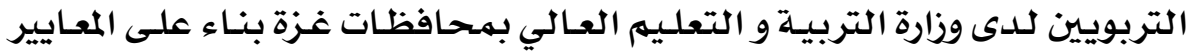

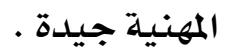

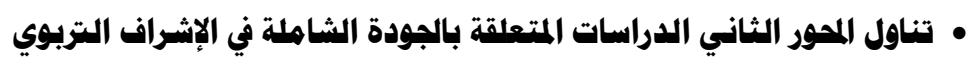

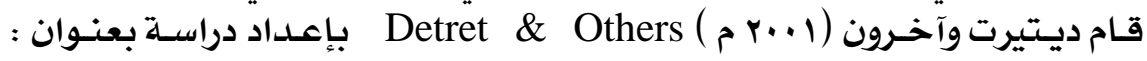

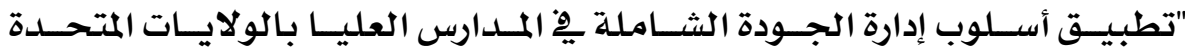

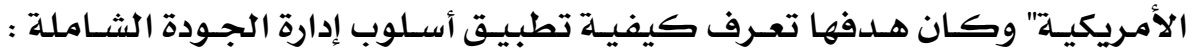

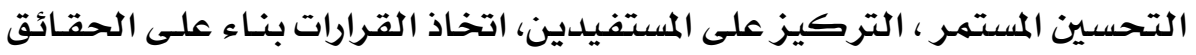

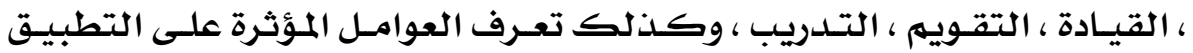

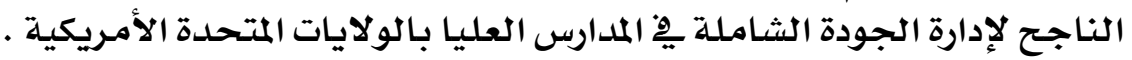

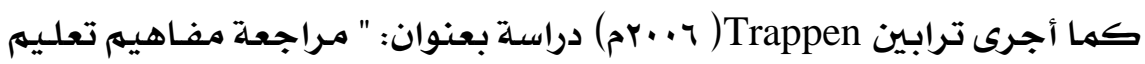

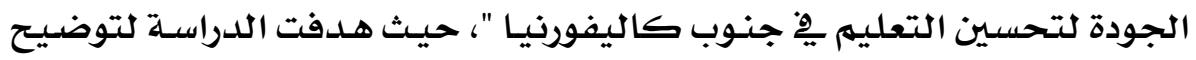

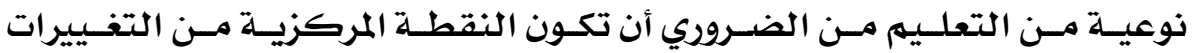

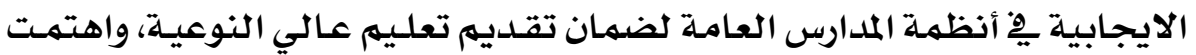

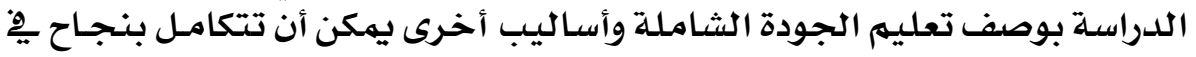

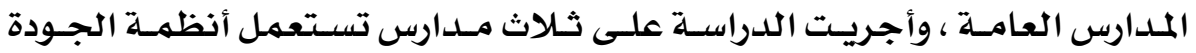

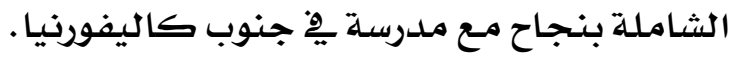

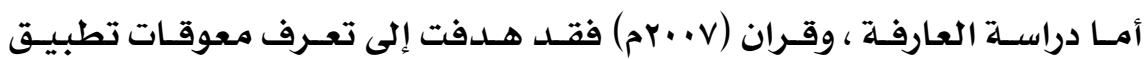

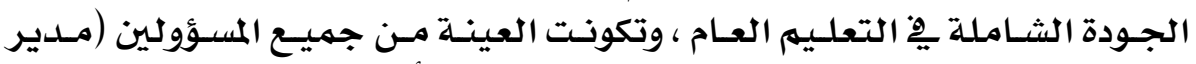

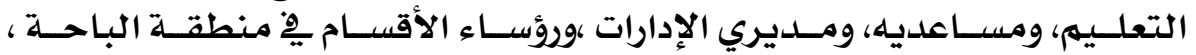

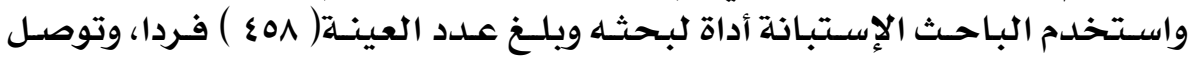

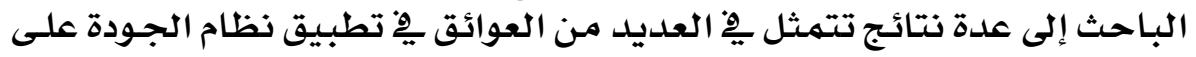

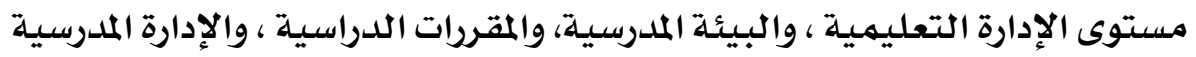

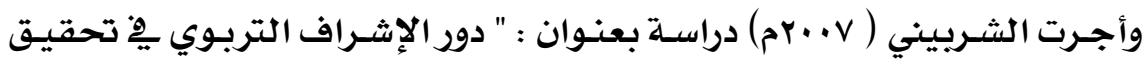

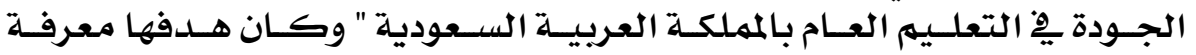

\section{$\varepsilon \odot Y$}




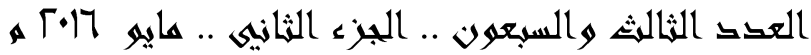

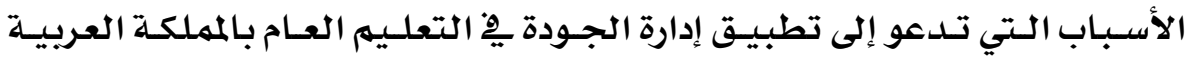

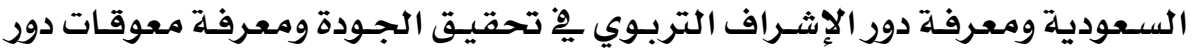

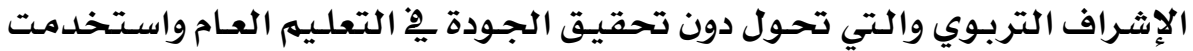

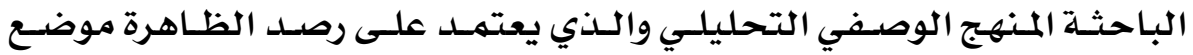

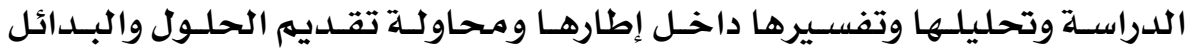

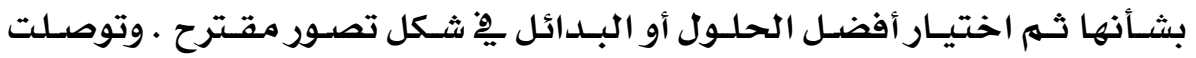

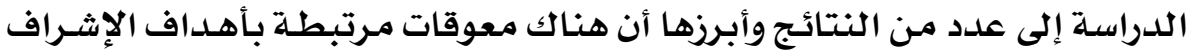

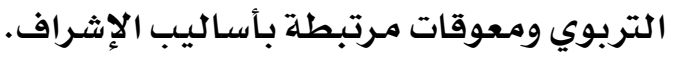

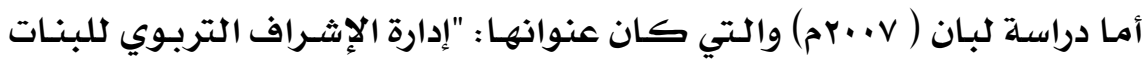

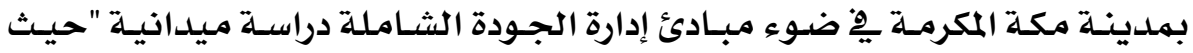

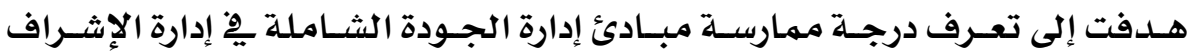

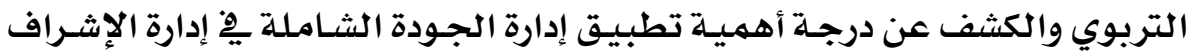

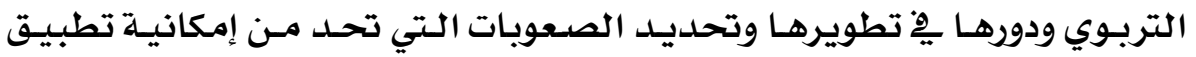

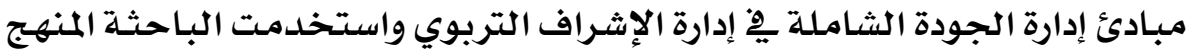

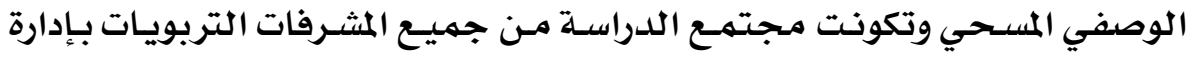

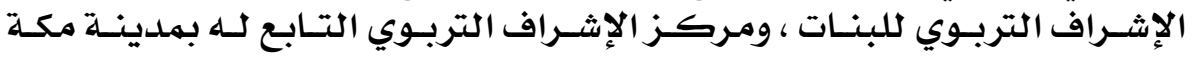

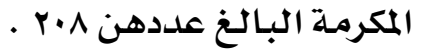

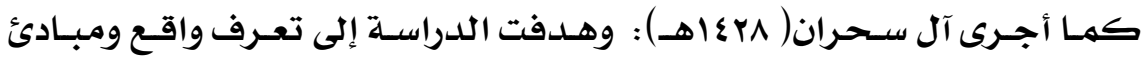

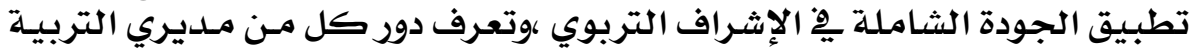

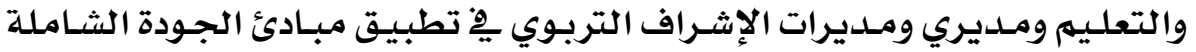

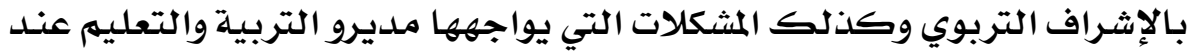

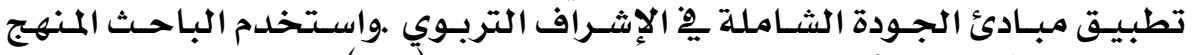

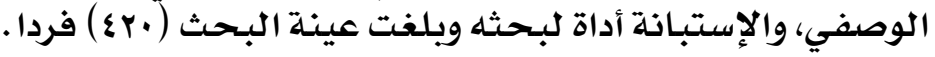

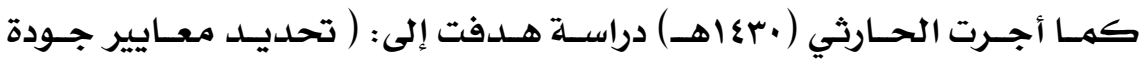

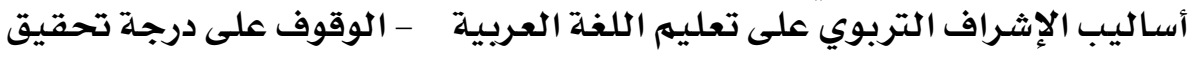

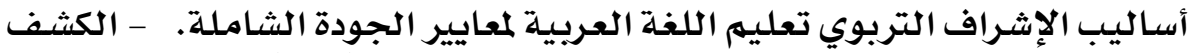

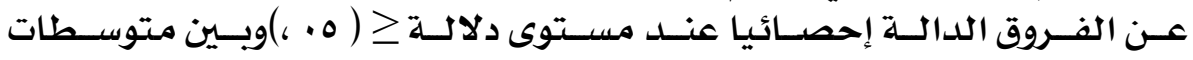

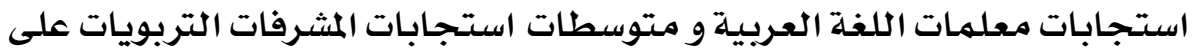

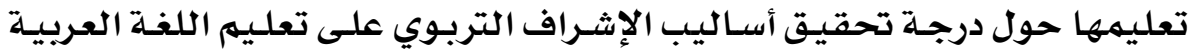

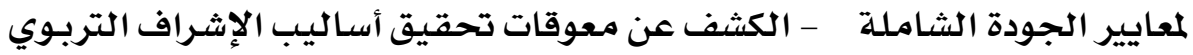

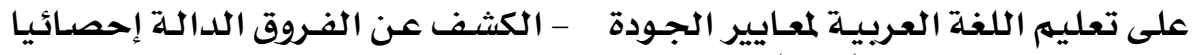

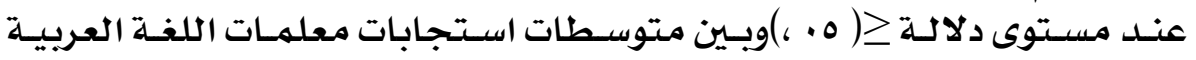

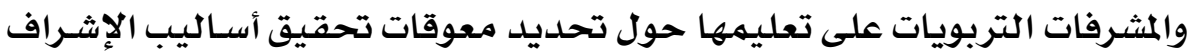

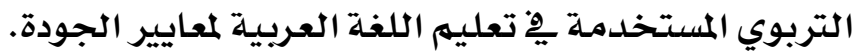

\section{$\varepsilon \otimes r$}




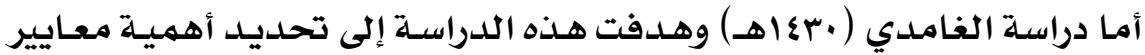

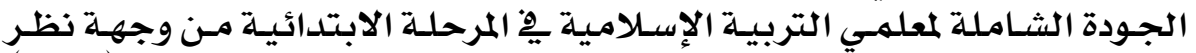

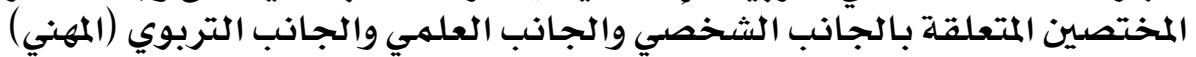

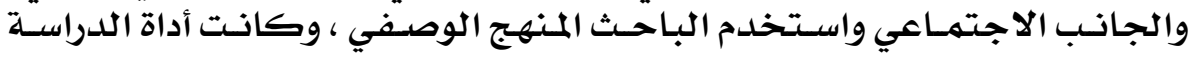

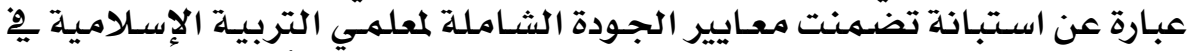

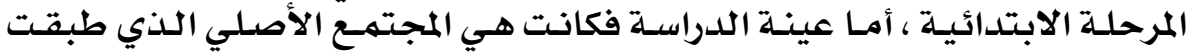

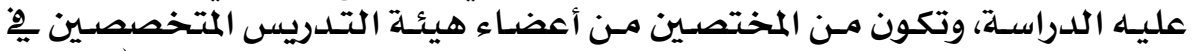

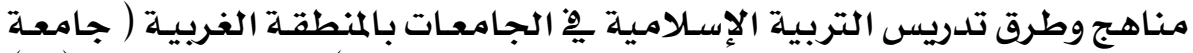

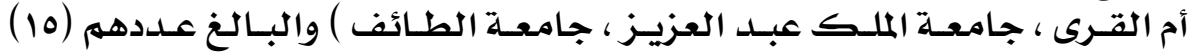

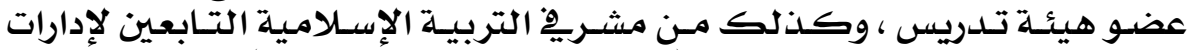

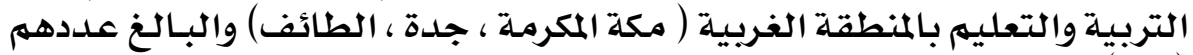
مشرفا (VV)

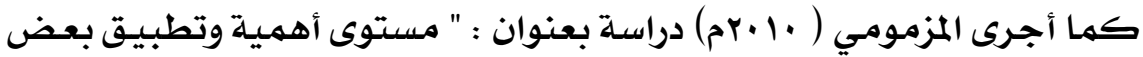

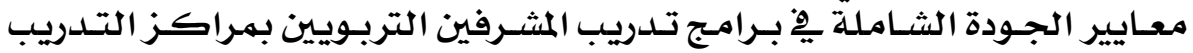

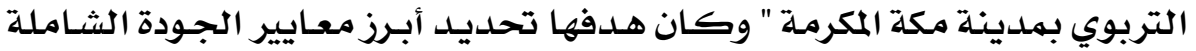

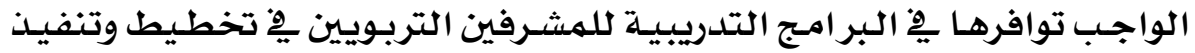

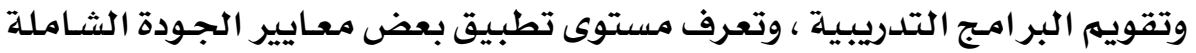

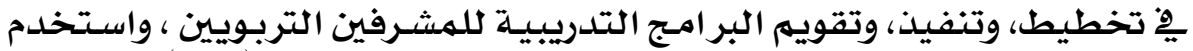

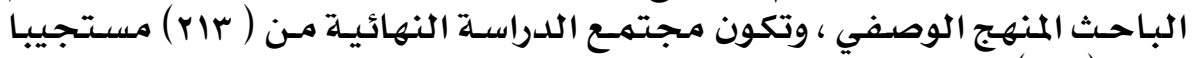

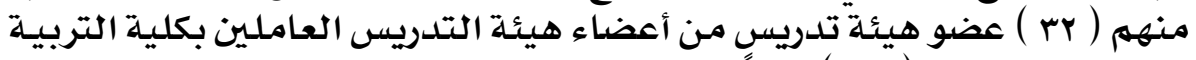

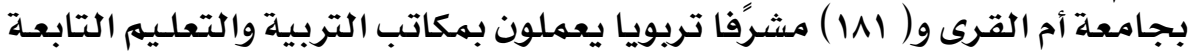

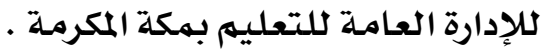

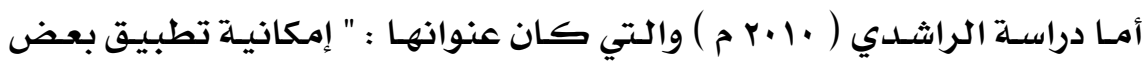

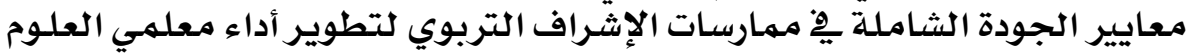

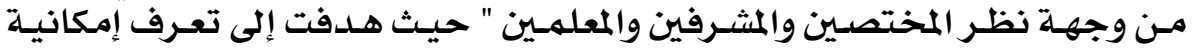

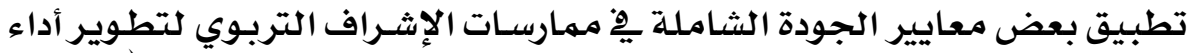

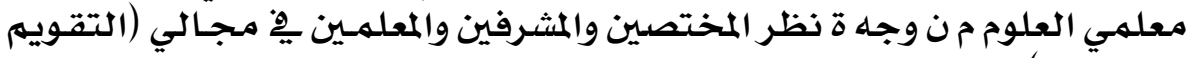

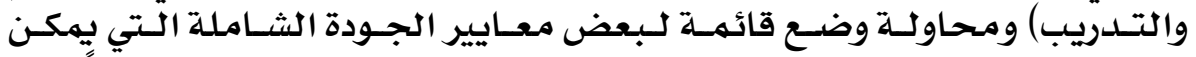

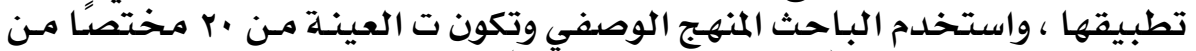

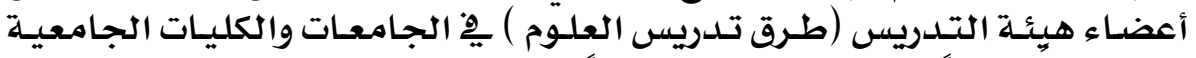

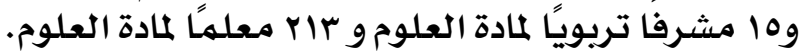

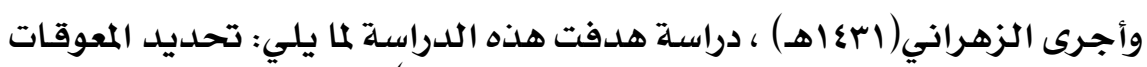

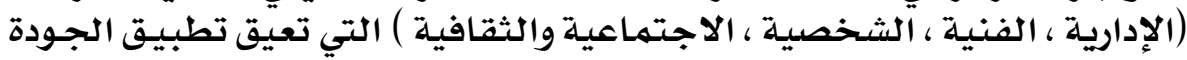

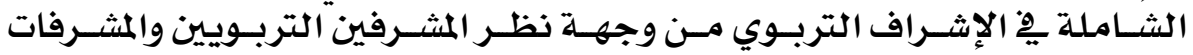

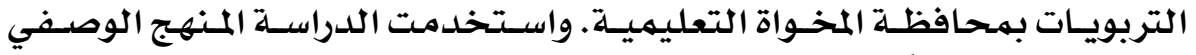

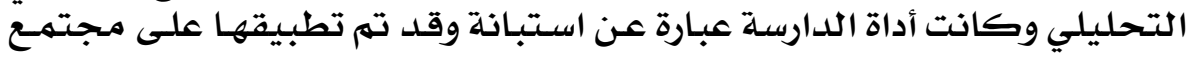

\section{$\varepsilon \circ \varepsilon$}




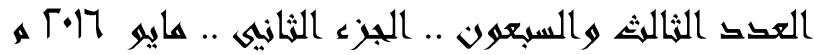

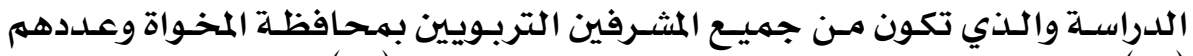

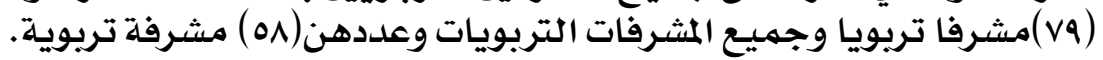

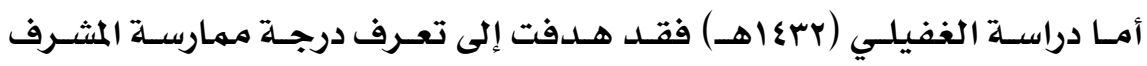

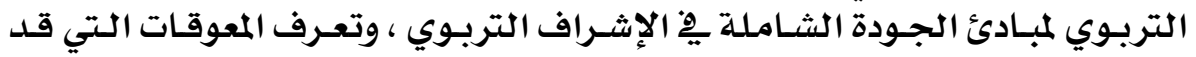

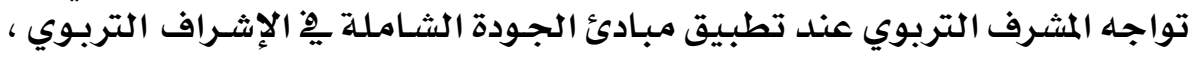

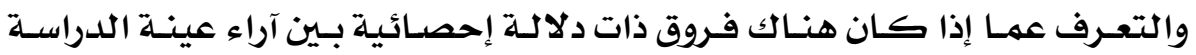

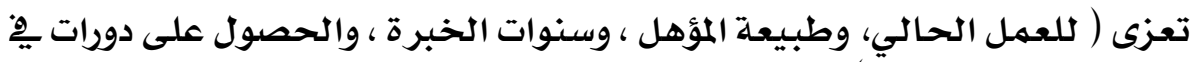
مجال الجودة الشاملة).

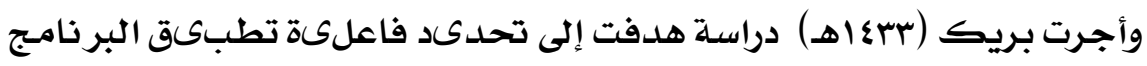

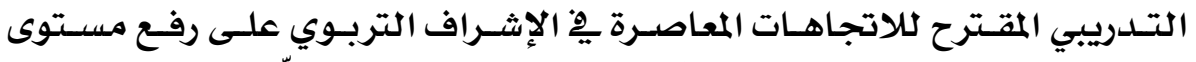

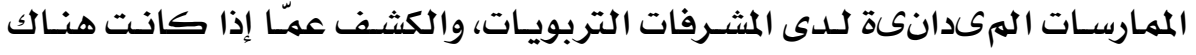

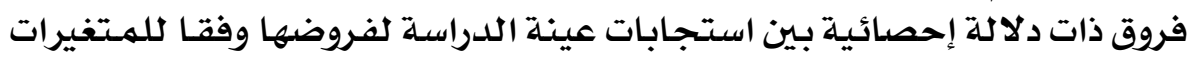

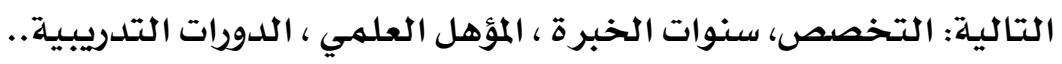

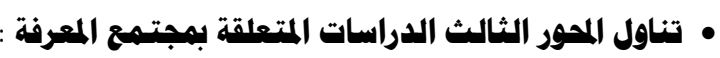

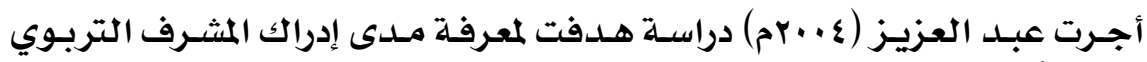

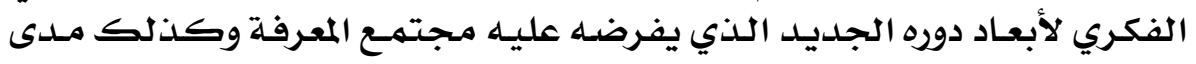

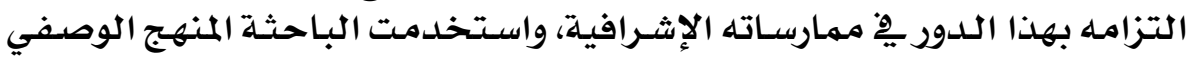

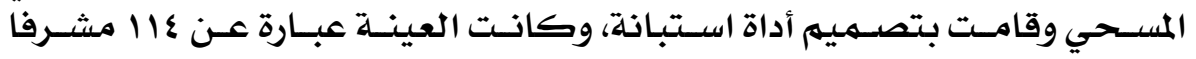
ومشرفة.

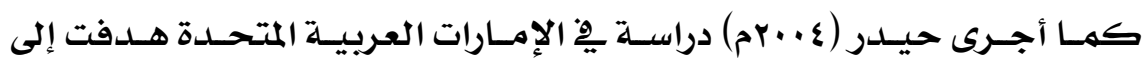

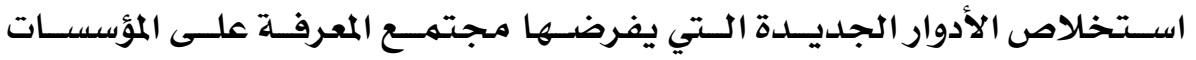

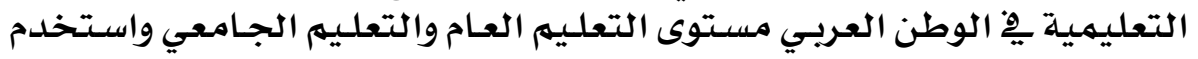

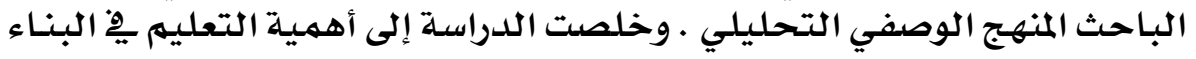

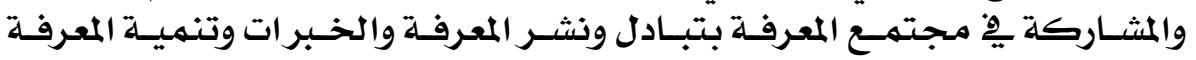

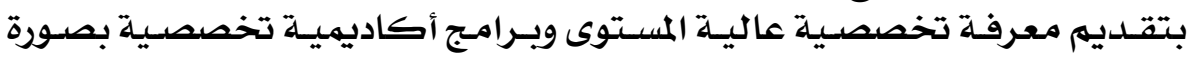

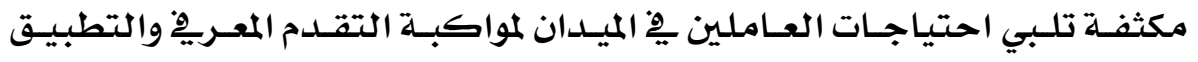

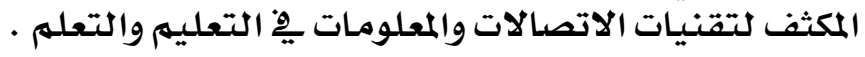

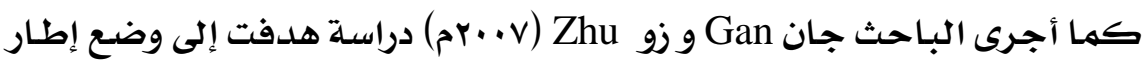

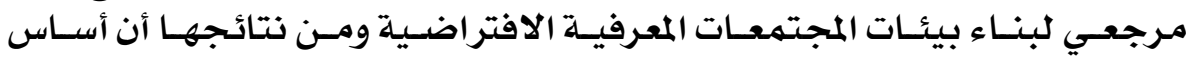

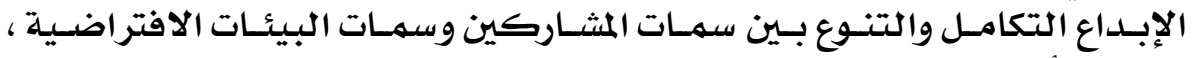

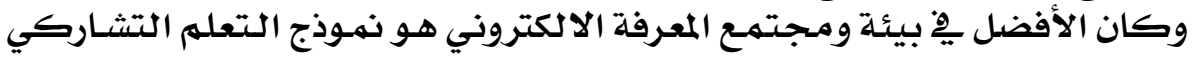

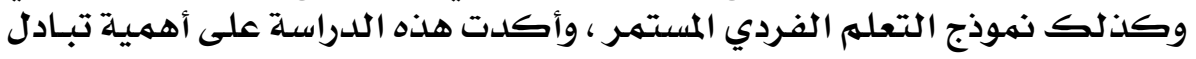

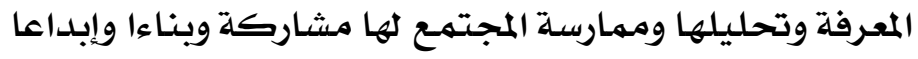

\section{$\varepsilon \diamond \diamond$}




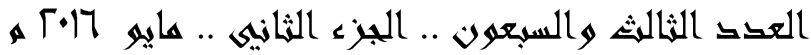

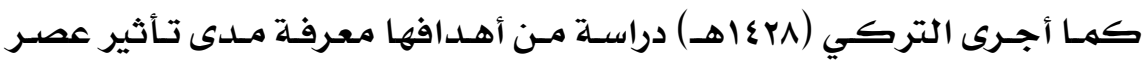

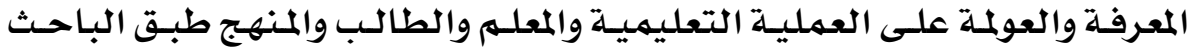

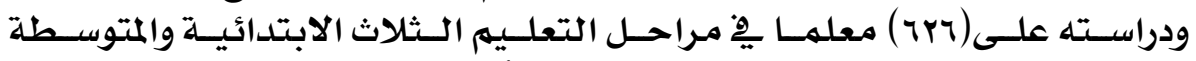

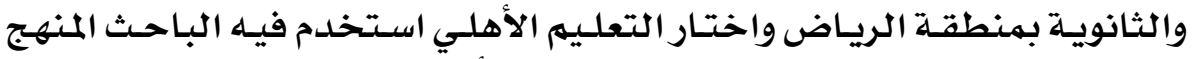

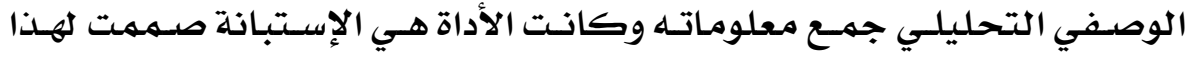

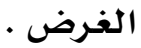

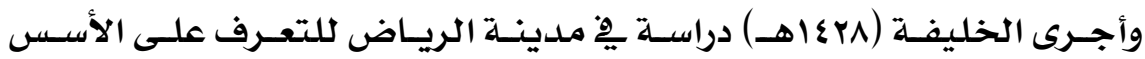

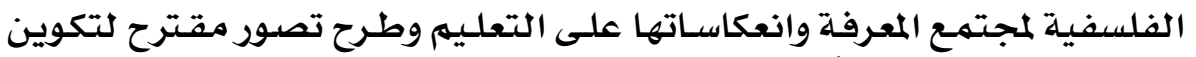

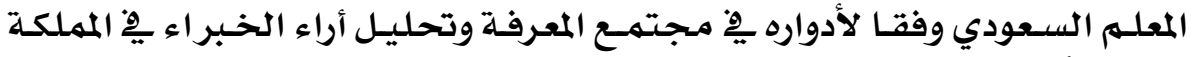

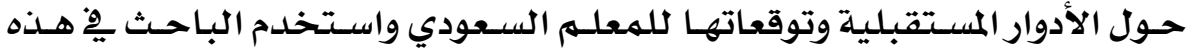

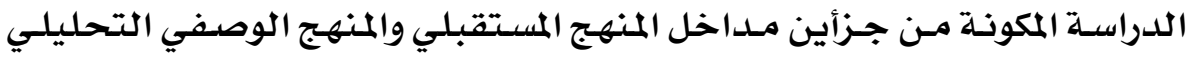

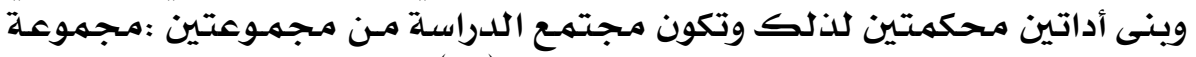

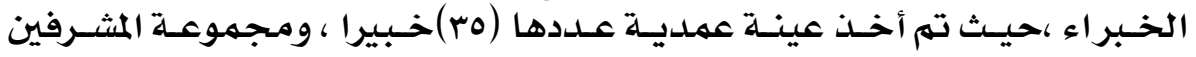

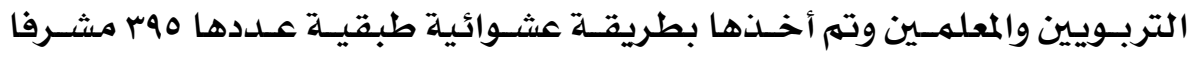
تربويا ومعلما المعلماينا

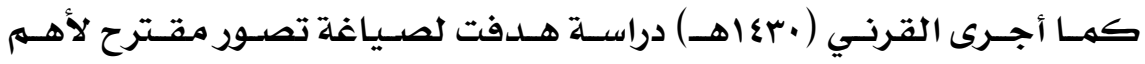

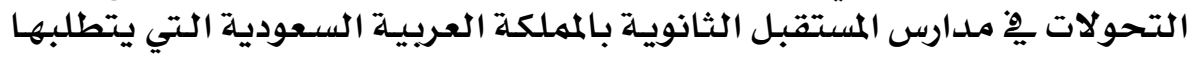

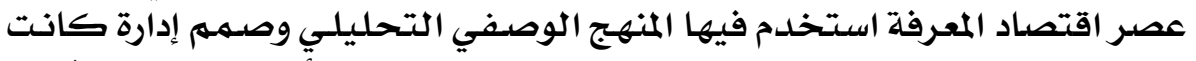

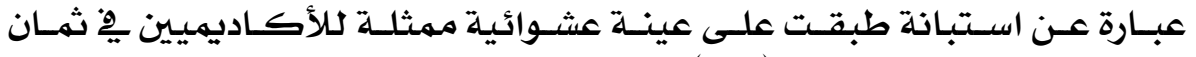

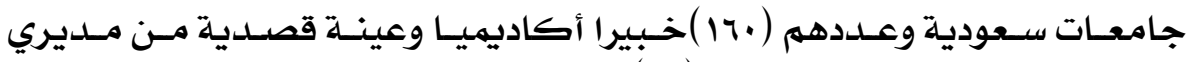

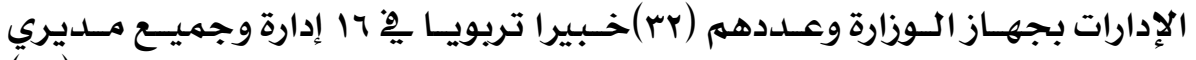

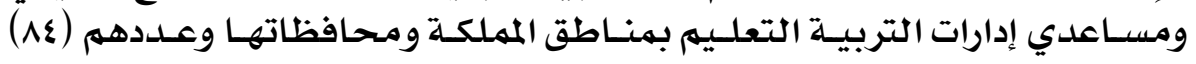
مديرا ومساعدا.

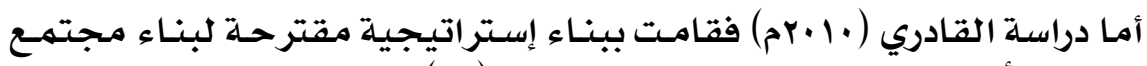

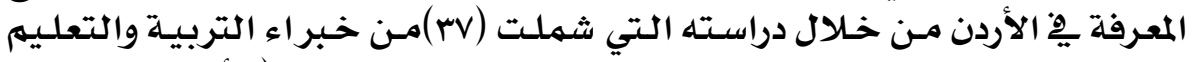

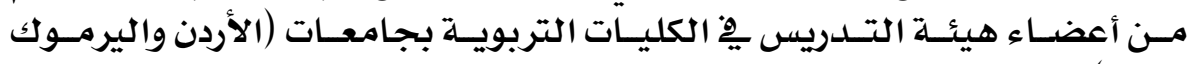

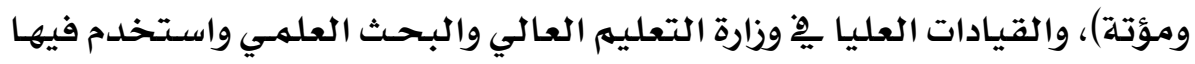

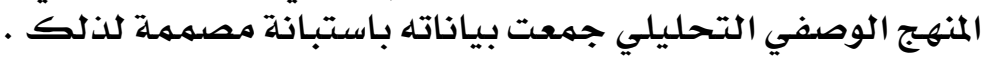

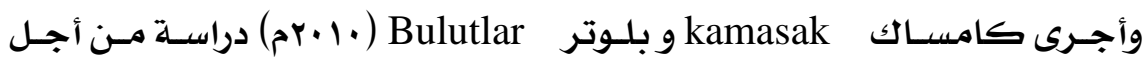

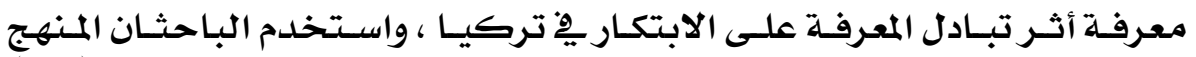

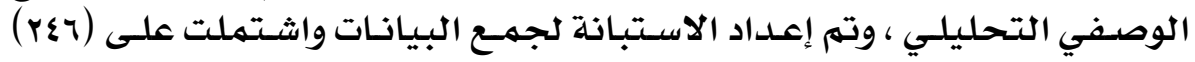

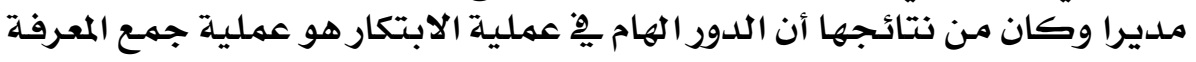

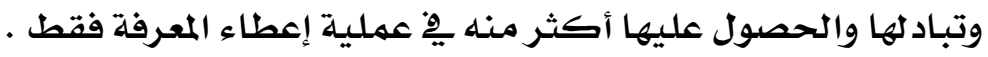

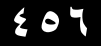




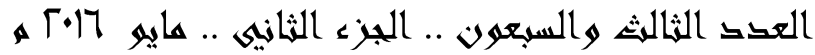

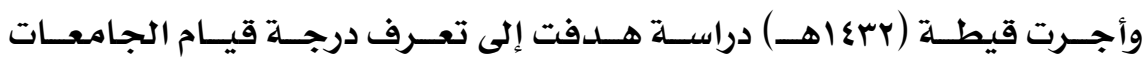

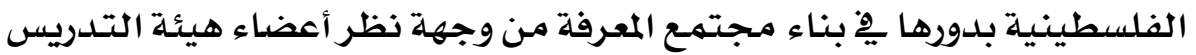

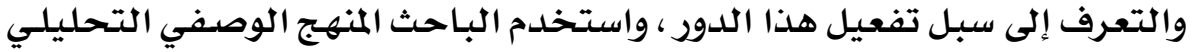

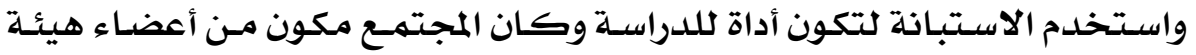

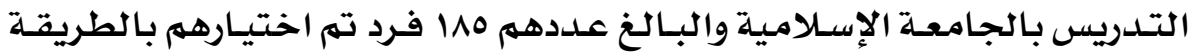

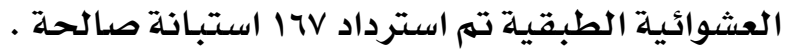

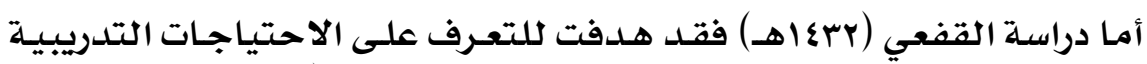

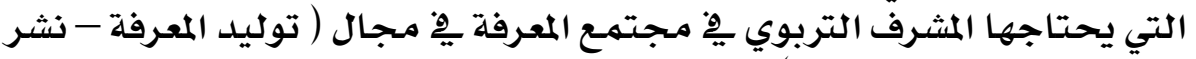

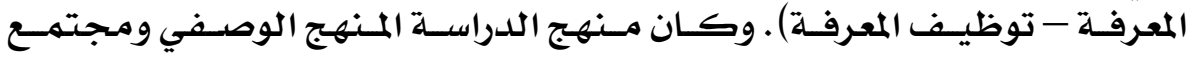

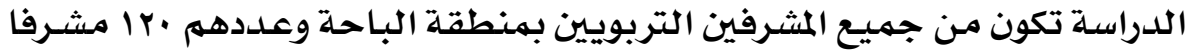

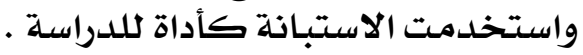

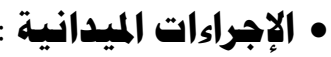

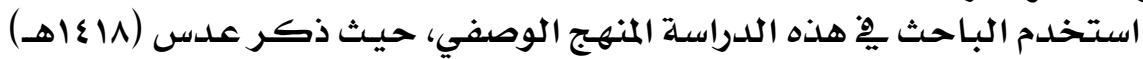

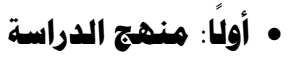

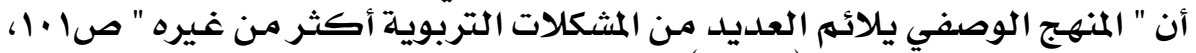

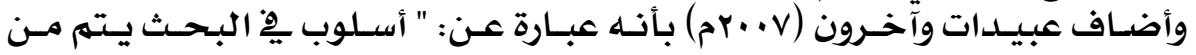

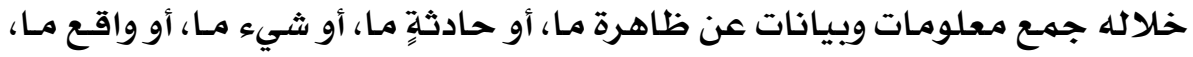

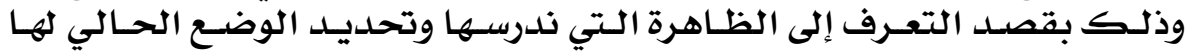

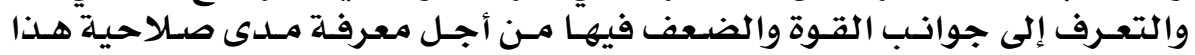

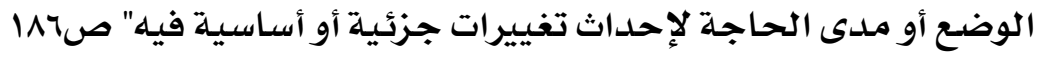

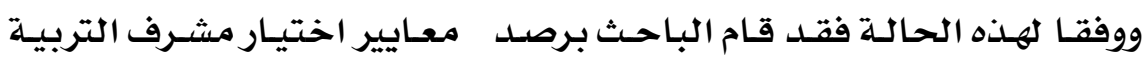

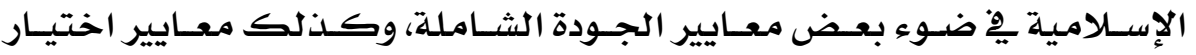

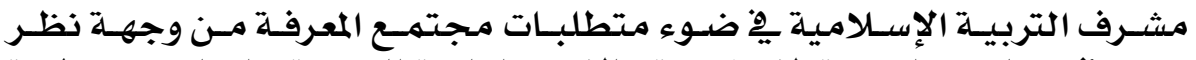

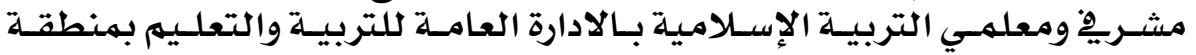
جازان.

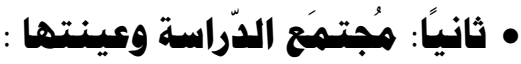 414

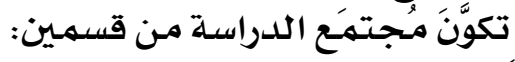

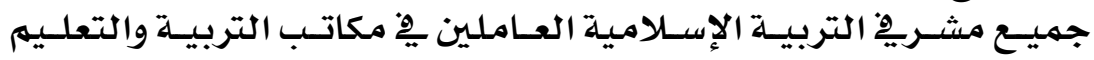

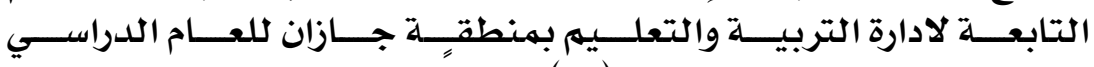

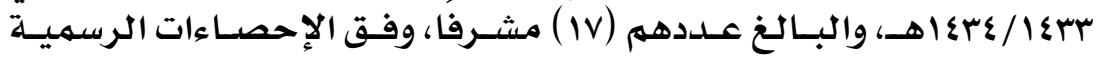

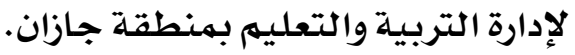

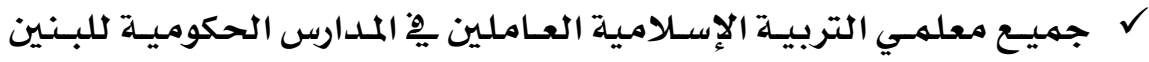

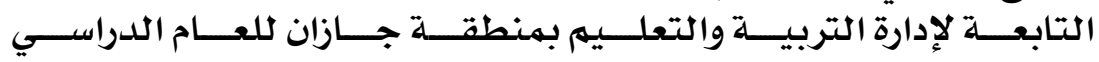

\section{$\varepsilon \odot \vee$}




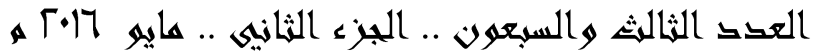

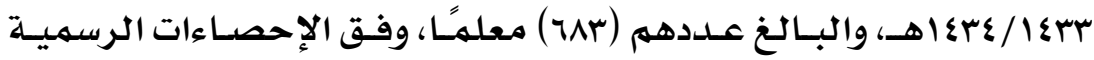

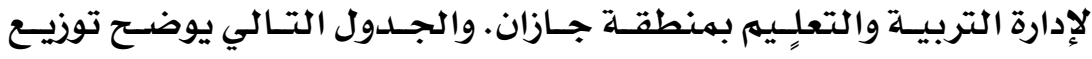

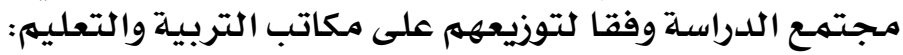

\section{4 مينة الدراسة:}

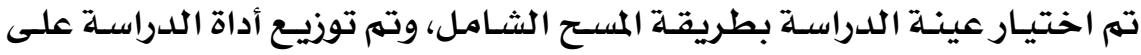

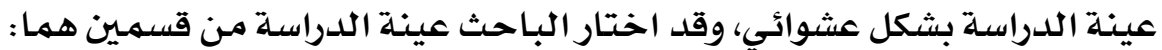

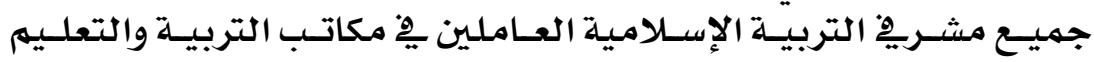

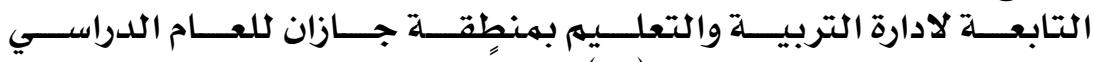

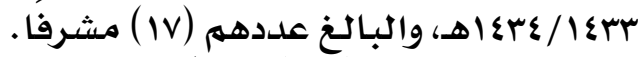

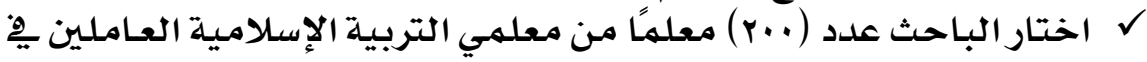

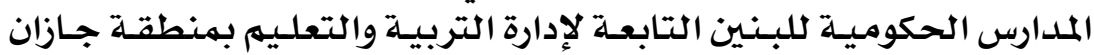

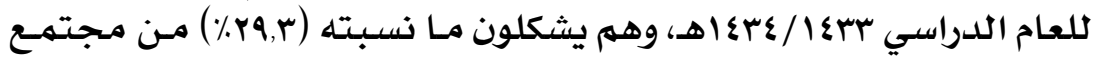
المعلمهين. تلعام التحن.

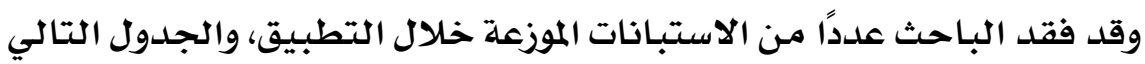

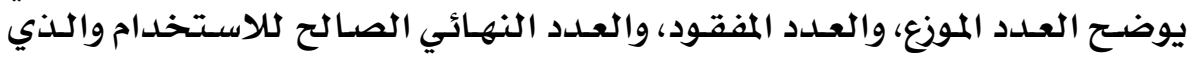

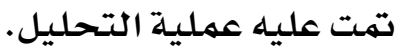

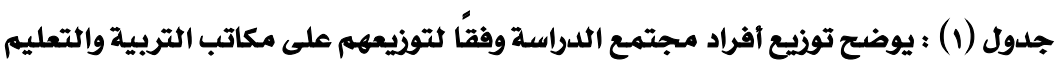

\begin{tabular}{|c|c|c|c|c|c|c|}
\hline \multicolumn{2}{|c|}{ المحموع } & \multicolumn{2}{|c|}{ المعلمين } & \multicolumn{2}{|c|}{ المشرفين التريوينين } & \multirow{2}{*}{ فئات المتغير } \\
\hline النسبة & العلدد & النسبة & العلدد & النسبة & العدد & \\
\hline$\%, r \cdot, \Lambda$ & 0. & $\% \backslash \wedge, 0$ & $\varepsilon$ & $\%, r, r$ & 0 & جازان \\
\hline$\% 19,9$ & ro & $\%, \wedge, 0$ & $\varepsilon$. & $\% 1,8$ & $r$ & أحد المسارحة \\
\hline$\% 10,7$ & ro & $\%$ Ir,A & $r$. & $\% 1, \wedge$ & $\varepsilon$ & أبى عريش \\
\hline$\% r r, q$ & 0. & $\% r r$, & 0. & $\% \cdot, 9$. & $r$ & صامطة \\
\hline$\% 1 \varepsilon, V$ & $r$. & $\%, \mathbf{I}, \Lambda$ & $r$. & $\% \cdot, 9$. & $r$ & العارضة \\
\hline$\% 0,1$ & 1. & $\% \varepsilon, 7$ & 1. & $\%, 0$, & 1 & فرسيان \\
\hline$\% 1 \ldots$ & YIV & $\%$ १Y,Y & $r \ldots$ & $\% \mathrm{~V}, \Lambda$ & IV & المحموع \\
\hline
\end{tabular}

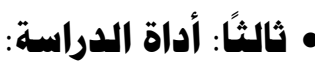

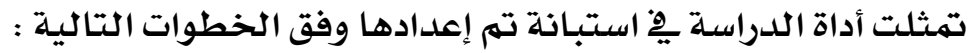
• الهدف هن أداة الدراسة:

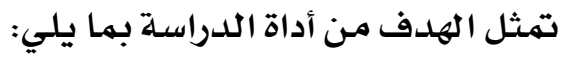

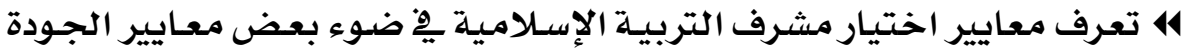

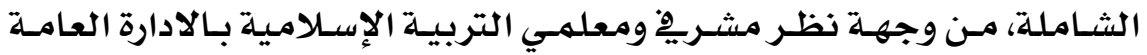

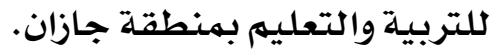

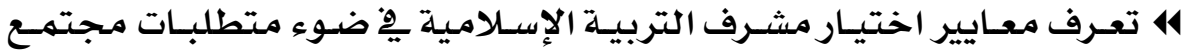

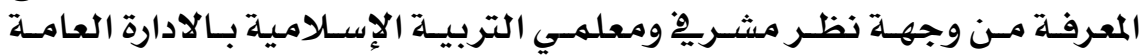

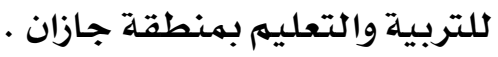

\section{$\varepsilon \otimes \wedge$}




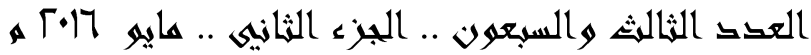

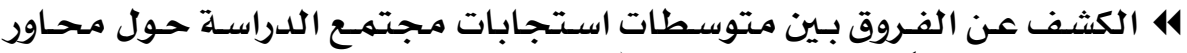

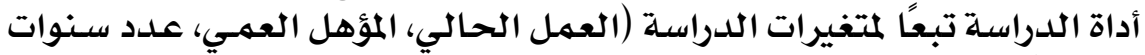

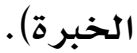

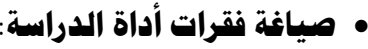

تمت صياغة فقرات أداة الدراسـة حسب مانب ما يلي:

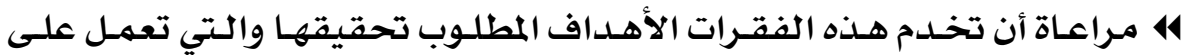

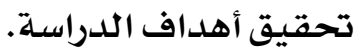

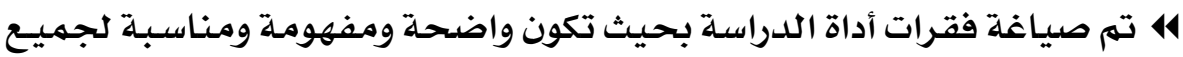

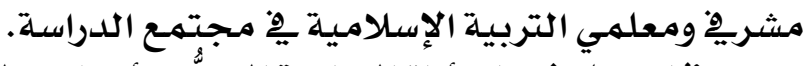

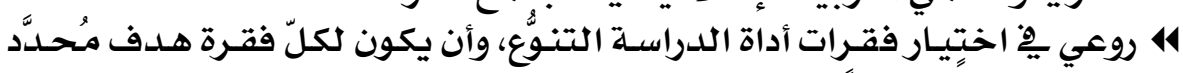

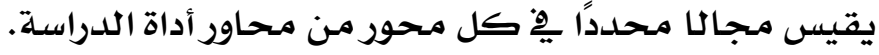

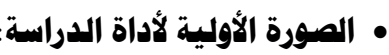

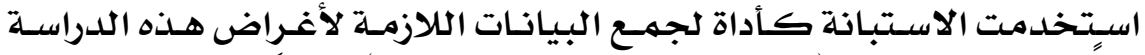

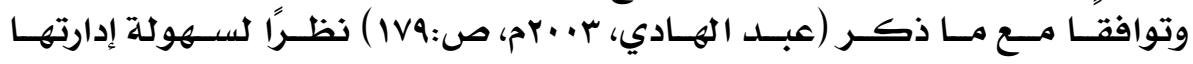

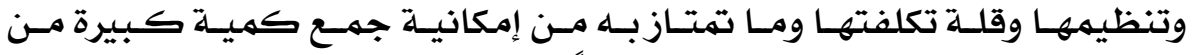

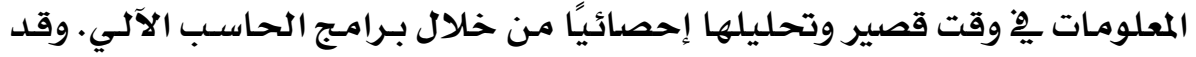

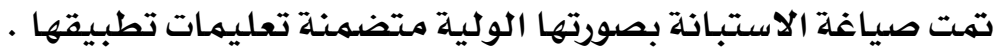

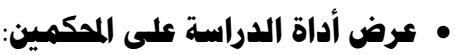

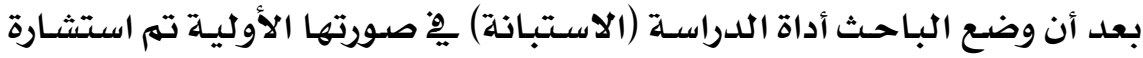

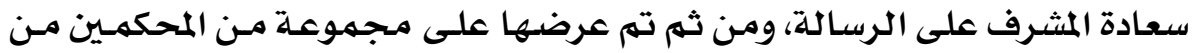

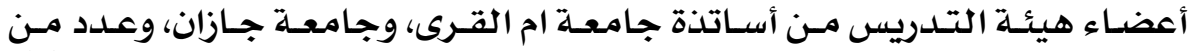

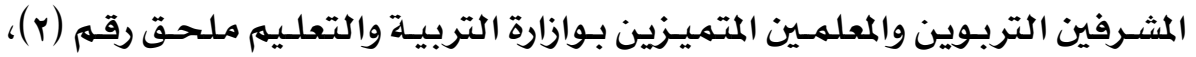

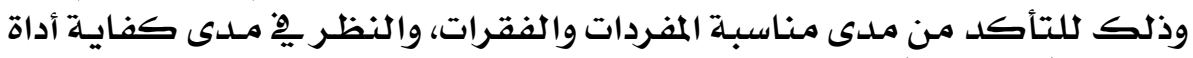

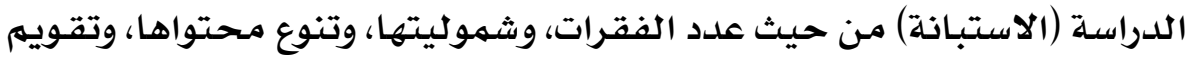

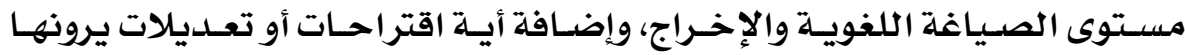
مناسبة.

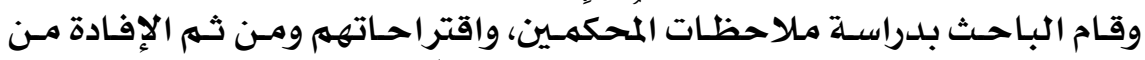

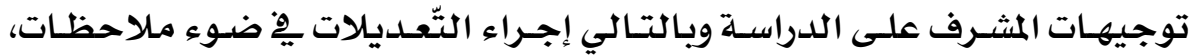

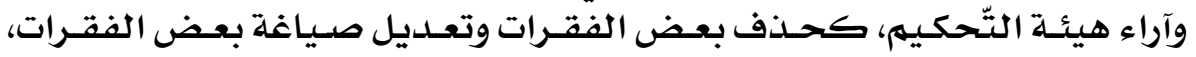
وتصحيح بعض أخطاء الصياءة التهية اللغوية وعلاماتهات الترقيه.

• الصورة النهائية لأداة الدراسة:

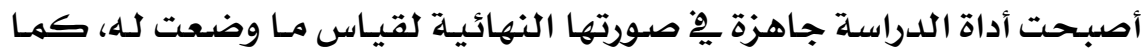
بالجدول (r): أداة

\section{$\varepsilon \otimes 9$}




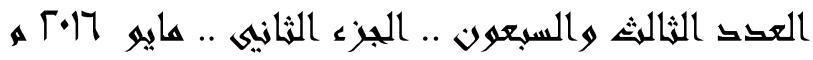

جلدول (r) : الصورة النهائية لأداة الدراسة

\begin{tabular}{|c|c|c|c|}
\hline موقع الفقرات & عدد الفقرات & المعايير والابعاد & محاور أداة الدراسة \\
\hline $0-1$ & 0 & الهلدفية والتركيز & \multirow{8}{*}{ 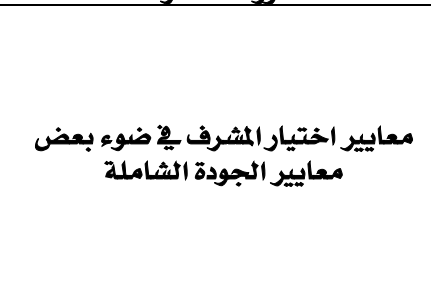 } \\
\hline $1 .-1$ & 0 & التخطيط السليم & \\
\hline $17-11$ & 7 & التحسين المستمر & \\
\hline$r Y-I V$ & 7 & القيادة الفعالة & \\
\hline$r v-r r$ & 0 & الابتكاروالتجديد & \\
\hline$r I-r \Lambda$ & $\varepsilon$ & التقويم العملي & \\
\hline$r q-r r$ & 0 & التغذية الراجعة & \\
\hline rq- 1 & m & مجموع الفقرات & \\
\hline $9-1$ & 9 & انتاج المعرفة & \multirow{4}{*}{ 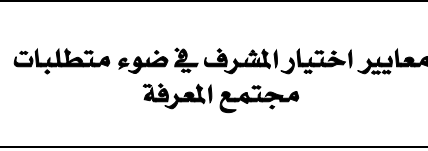 } \\
\hline $1 \varepsilon-1$ & 0 & ثشر المعرفة & \\
\hline$r Y-10$ & $\Lambda$ & توظيف المعرفة & \\
\hline$r r-1$ & YY & محموع الفقرات & \\
\hline \multicolumn{2}{|c|}{ OA } & \multicolumn{2}{|c|}{ إجمالى عدد الفقرات بِ الصورة الأولية } \\
\hline
\end{tabular}

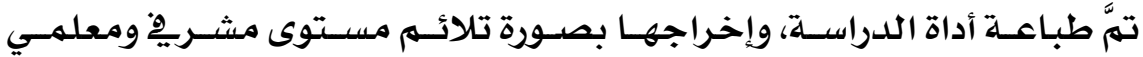

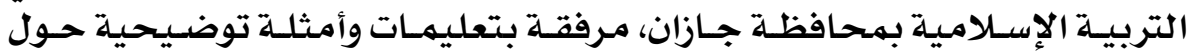

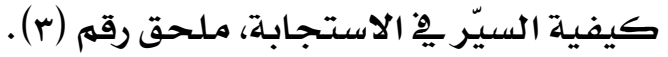

• صدق أداة الدراسة:

تهم قياس صدل ادق أداة الدراسة : مـن خلال:

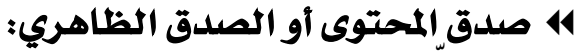

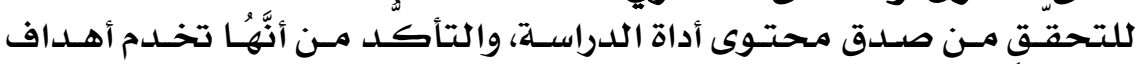

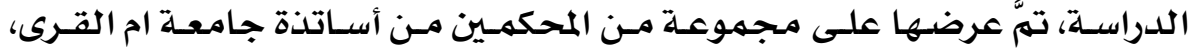

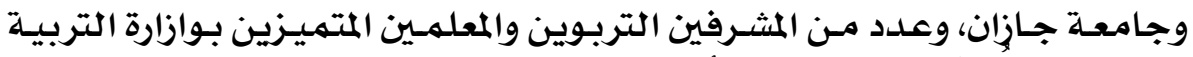

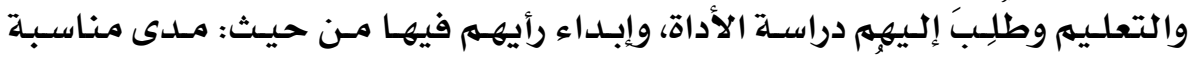

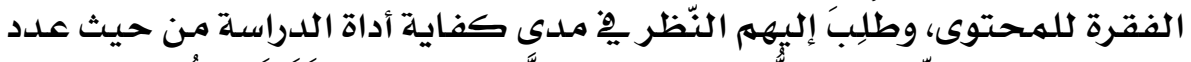

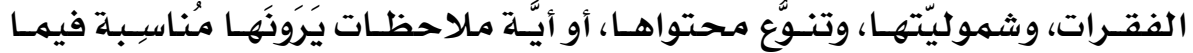

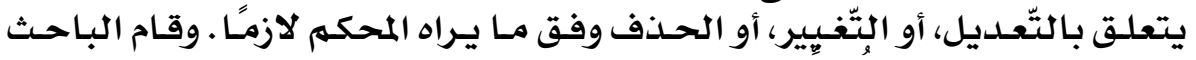

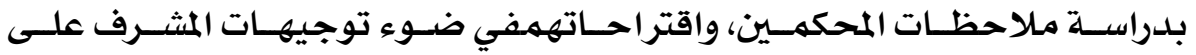

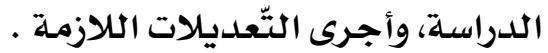

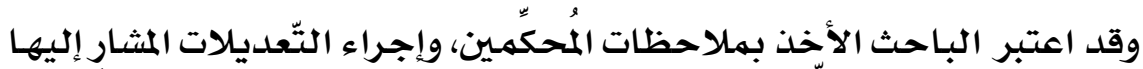

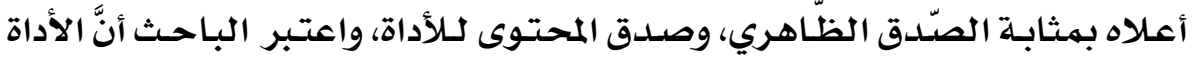

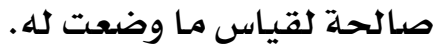

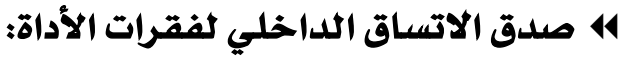

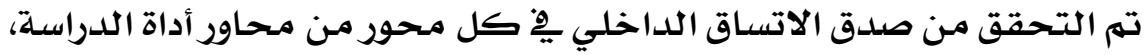

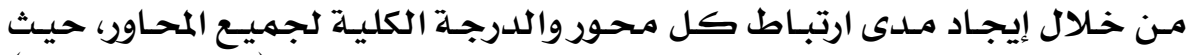

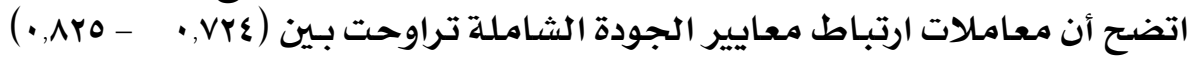

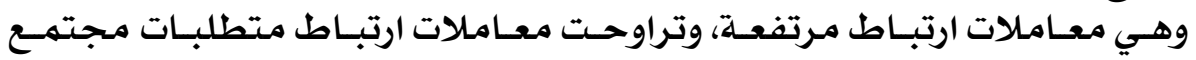

\section{$\varepsilon 7$.}




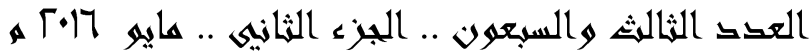

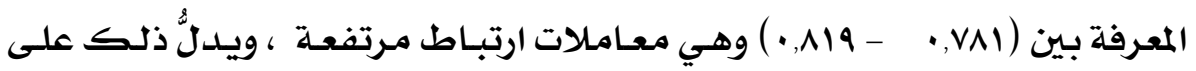

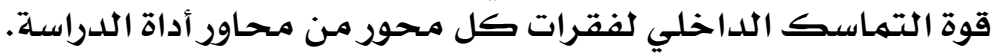
• بات أداة الدراسة:

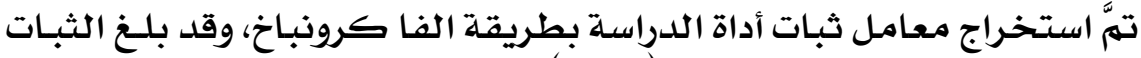

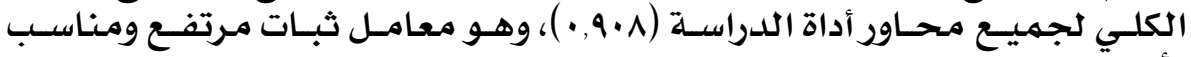

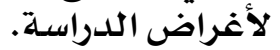

\section{• إجراءات تطبيق أداة الدراسة الدراسة:}

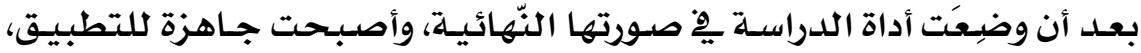

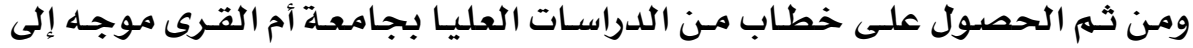

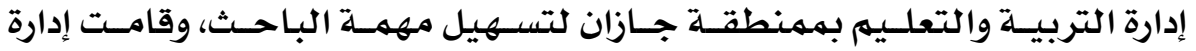

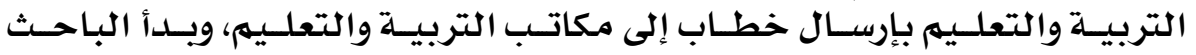

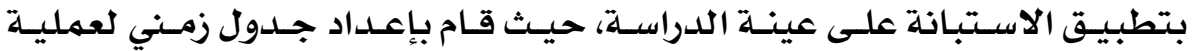

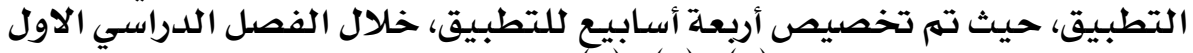

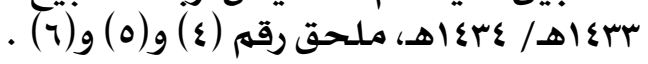

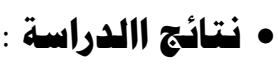

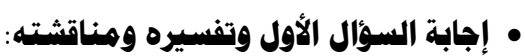

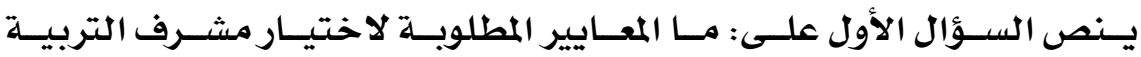

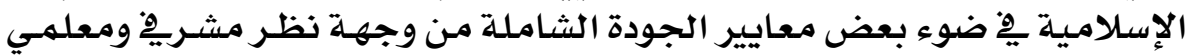

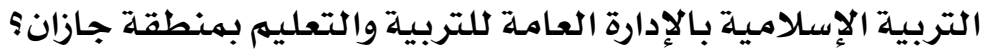

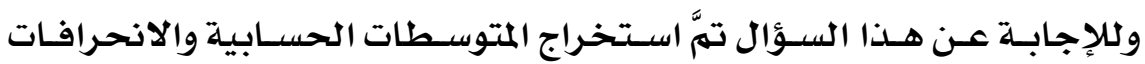

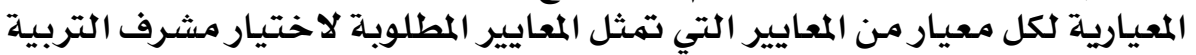

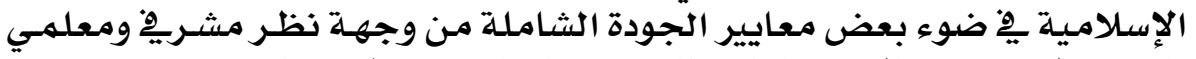

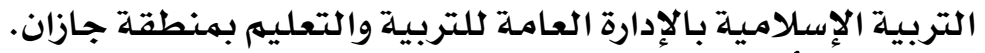

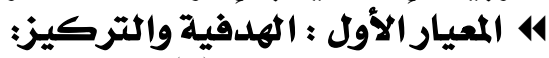

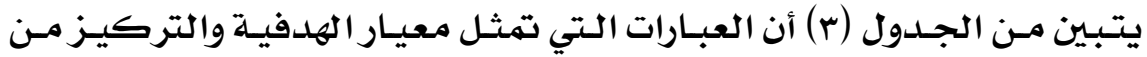

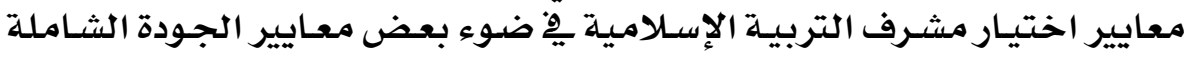

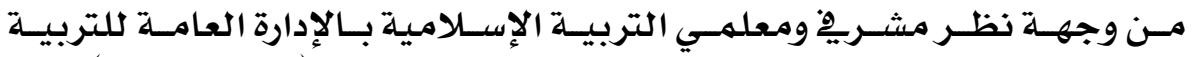

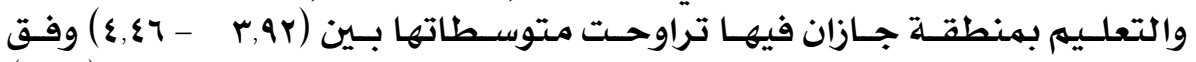

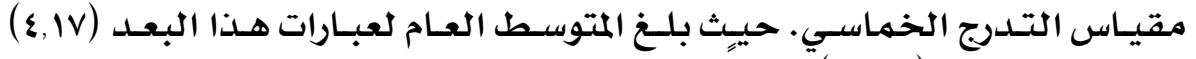

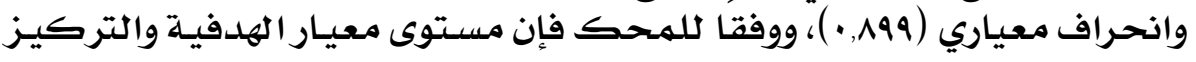

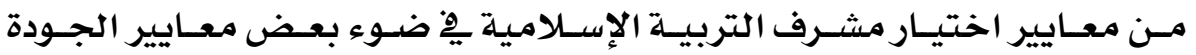

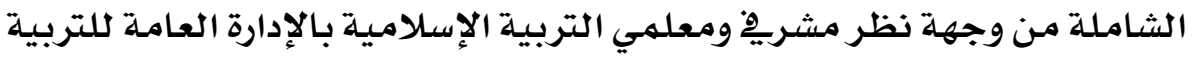

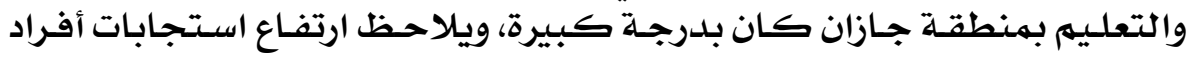

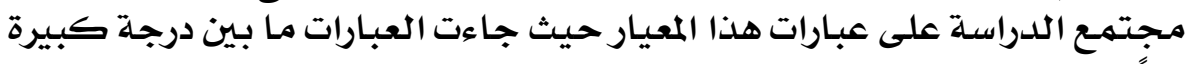
جدًا وكبيرة.

\section{\&71}




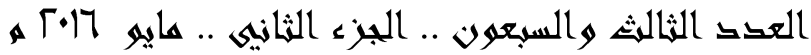

جدول (r) : المتوسّطات الحسابية والانحرافات المعيارية لمعيار الهدفية والتركيز من معايير اختيار مشرف التربية الإسلامية يُ ضوء بعض معايير الجودة الشاملة

\begin{tabular}{|c|c|c|c|c|c|c|c|}
\hline \multicolumn{3}{|c|}{ الإجمالي } & 家 & है & \multirow{2}{*}{ تنازليًا حسبب المتوسطارة } & \multirow{2}{*}{ 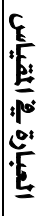 } & \multirow{2}{*}{$\begin{array}{l}: E \\
E_{i}\end{array}$} \\
\hline E & E & $\underline{E}$ & $E$ & $E$ & & & \\
\hline كبيرة درجًا & .rvo & \&.\&7 & 4.44 & 4.71 & وضع أهلافية الإثرافتها على تعليم التربية & 1 & 1 \\
\hline كبيرة جرجة & ( & \&.Y & 4.22 & 4.70 & تحديد أهداف الملاحظة الصفية الإسلامية بالتعاون مع & $r$ & $r$ \\
\hline كبيرة &. $.9 \varepsilon V$ & $\varepsilon .1 \varepsilon$ & 4.10 & 4.59 & القدرة على تحديد الأهداف المتجددة لعمليات & $\varepsilon$ & $r$ \\
\hline كبيرة &. .107 & $\varepsilon . \cdot 1$ & 4.06 & 4.29 & القدرة على تنسيق جهود الأهداف التريوية . & 0 & $\varepsilon$ \\
\hline كبيرة & $1 . .77$ & r.9r & 3.89 & 4.29 & 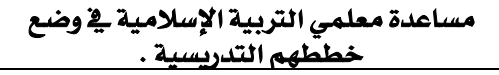 & $r$ & ○ \\
\hline كبيرة &..$\wedge 99$ & \&.1V & 4.14 & 4.52 & المتوسط العام & & \\
\hline
\end{tabular}

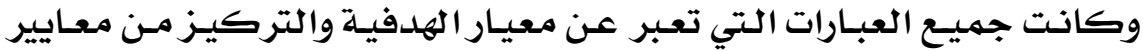

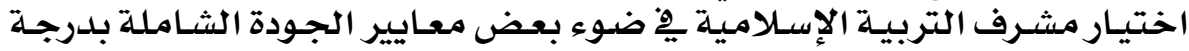

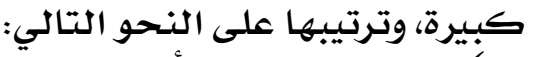

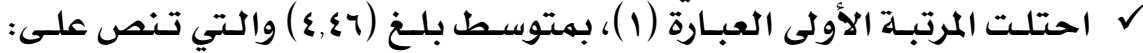

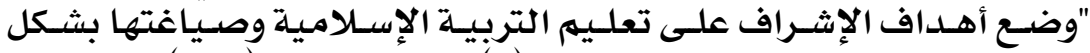

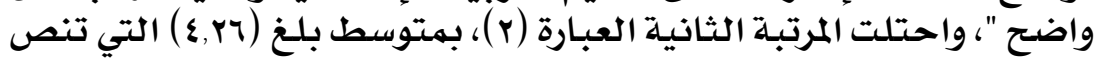

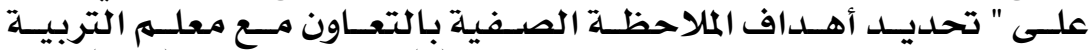

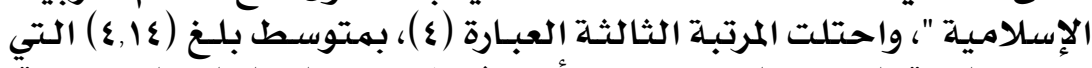

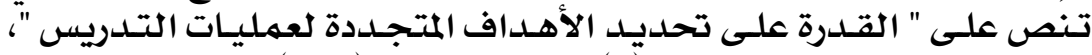

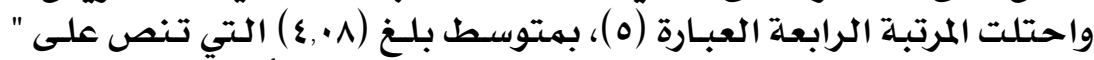

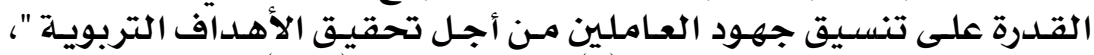

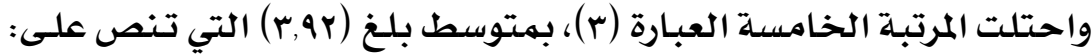

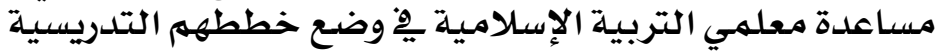

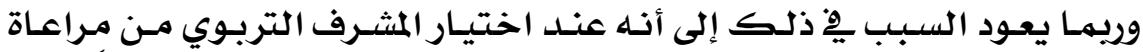

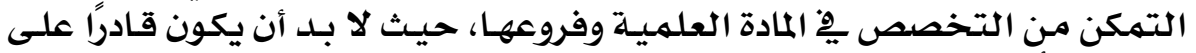

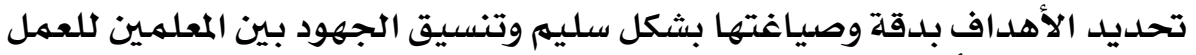

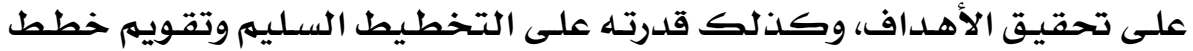

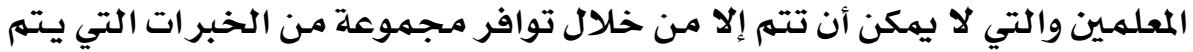

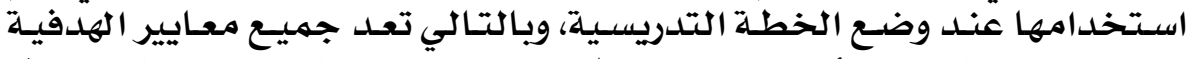

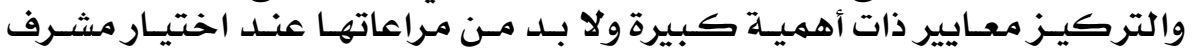
التربية الإسلاميلة.

\section{$\varepsilon 7 \%$}




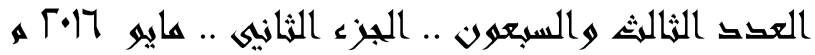

41 المعيار الثاني: التخطيط السليم: جلئ

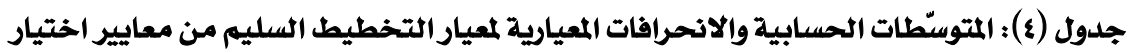

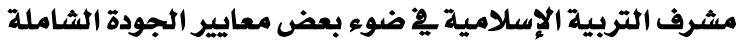

\begin{tabular}{|c|c|c|c|c|c|c|c|}
\hline \multicolumn{3}{|c|}{ الإجمالي } & 蔫 & 孯 & \multirow{2}{*}{ 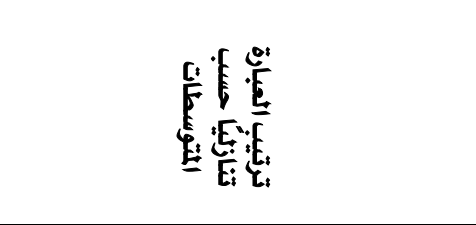 } & \multirow{2}{*}{ 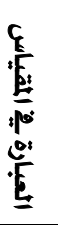 } & \multirow{2}{*}{$\underline{E}$} \\
\hline 整 & E & $\underline{E}$ & $\underline{E}$ & $\underline{E}$ & & & \\
\hline كبيرة & $\cdot, M 1$ & 8,19 & 4.13 & 4.82 & تمكن المشرف مستغلا كن إعافة الإمكانة خملات والقدراتية & 1 & 1 \\
\hline كبيرة & • (1/4 & $\varepsilon, \cdots$ & 3.95 & 4.59 & المرونة ـ2 التخطيط . & 9 & $r$ \\
\hline كبيرة & •,941 & r.१९ & 3.98 & 4.12 & 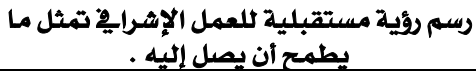 & $\wedge$ & $r$ \\
\hline كبيرة & $1, \cdot 1 V$ & r,q. & 3.88 & 4.18 & 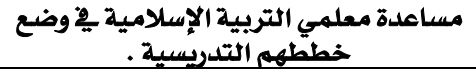 & $v$ & $\varepsilon$ \\
\hline كبيرة & $1,+19$ & r,Aт & 3.80 & 4.47 & المرغوية والمناسبة تخطيط والمستجلدة مشعات المعلمي التربية المهني & 1. & ○ \\
\hline كبيرة & ד97, & r,१9 & 3.95 & 4.44 & المتوسط العام & & \\
\hline
\end{tabular}

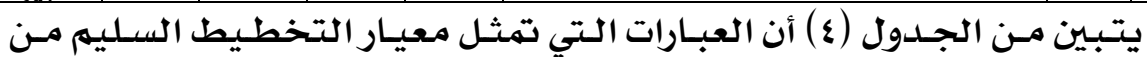

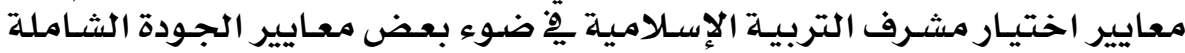

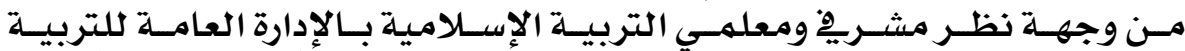

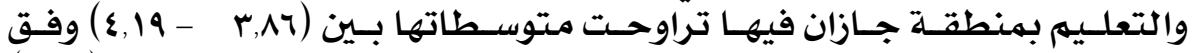

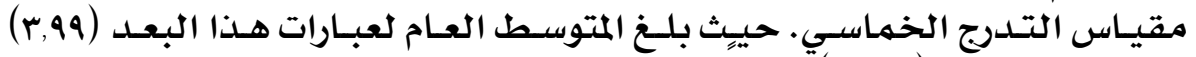

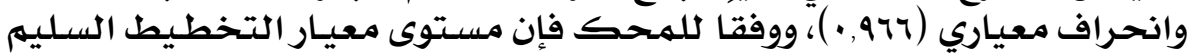

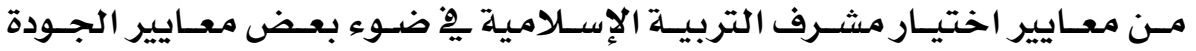

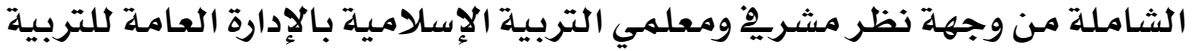

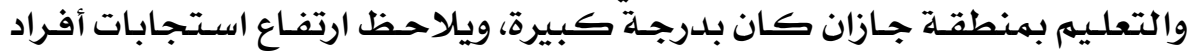

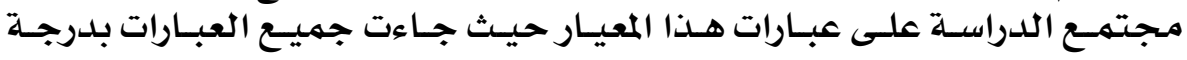
كبيرة.

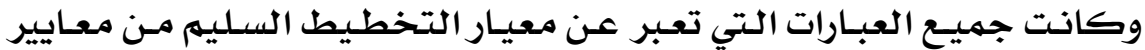

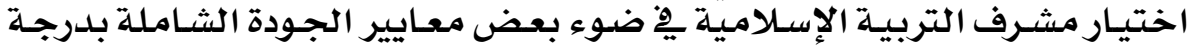

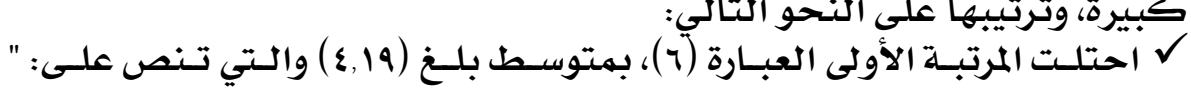

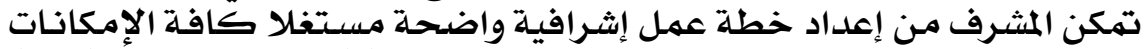

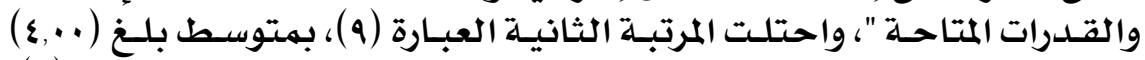

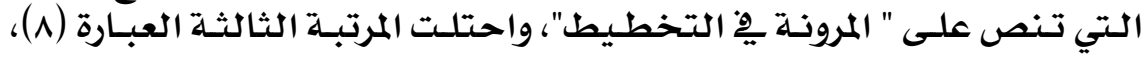

\section{$\varepsilon 7 \%$}




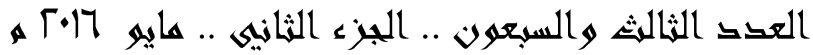

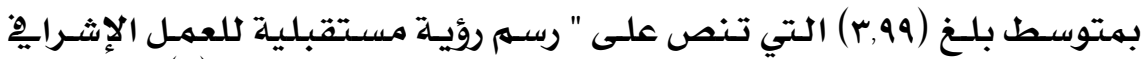

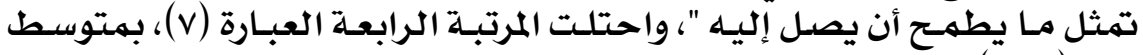

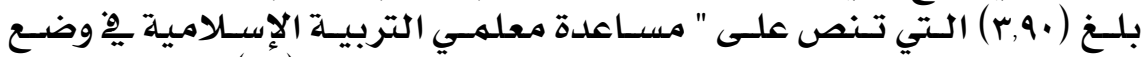

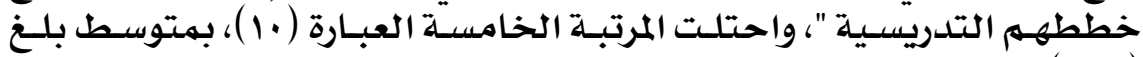

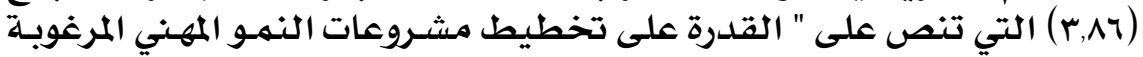

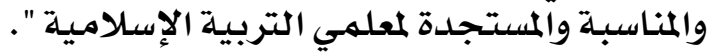

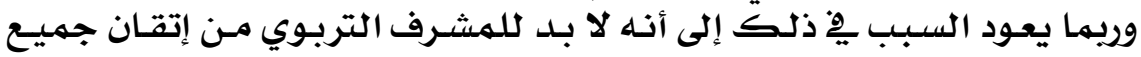

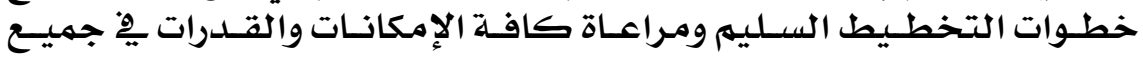

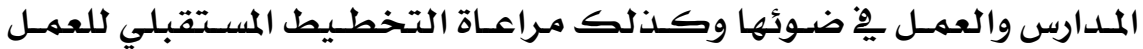

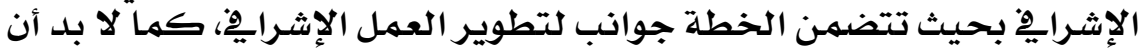

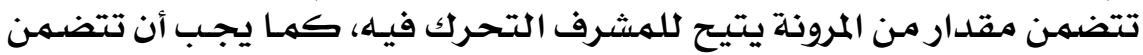

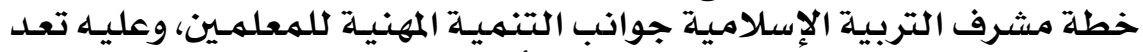

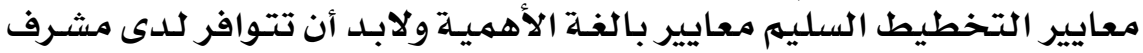

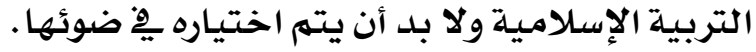

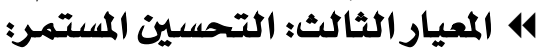

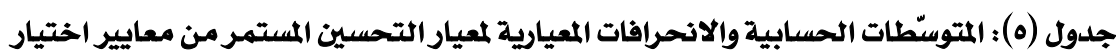

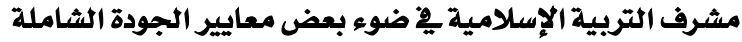

\begin{tabular}{|c|c|c|c|c|c|c|c|}
\hline \multicolumn{3}{|c|}{ الإجمالي } & $E$ & 它 & \multirow{2}{*}{ تنازيًا حتبب المتّوسطات } & \multirow{2}{*}{ 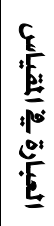 } & \multirow[b]{2}{*}{$\underline{E}$} \\
\hline$\underline{E}$ & E. & 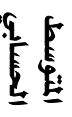 & $E$ & $E$ & & & \\
\hline ك كبيرةجداً & $\cdot, A \cdot 0$ & $\varepsilon, Y r$ & 4.20 & 4.53 & 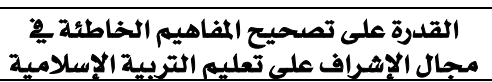 & 11 & 1 \\
\hline كبيرة & ra & $\varepsilon, .4$ & 4.03 & 4.47 & القابلية للتغيير والتطظوير للأفضل ومواكبة & 10 & $r$ \\
\hline كبيرة & 田 & r.91 & 3.95 & 4.24 & المتلاك النظرة الاستفادة التطوير العمل السابل الأجل. & 17 & $r$ \\
\hline كبيرة & - avr & $r, 97$ & 3.91 & 4.65 & 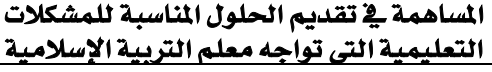 & $1 \varepsilon$ & $\varepsilon$ \\
\hline كبيرة & $1, \cdot 17$ & $r, 90$ & 3.90 & 4.59 & تحديثا مستمراً ووظيفيا يرتبط بحمادة التعاجيمية & ir & - \\
\hline كبيرة & $\bullet, 910$ & $r, 94$ & 3.89 & 4.29 & إلإشراث تغيرلى تعليم التربية الإسلآمية مجات. & ir & 1 \\
\hline | دبيرة & $\cdot, 9 \leqslant 9$ & $\varepsilon, \cdot Y$ & 3.98 & 4.46 & المتوسط العام & & \\
\hline
\end{tabular}

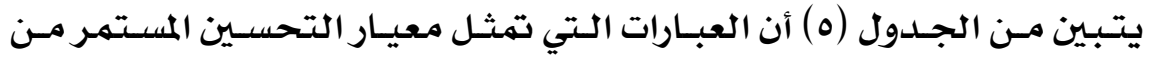

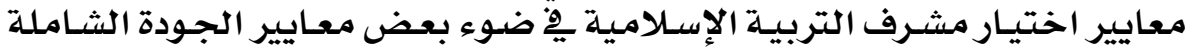

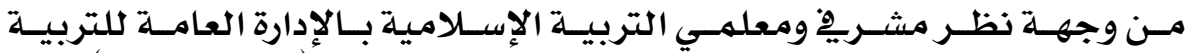

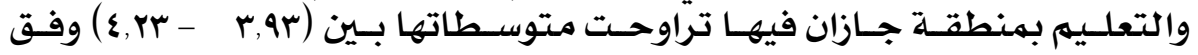

\section{$\varepsilon 7 \varepsilon$}




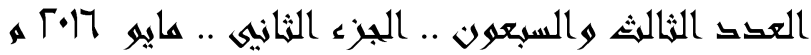

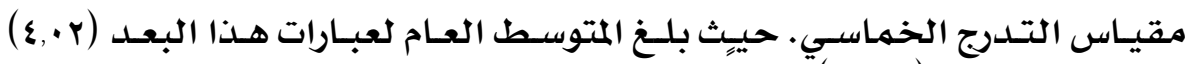

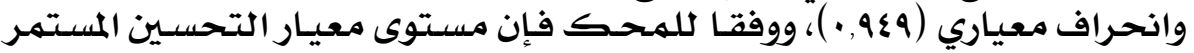

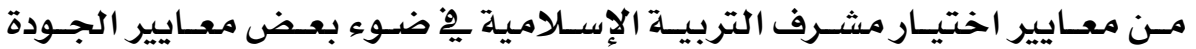

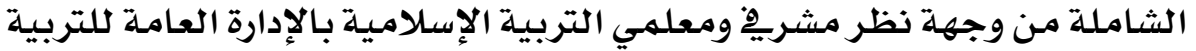

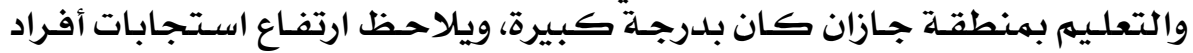

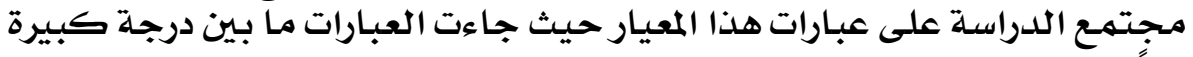
جدًا وكبيرة.

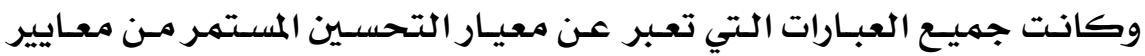

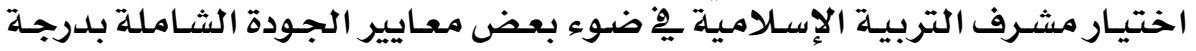

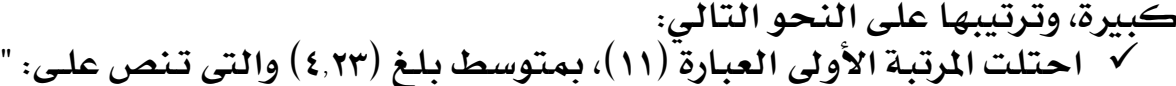

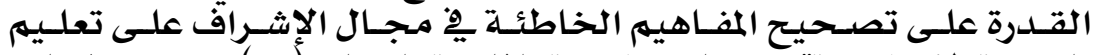

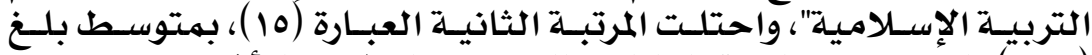

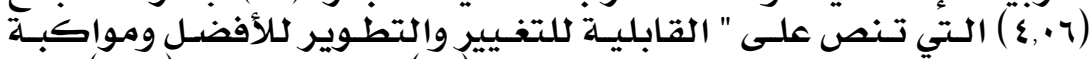

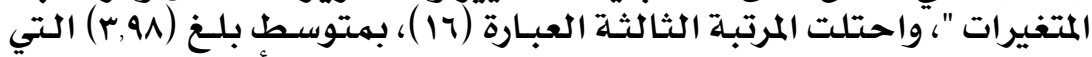

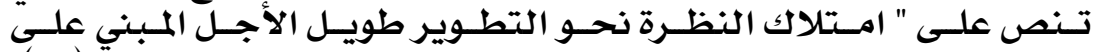

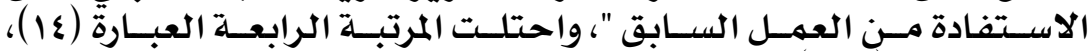

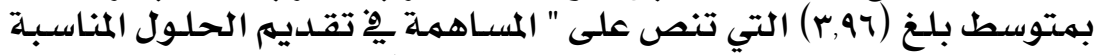

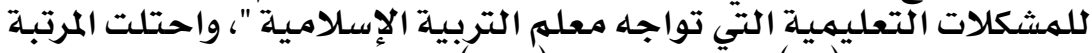

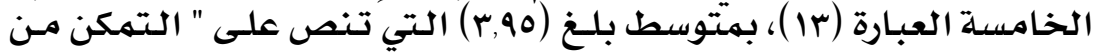

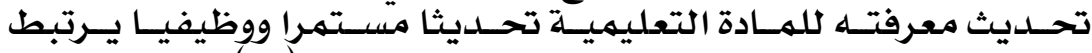

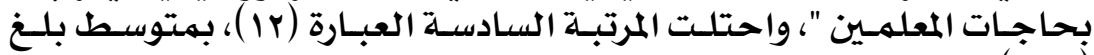

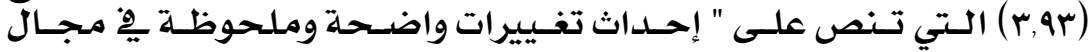
الإشراف على تعليم التربية الإسلاميلة ".

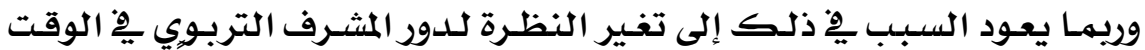

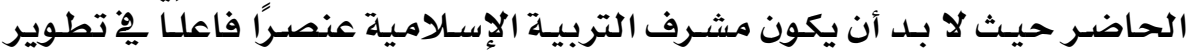

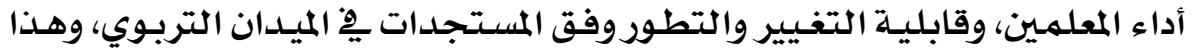

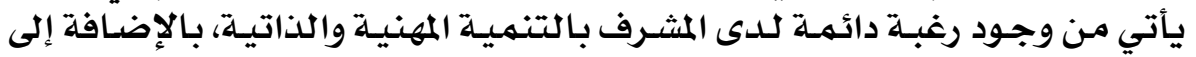

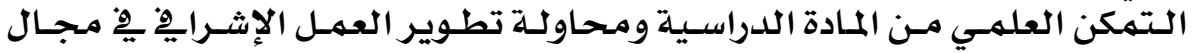

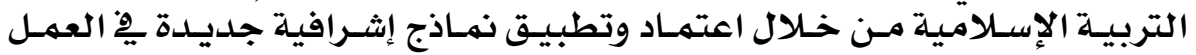

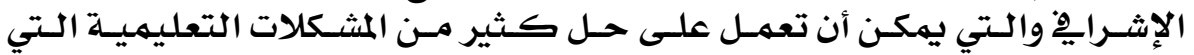

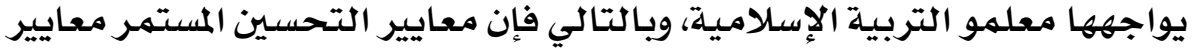

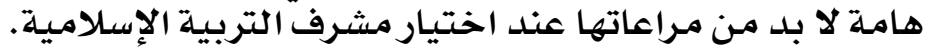

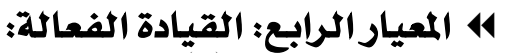

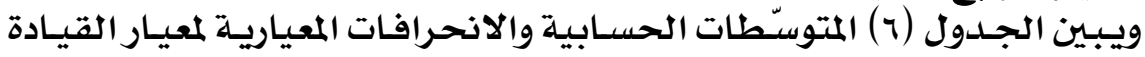

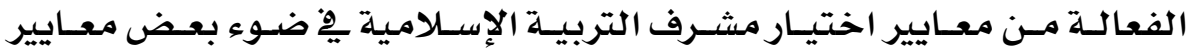
الجودة الشاملة :

\section{$\varepsilon 70$}




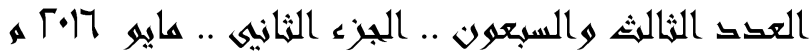

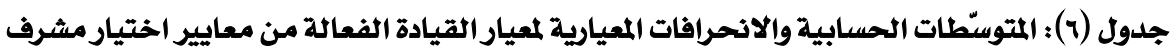

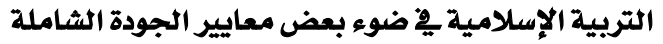

\begin{tabular}{|c|c|c|c|c|c|c|c|}
\hline \multicolumn{3}{|c|}{ الإجمالي } & E & 资 & \multirow{2}{*}{ تنازبيًا حسبب المتبوسطات } & \multirow{2}{*}{$\begin{array}{l}\underline{E} \\
\underline{E} \\
\underline{E} \\
\underline{E} \\
\underline{E} \\
\underline{E} \\
\underline{E}\end{array}$} & \\
\hline التقدير & 占 & $\underline{E}$ & $E$ & $\underline{E}$ & & & \\
\hline كبيرة دجداً & •,^£V & $\varepsilon, \mu \varepsilon$ & 4.31 & 4.65 & اتصاف المشرف بالثقة بالنفس & iv & 1 \\
\hline | دبيرة & $1, \cdot \cdot r$ & $\varepsilon, 1 \varepsilon$ & 4.11 & 4.47 & مراعاة مشرف التربية العندالإسلامية المعلمين تحقيق & rI & $r$ \\
\hline 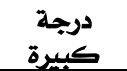 & •,MY & $\varepsilon, 1 r$ & 4.07 & 4.64 & القدرة على الإقناع والتأثير & in & $r$ \\
\hline كبيرة & •,990 & $\varepsilon, \cdot \vee$ & 4.02 & 4.59 & 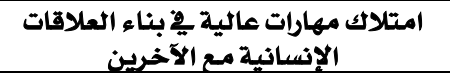 & rr & $\varepsilon$ \\
\hline 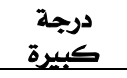 & $\cdot, 9 \cdot 1$ & $\varepsilon, \cdot r$ & 3.98 & 4.47 & 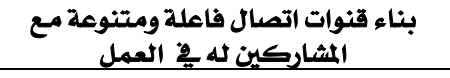 & $r$ & ○ \\
\hline كبيرة & - $9 v$. & $r, 99$ & 3.94 & 4.53 & القدرة على اتخاذ القرارات الفعالة & 19 & 7 \\
\hline 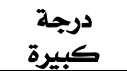 & (arr & $\varepsilon, 11$ & 4.07 & 4.56 & المتوسط العام & & \\
\hline
\end{tabular}

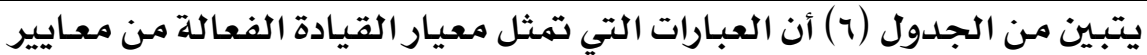

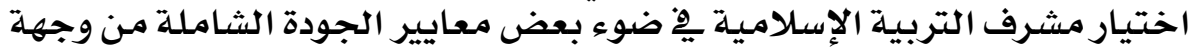

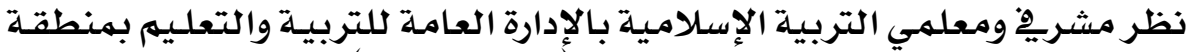

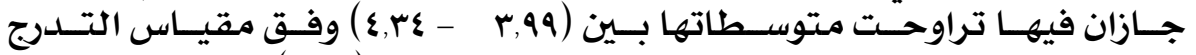

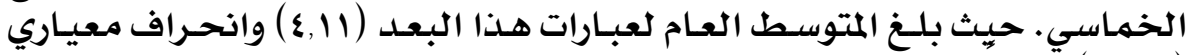

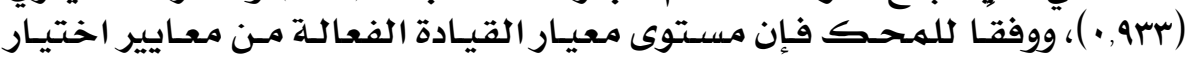

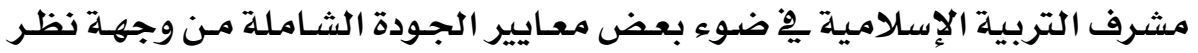

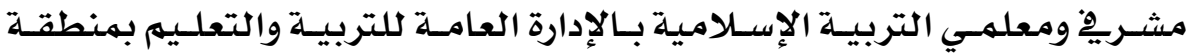

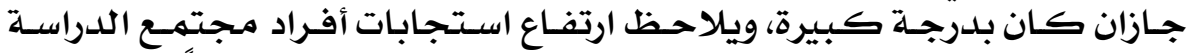

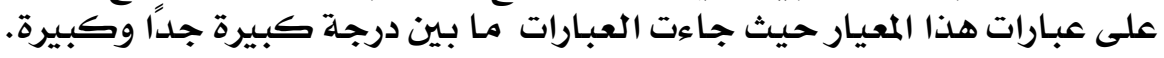

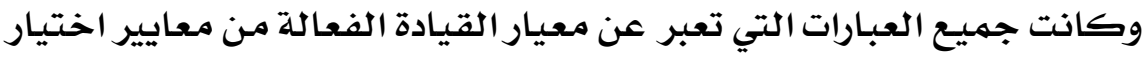

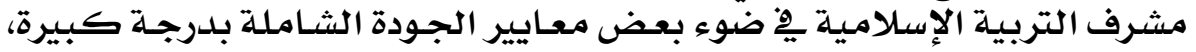

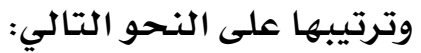

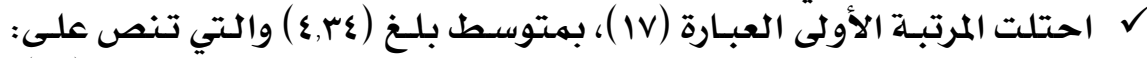

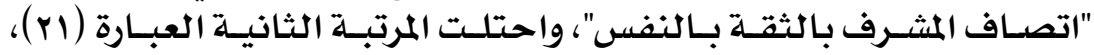

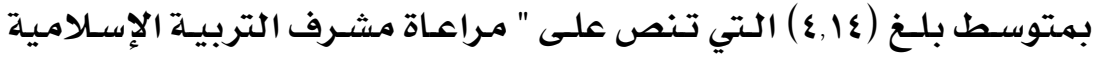

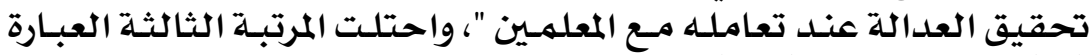

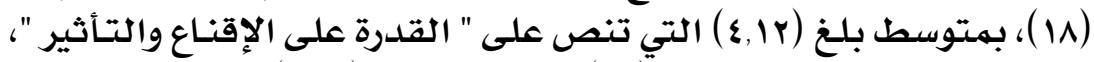

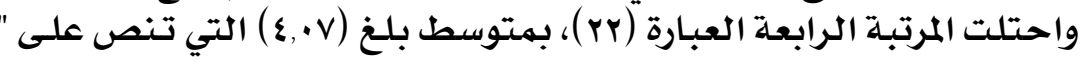

\section{$\varepsilon 77$}




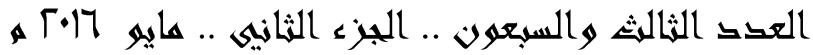

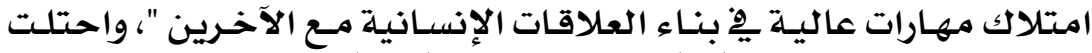

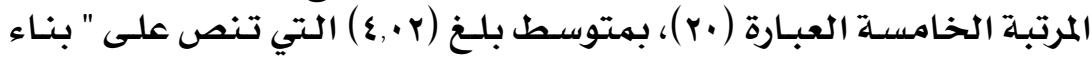

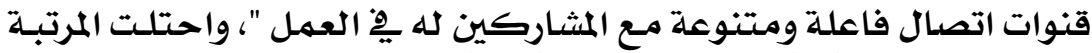

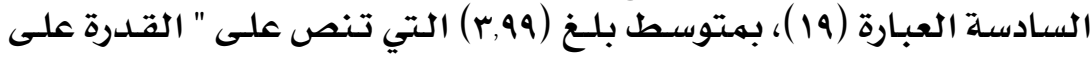
اتخاذ القرارات الفعالة ".

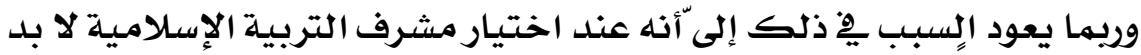

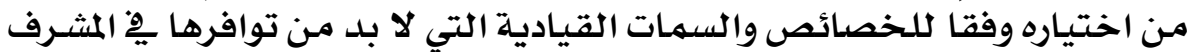

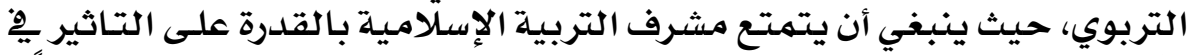

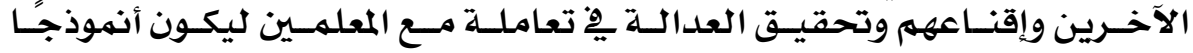

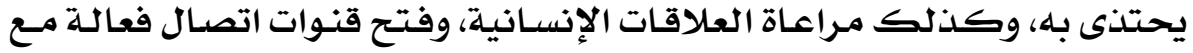

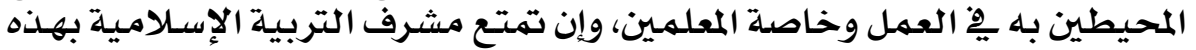

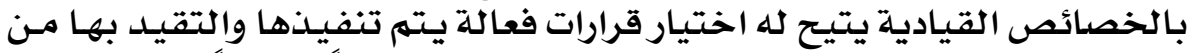

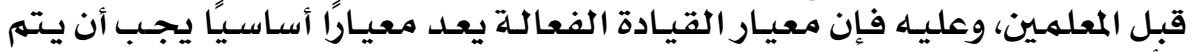

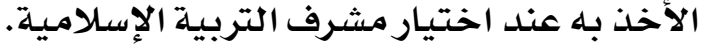

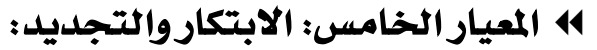

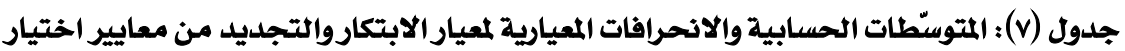

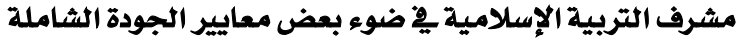

\begin{tabular}{|c|c|c|c|c|c|c|c|}
\hline & | (إجمالي & & E & 点 & & $\underline{E}$ & if \\
\hline$\underline{E}$ & E & $\underline{E}$ & $E$ & $E$ & تنازليًا حسب المتوسطات & 莫 & $\underline{\underline{E}}$ \\
\hline كرجيرة & $\cdot, \wedge 91$ & $\varepsilon, .4$ & 4.01 & 4.71 & حث المعلمين على الإبداع والتجديد يج جالتدريد & rq & 1 \\
\hline 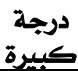 & . 999 & $\varepsilon, 0$ & 4.00 & 4.59 & استخدام أساليب ووسائل مبتكرة . & rr & r \\
\hline درجيرة & I & r.,9 & 3.94 & 4.58 & القدرة على تطوير ادوات تقويمية . & $\mathrm{rv}$ & $r$ \\
\hline درجيرة & $\cdot 9 M$ & r.q. & 3.84 & 4.57 & تنمية مهارات التفكير الناقد . & $r \varepsilon$ & $\varepsilon$ \\
\hline كرجيرة & $1, \cdot r$ & $r, \wedge 9$ & 3.82 & 4.65 & تنمية مهارات التفكير الإبتكاري . & ro & 0 \\
\hline 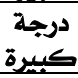 & - & r.91 & 3.92 & 4.62 & المتوسط العام & & \\
\hline
\end{tabular}

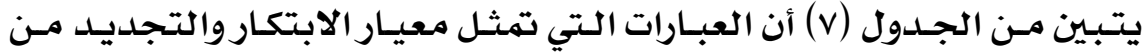

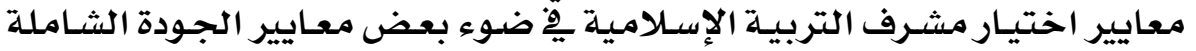

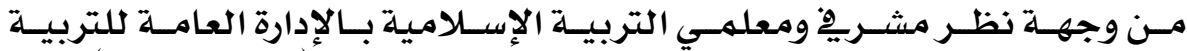

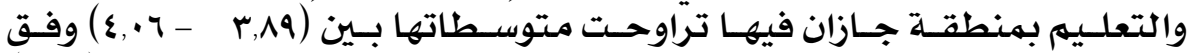

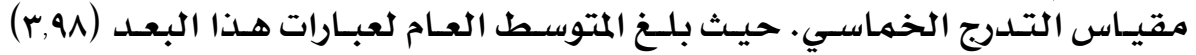

\section{$\varepsilon 7 V$}




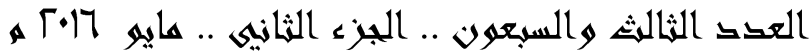

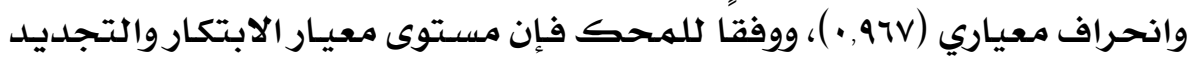

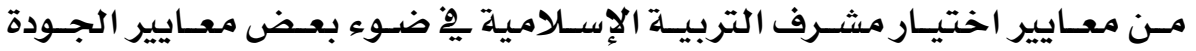

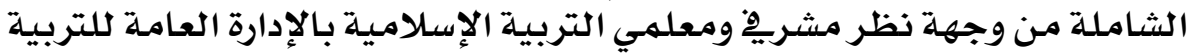

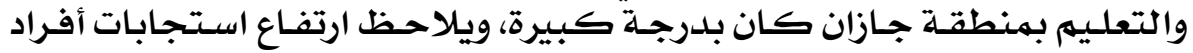

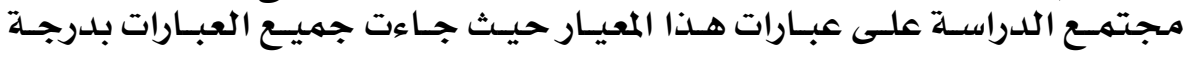
كبيرة.

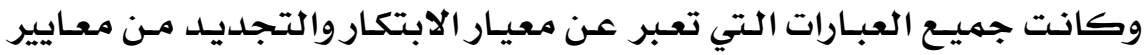

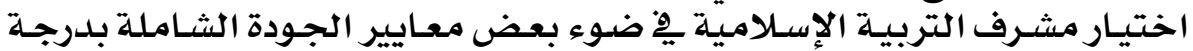

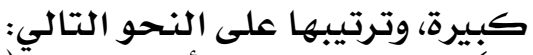

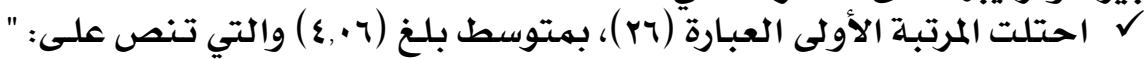

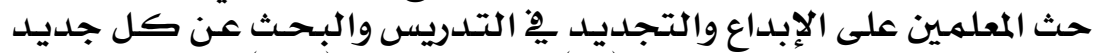

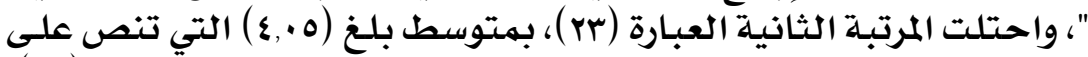

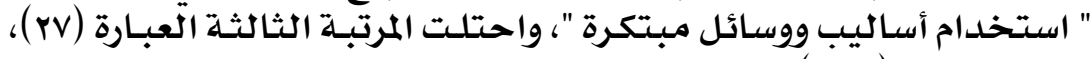

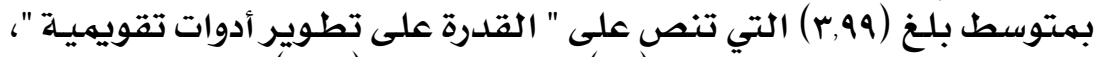

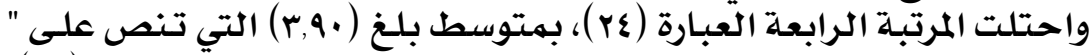

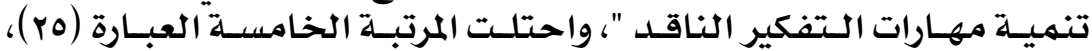

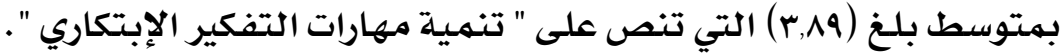

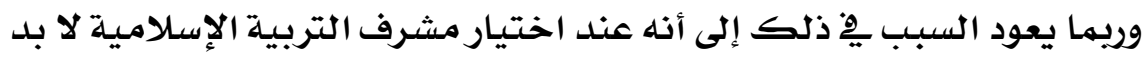

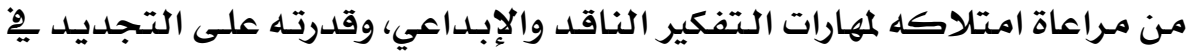

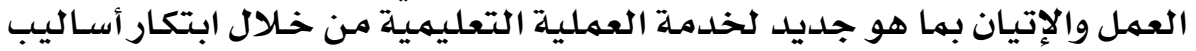

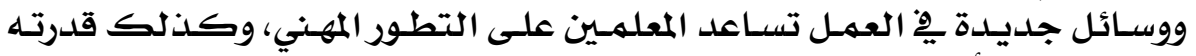

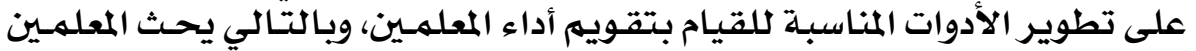

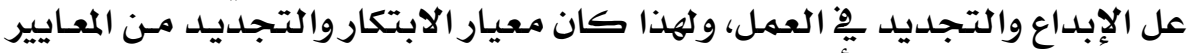

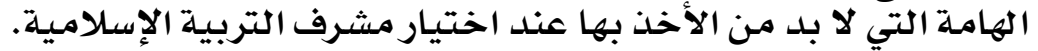
414

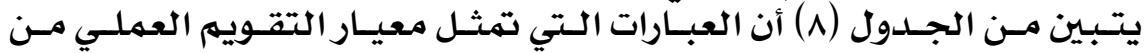

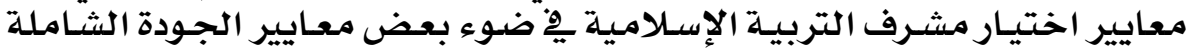

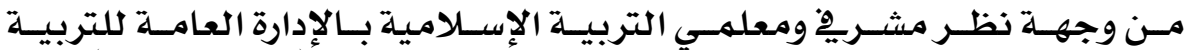

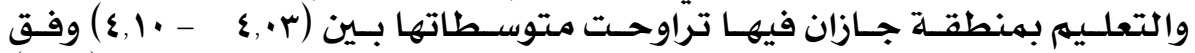

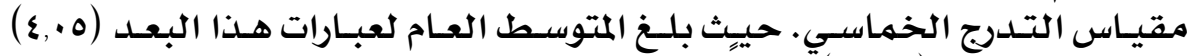

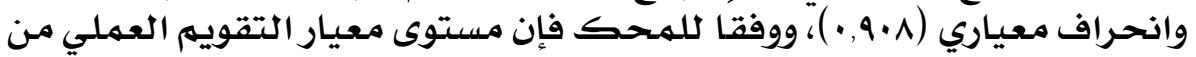

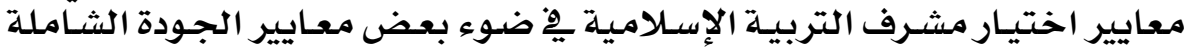

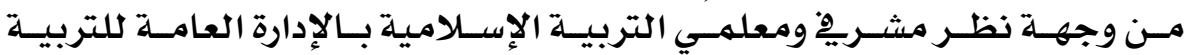

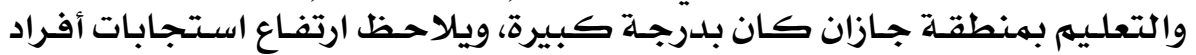

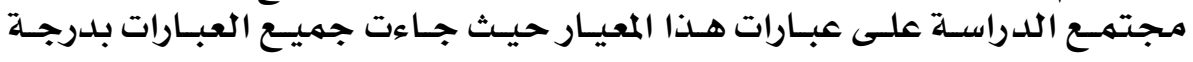
كبيرة.

\section{$\varepsilon 4 \wedge$}




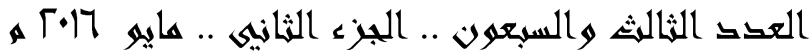

جدول (^) : المتوستطات الحسابية والانحرافات المعيارية لمعيار التقويم العملي من معايير اختيار مشرف

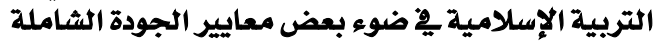

\begin{tabular}{|c|c|c|c|c|c|c|c|}
\hline & ل لإجمالي & & $\underline{E}$ & 苞 & & $\frac{\underline{E}}{\underline{E}}$ & \\
\hline E & 㝵是 & $\underline{E}$ & $E$ & $E$ & المتوسطات & E. & \\
\hline كبيرة & הTוג, & $\varepsilon, 1$. & 4.08 & 4.36 & القدرة على تقييم البرامج وإللقاءات والخطط & rq & 1 \\
\hline كبيرة & • MA & $\varepsilon,-\varepsilon$ & 4.02 & 4.35 & التمكن من تقويم الأنشطة التي تشارك فيها & r. & $r$ \\
\hline كبيرة & •, $90 \varepsilon$ & $\varepsilon, r$ & 3.99 & 4.59 & 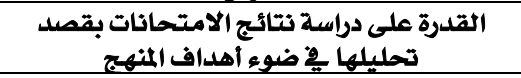 & YA & $r$ \\
\hline 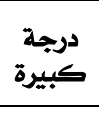 & - 94 . & $\varepsilon, r$ & 3.98 & 4.41 & 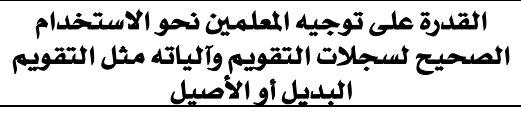 & ri & $\varepsilon$ \\
\hline 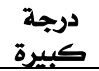 & $\cdot 9 \cdot 1$ & $\varepsilon, 0$ & 4.02 & 4.43 & المتوسط العام & & \\
\hline
\end{tabular}

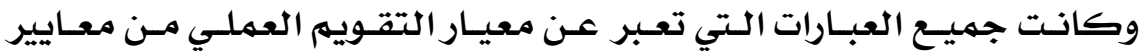

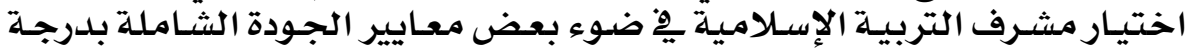

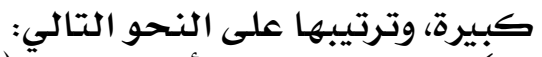

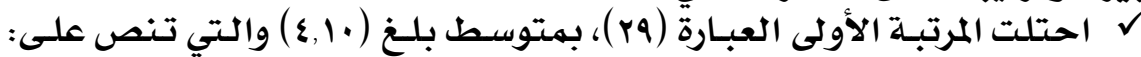

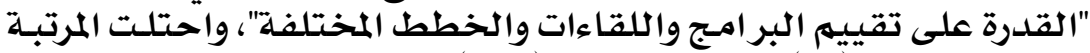

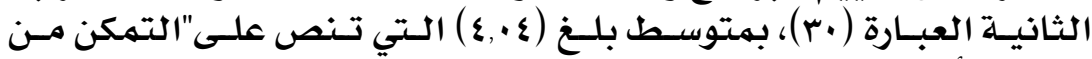

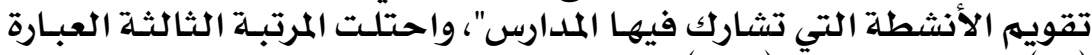

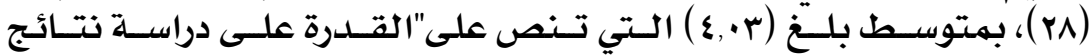

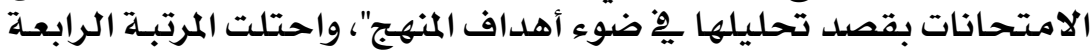

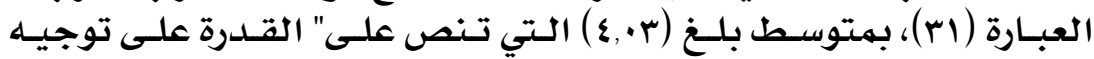

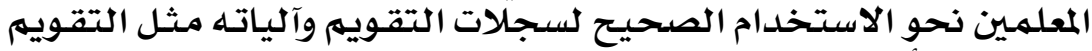

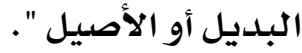

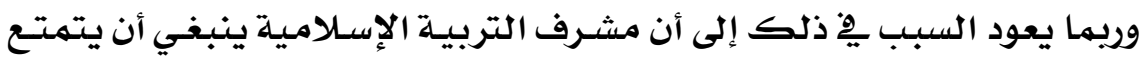

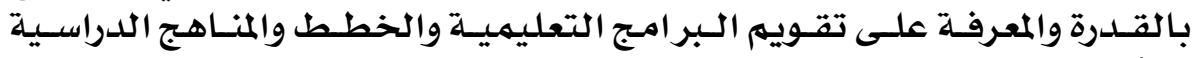

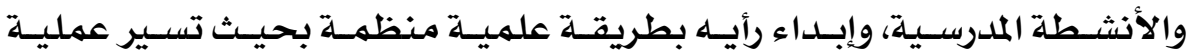

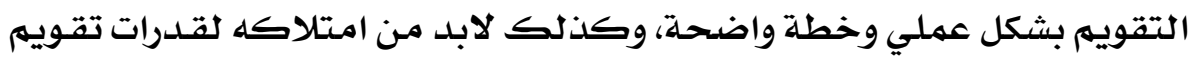

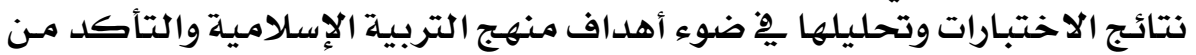

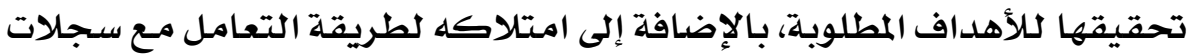

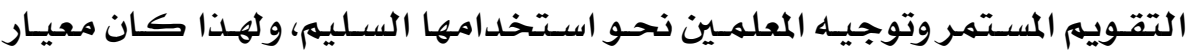

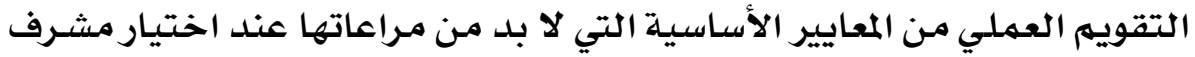

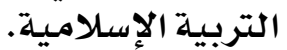

\section{9}




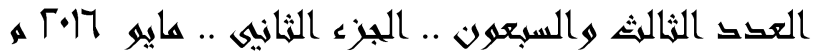

(14 المعيار السابع: التغذذية الراجعة:

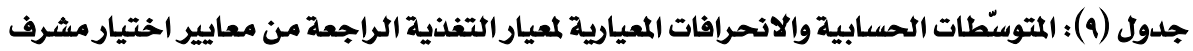

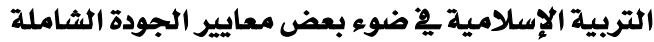

\begin{tabular}{|c|c|c|c|c|c|c|c|}
\hline & | (إجمالي & & $\frac{E}{E}$ & 悹 & & $\underbrace{\varepsilon}_{t}$ & \\
\hline 梠 & $\begin{array}{l}5 \\
E \\
\underline{E}\end{array}$ & $\underline{E}$ & $\underline{E}$ & $\underline{E}$ & تنازليًا حسب المتوسطات & $\underline{\underline{E}}$ & $\underline{E}$ \\
\hline كبيرة & "90\% & $\varepsilon, 10$ & 4.09 & 4.82 & 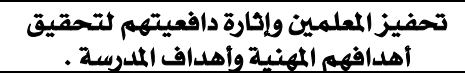 & rY & 1 \\
\hline كبيرة & $\cdot, 9 r V$ & r,१६ & 3.89 & 4.53 & متابعة أر التدريب على المعلمين وانعكاسه & $r \varepsilon$ & r \\
\hline كبيرة & (97) & r,qYo & 3.86 & 4.41 & تحليل عملية التدريس بالتشارك ميع المعلم & rr & $r$ \\
\hline كبيرة & •, 4 Y & $r, \wedge 0$ & 3.81 & 4.47 & رصد مدى تحقق أهداف المنهج • & ro & $\varepsilon$ \\
\hline كبيرة & $1, \cdot Y \varepsilon$ & r,A & 3.80 & 4.35 & القدرة على استخدام المعززات المتنوعة . & mi & ○ \\
\hline كبيرة & $\cdot 9 \times 1$ & r.१६ & 3.89 & 4.52 & المتوسط العام & & \\
\hline
\end{tabular}

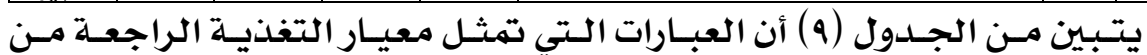

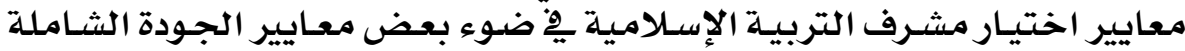

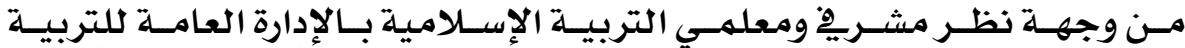

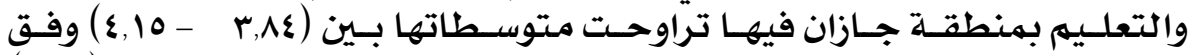

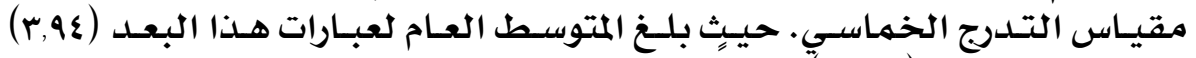

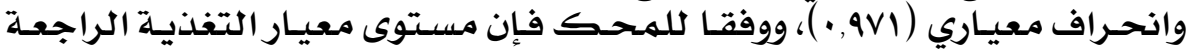

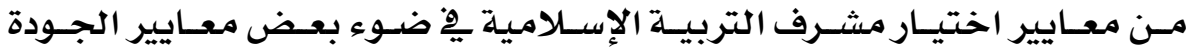

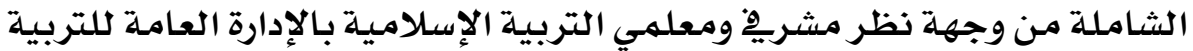

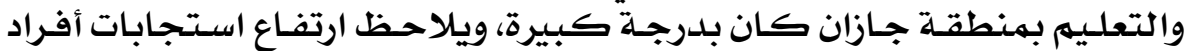

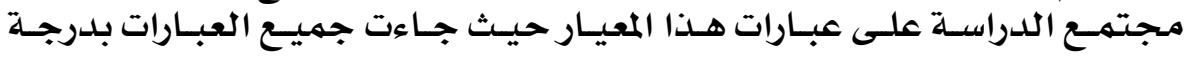
كبيـرة.

وكانت جميـع العبـارات الـتي تعـبر عن معيـار التغذذيـة الراجعـة مـن معـايير

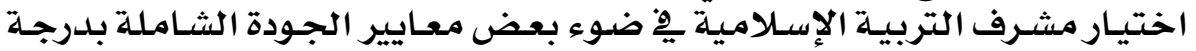

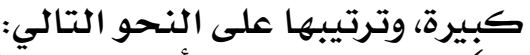

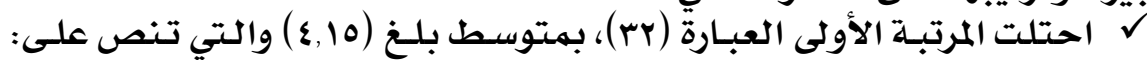

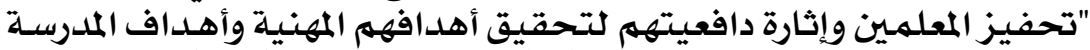

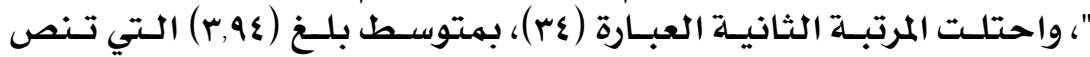

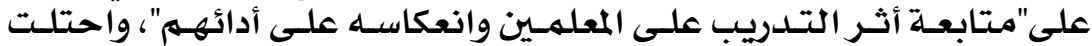

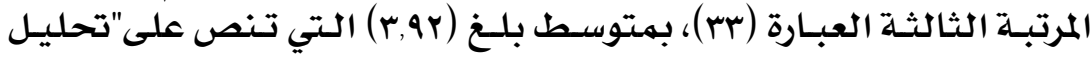

\section{$\varepsilon V$.}




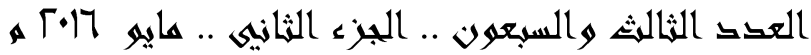

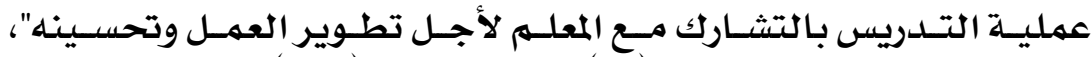

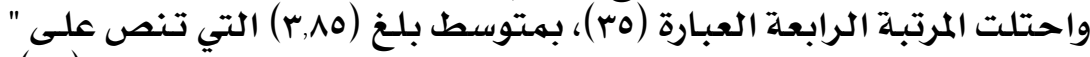

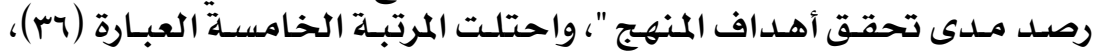

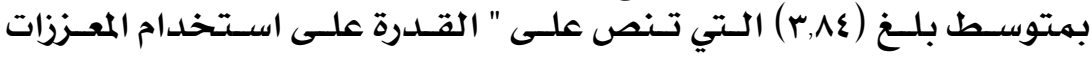
المتنوعة ".

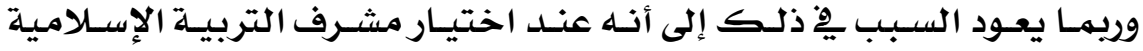

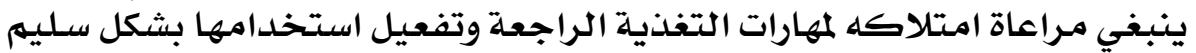

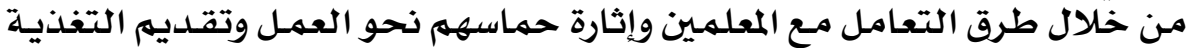

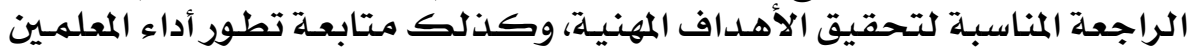

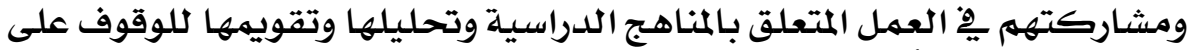

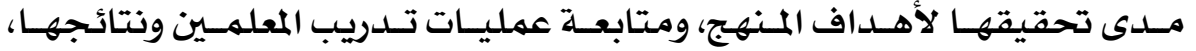

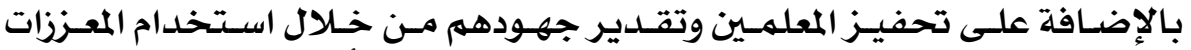

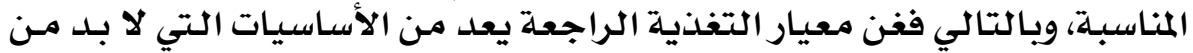

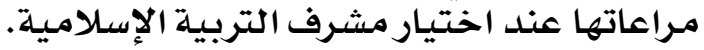

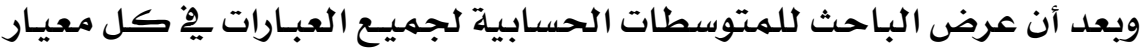

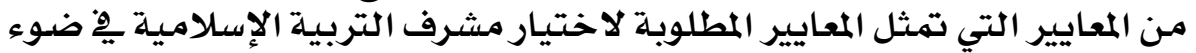

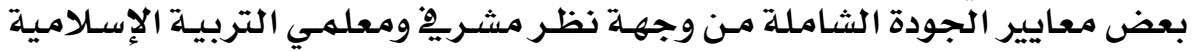

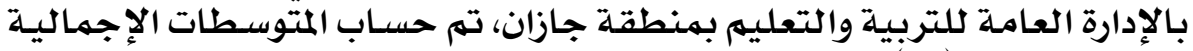

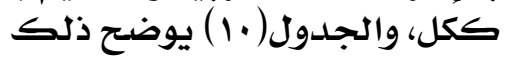

جلول (.1): المتوسّطات الحسابية الإجمالية والانحرافات المعيارية للمعايير المطلوبة لاختيار مشرف

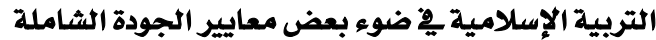

\begin{tabular}{|c|c|c|c|c|c|c|}
\hline \multicolumn{3}{|c|}{ الاجمالي } & المعلمين & المشرفين & \multirow[b]{2}{*}{ تنازبيًا حسبب المتوسيير } & \multirow[b]{2}{*}{ p } \\
\hline التقدير & الانحراف المعياري & الحستوسط & المتوسط & المتوسط & & \\
\hline درجة كبيرة & $\cdot, \wedge 99$ & $\varepsilon, 1 V$ & 4.14 & 4.52 & الهدفية والتركيز & 1 \\
\hline درجة كبيرة & (1) & $\varepsilon, 11$ & 4.07 & 4.56 & القيادة الفعالة & $r$ \\
\hline درجة كبيرة & $\cdot, 9 \cdot 1$ & $\varepsilon, \cdot 0$ & 4.02 & 4.43 & التقويم العملى & $r$ \\
\hline درجة كبيرة & $\bullet, 9 £ 9$ & $\varepsilon,+r$ & 3.98 & 4.46 & التحسين المستمر & $\varepsilon$ \\
\hline درجة كبيرة &., 974 & $r, 99$ & 3.95 & 4.44 & التخطيط السليم & 0 \\
\hline درجة كبيرة &., $97 \mathrm{~V}$ & $r, q \Lambda$ & 3.92 & 4.62 & الابتكاروالتجديل & 7 \\
\hline درجة كبيرة & $\cdot, 9 \mathrm{VI}$ & $r, q \varepsilon$ & 3.89 & 4.52 & التغذية الراجعة & $v$ \\
\hline درجة كبيرة & $\cdot, 9 \varepsilon Y$ & $\varepsilon, \cdot \varepsilon$ & 4.00 & 4.51 & المتوسط الإجمالى & \\
\hline
\end{tabular}

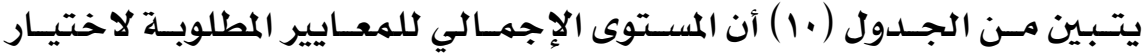

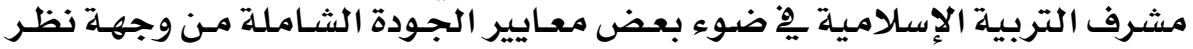

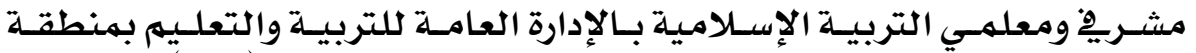

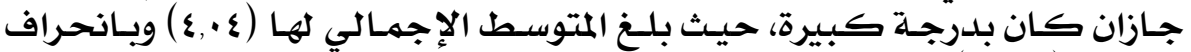

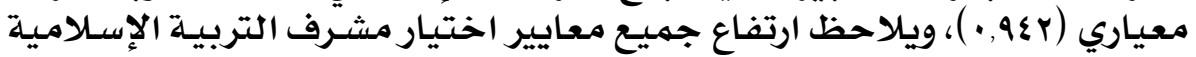

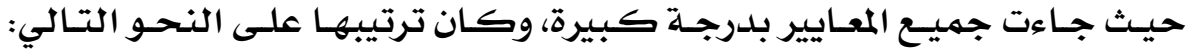

\section{$\varepsilon \vee 1$}




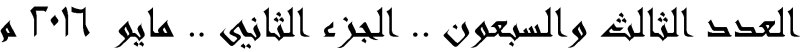

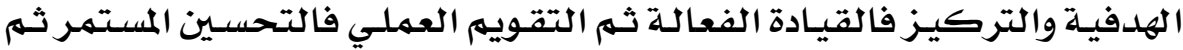

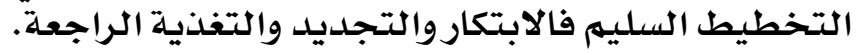

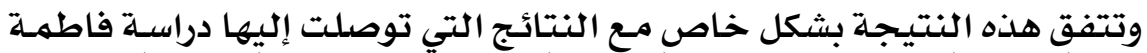

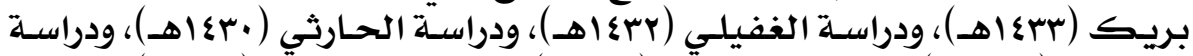

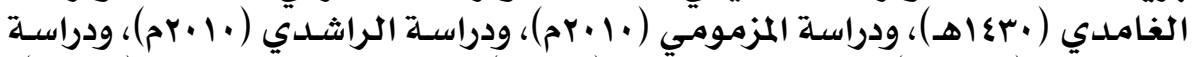

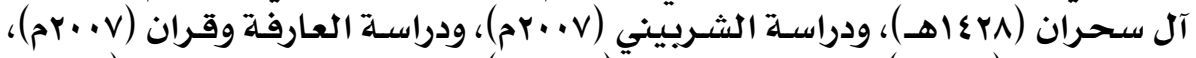

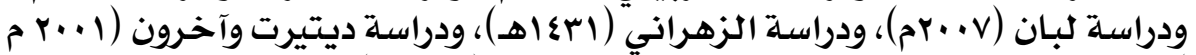
توفر Detret \& Others ( توفر معايير الجودة الشاملة عند اختيار المشرفين التربويين.

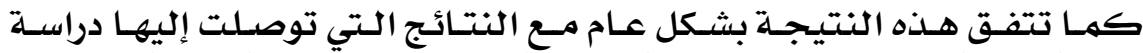

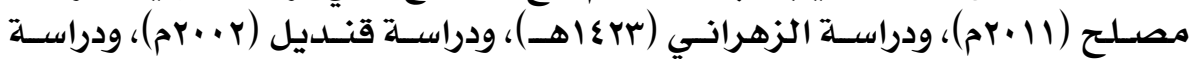

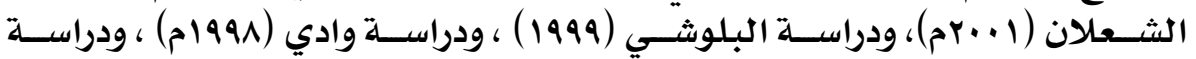

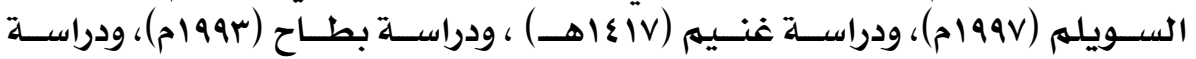

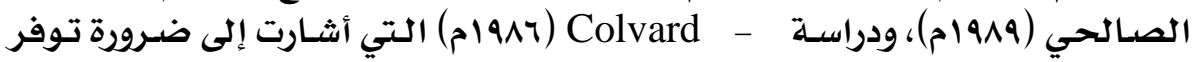

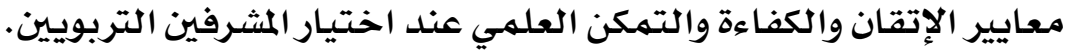

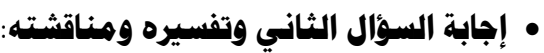

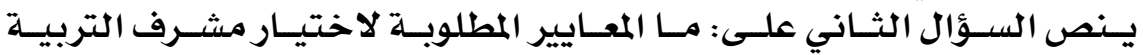

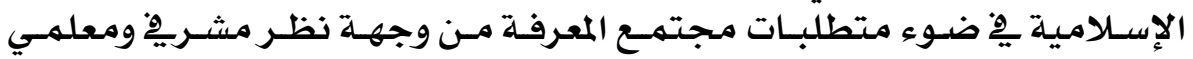

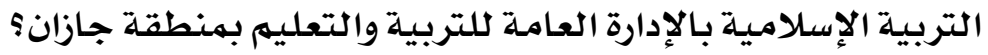

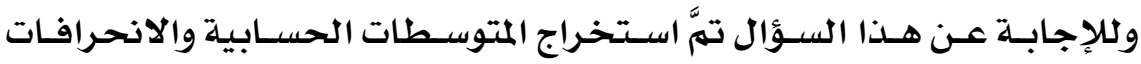

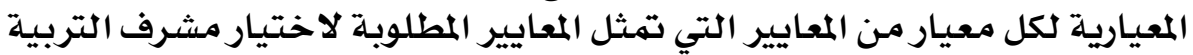

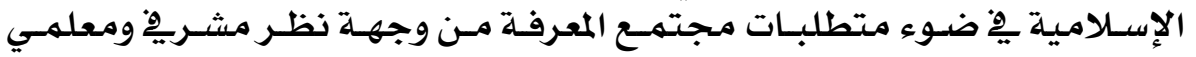

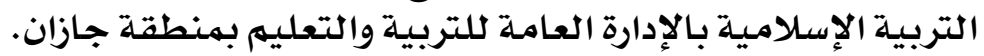

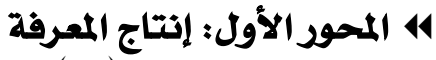

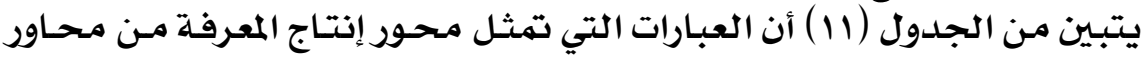

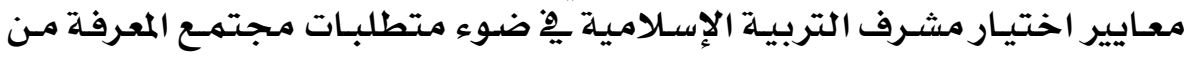

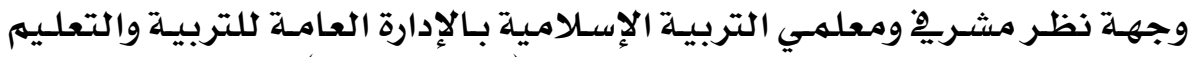

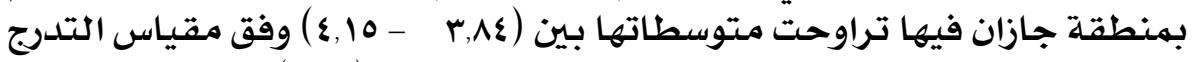

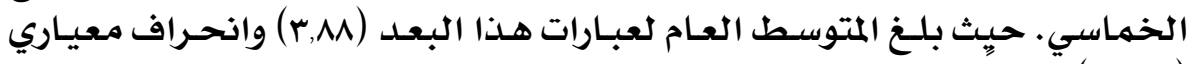

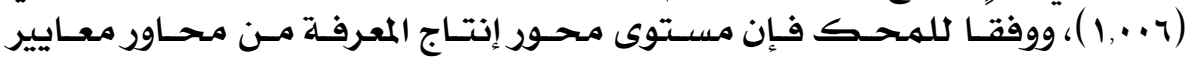

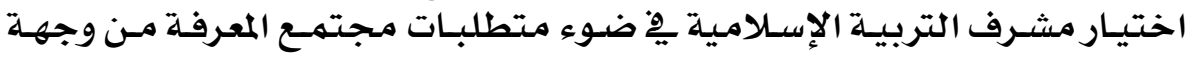

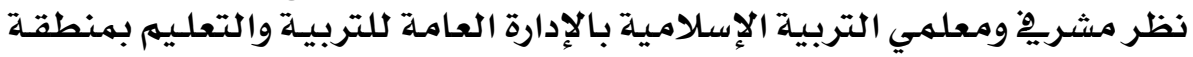

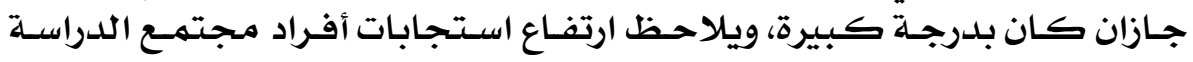

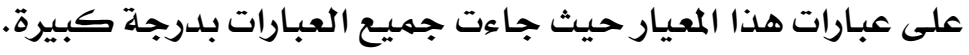

\section{$\varepsilon \vee Y$}




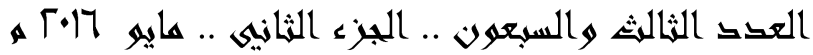

جدول (11): المتوس"طات الحسابية والانحرافات المعيارية لمحور إنتاج المعرفة من محاور معايير اختيار

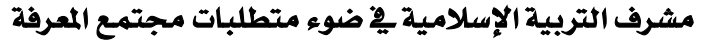

\begin{tabular}{|c|c|c|c|c|c|c|c|}
\hline & إِجمالي & & E & . & & $\underline{E}$ & \\
\hline 䈏 & 焉定 & 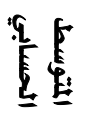 & $\underline{E}$ & $\underline{E}$ & تنازيًا حسب المتوسطات & 焉 & $\underline{\underline{E}}$ \\
\hline ك كبيرة & •,AV. & $\varepsilon, 0$ & 4.02 & 4.35 & 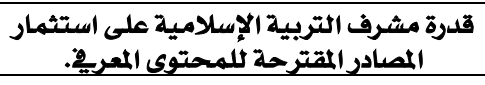 & 1 & 1 \\
\hline كبيرة & 迎, & $\varepsilon, .1$ & 3.99 & 4.29 & القدرة على استخدام تقنية المكتبات ومصادر & $\varepsilon$ & r \\
\hline كرجيرة & •,AV & $\varepsilon, \cdot \cdot$ & 3.97 & 4.28 & الإلمام بإجراءات البحث العلمي التريوي. & $r$ & $r$ \\
\hline كبيرة & •, 904 & $r .90$ & 3.91 & 4.27 & 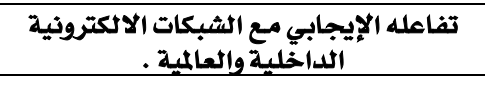 & • & $\varepsilon$ \\
\hline ك كبيرة & , 909 & r.ar & 3.88 & 4.41 & القدرة على استخدام أسلوب حل المككلات & $\wedge$ & • \\
\hline ك كبيرة &., 919 & $r, 10$ & 3.83 & 4.06 & الإِمام بطرق ابتكار المعرفة. & $r$ & 9 \\
\hline ك كبيرة & 1,121 & r.v\& & 3.70 & 4.12 & الاهتمام بكتابة البحورث وحضور الندوات & 1 & $v$ \\
\hline كبيرة & $1,1 v \varepsilon$ & $r, v 1$ & 3.65 & 4.40 & امتلاكك مهارات التعلم المستمر مدى الحياة. & 9 & $\wedge$ \\
\hline كبيرة & 1,rYq & $r, v \cdot$ & 3.64 & 4.29 & 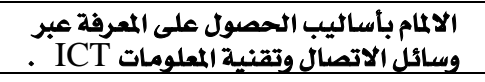 & $\begin{array}{rl}v & r \\
\end{array}$ & 9 \\
\hline 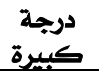 & $1, \cdots r$ & r,M & 3.84 & 4.28 & المتوسط العام & & \\
\hline
\end{tabular}

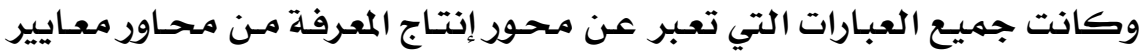

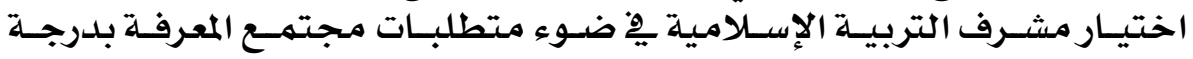

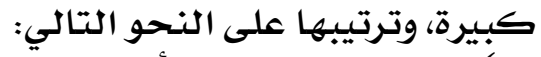

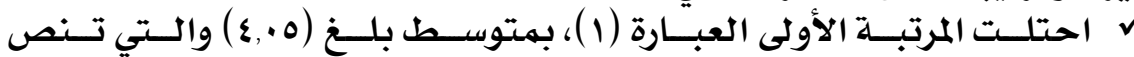

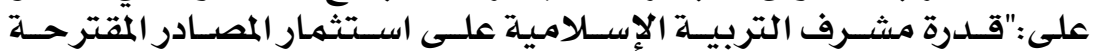

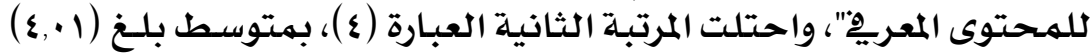

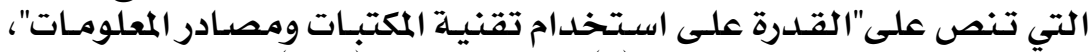

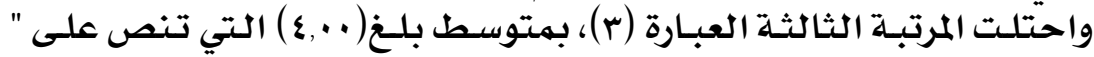

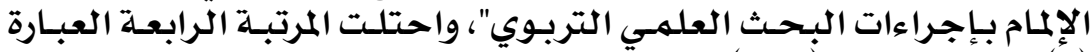

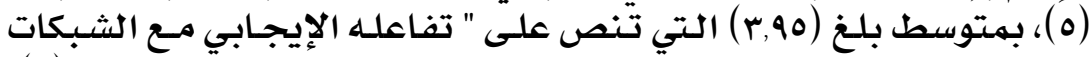

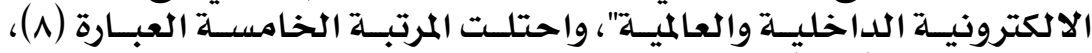

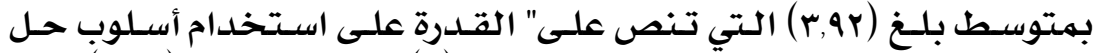

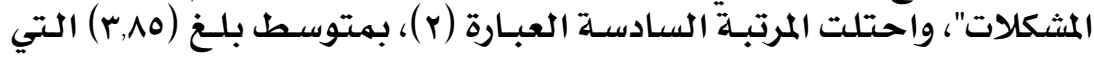

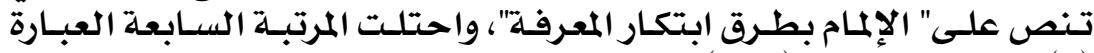

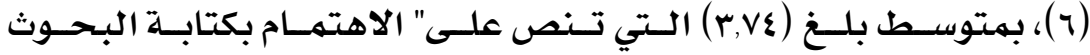

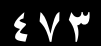




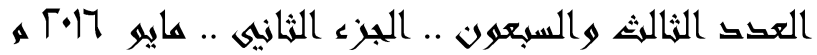

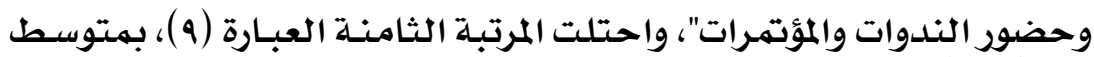

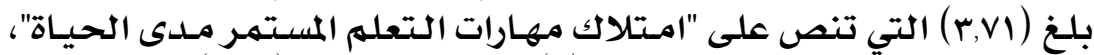

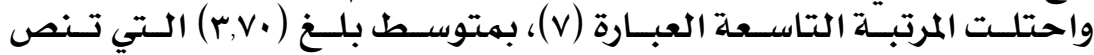

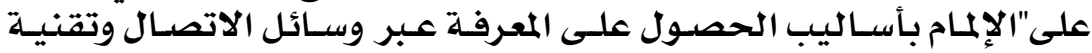

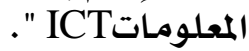

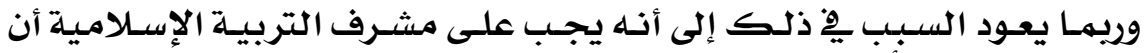

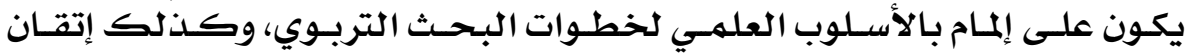

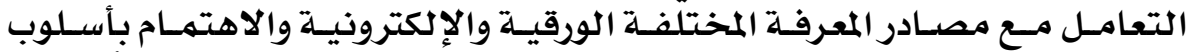

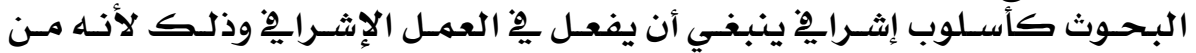

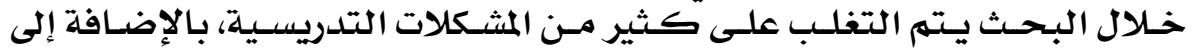

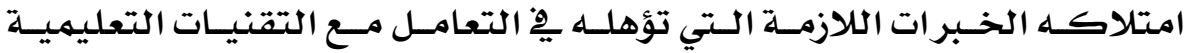

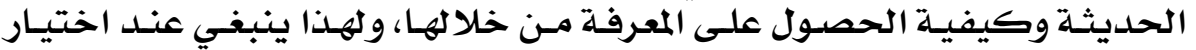

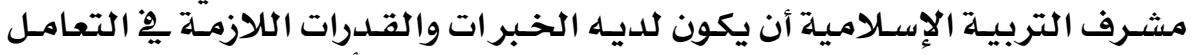

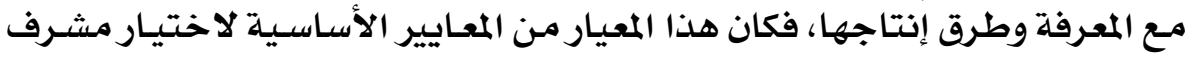

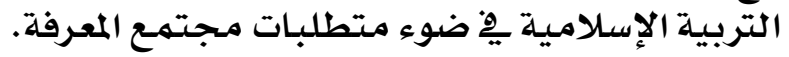
414

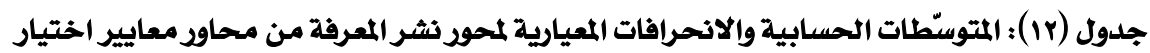

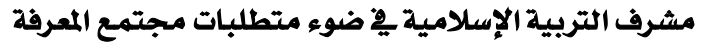

\begin{tabular}{|c|c|c|c|c|c|c|c|}
\hline & لإجمالي & & E & . & & $\frac{E}{E_{i}}$ & \\
\hline 䈏 & 点 & $\underline{E}$ & $\underline{E}$ & 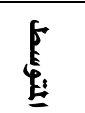 & تنازليًا حسب المتوسطات & E & $\underline{\underline{E}}$ \\
\hline 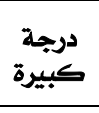 & . & $\varepsilon, 1 \%$ & 4.08 & 4.71 & 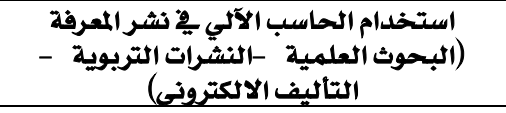 & 1. & 1 \\
\hline 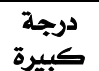 & •,970 & $\varepsilon, \cdot 1$ & 3.98 & 4.35 & 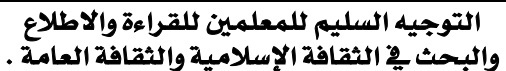 & 11 & r \\
\hline كرجيرة & $1,+\varepsilon 0$ & $r, A Y$ & 3.77 & 4.41 & التمكن من توظيف الأساليب الإشرافية لنشر & $1 \varepsilon$ & $r$ \\
\hline كبيرة & $1,-81$ & r.va & 3.76 & 4.06 & 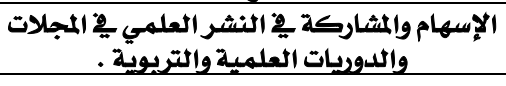 & ir & $\varepsilon$ \\
\hline كبيرة & 1,104 & r.,09 & 3.56 & 3.94 & إتقان مهارات التعليم عن بعد . & ir & - \\
\hline كبيرة & $1, \cdot \mathrm{rV}$ & $r, A V$ & 3.83 & 4.29 & المتوسط العام & & \\
\hline
\end{tabular}

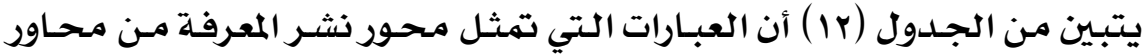

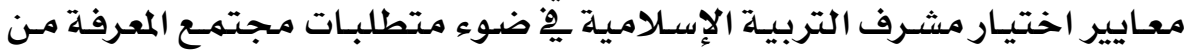

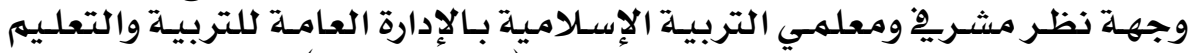

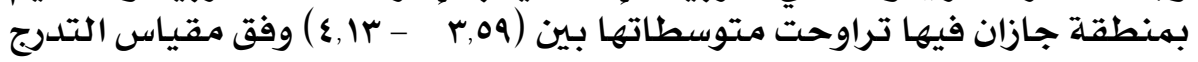

\section{$\varepsilon \vee \varepsilon$}




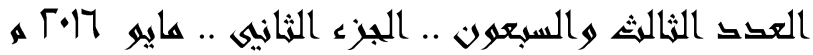

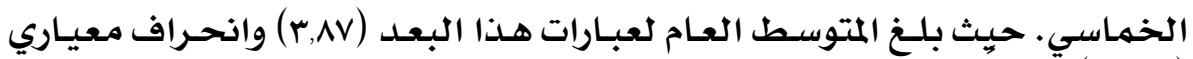

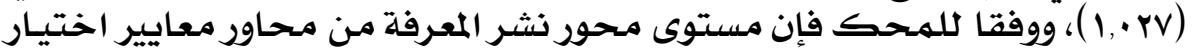

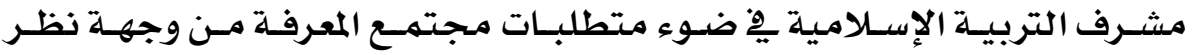

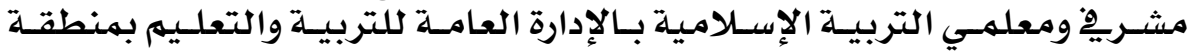

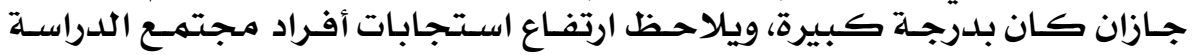

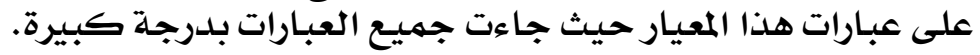

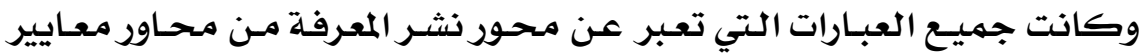

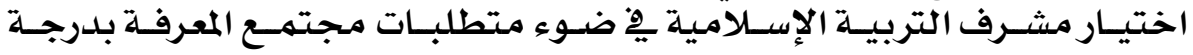

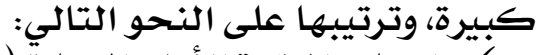

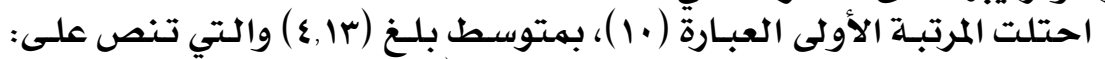

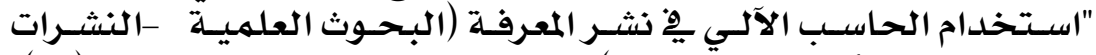

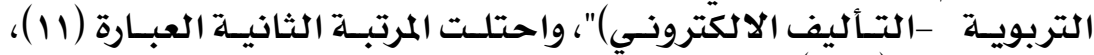

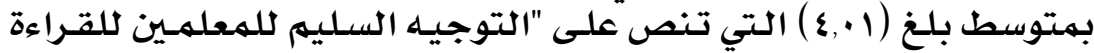

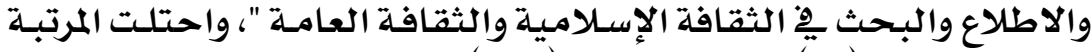

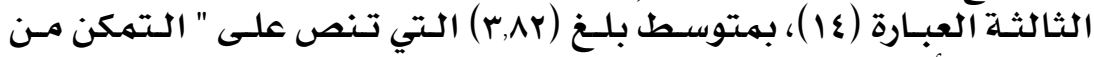

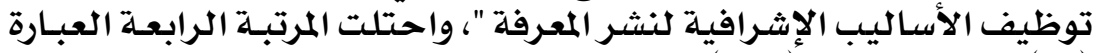

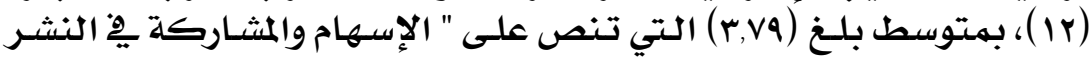

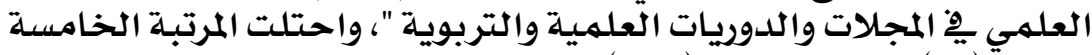

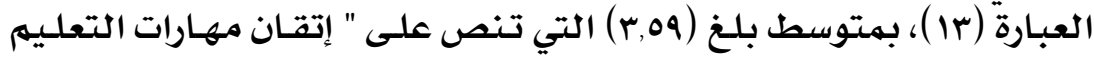

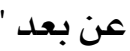

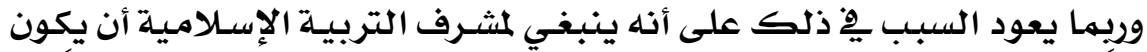

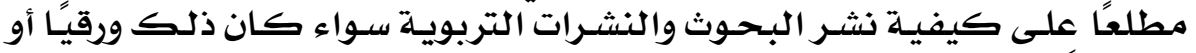

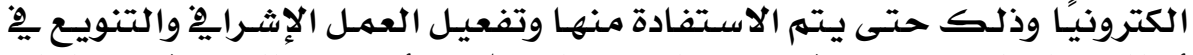

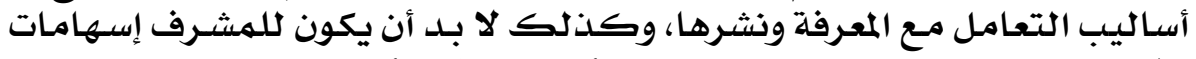

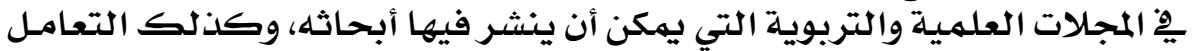

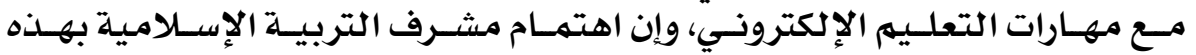

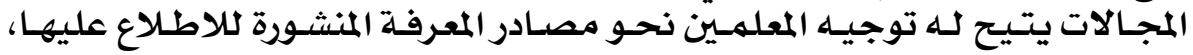

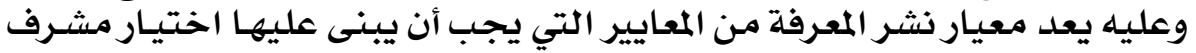

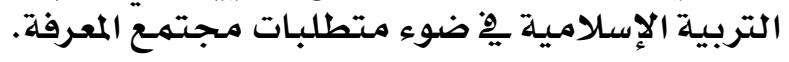

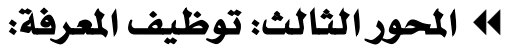

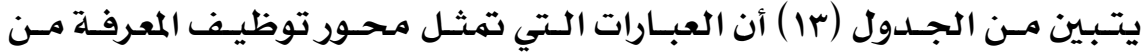

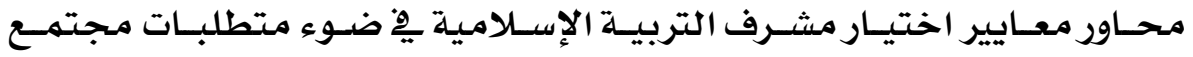

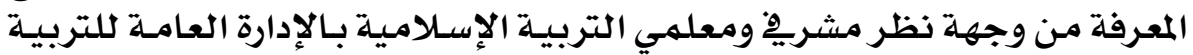

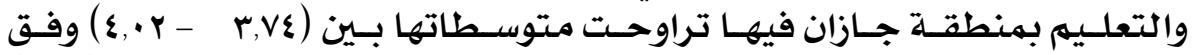

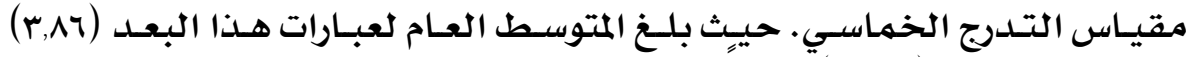

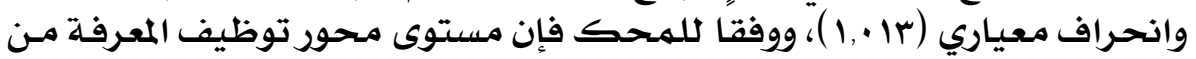

\section{$\varepsilon \vee 0$}




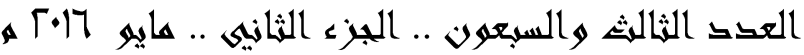

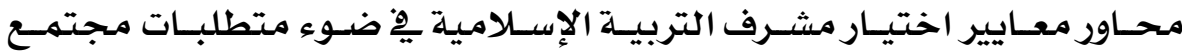

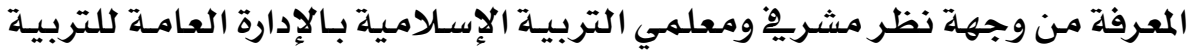

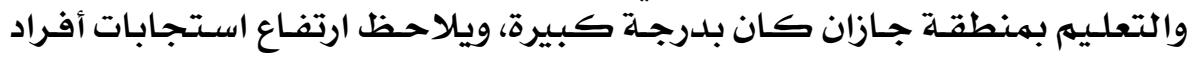

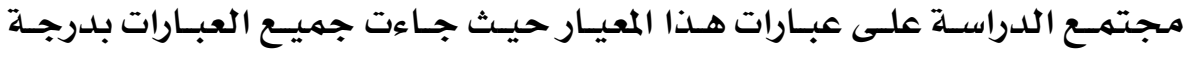
كبيرة.

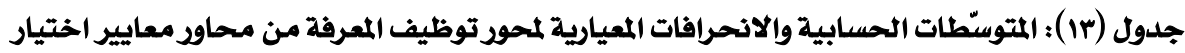

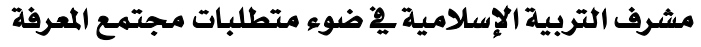

\begin{tabular}{|c|c|c|c|c|c|c|c|}
\hline & لإجممالي & & E & 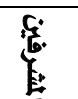 & & E & \\
\hline 䈏 & 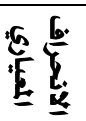 & $\underline{E}$ & $\underline{E}$ & $E$ & تنازليًا حسبيب المتبوسطات & $\underline{\underline{E}}$ & $\underline{\underline{E}}$ \\
\hline 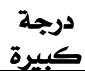 & - 978 & $\varepsilon, \cdot r$ & 3.98 & 4.44 & استخدام المعرفة لمواجهة المشكلات التريوية . & 10 & 1 \\
\hline كبيرة - كرجة & $1, \cdots$ & $\varepsilon, \cdot \cdot$ & 3.95 & 4.59 & استخدام التقنيات الحديثلة فِ طرق تلدريس الإسلامية. & rr & $r$ \\
\hline 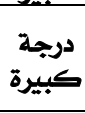 & $1,0$. & r.qr & 3.88 & 4.41 & 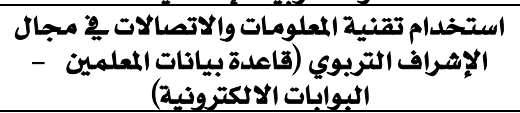 & $r$. & $r$ \\
\hline كبيرة & $\cdot, 910$ & ז'ו r r & 3.82 & 4.24 & 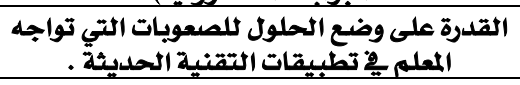 & iv & $\varepsilon$ \\
\hline 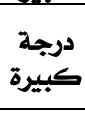 & •, $91 \varepsilon$ & $\Gamma, \wedge \varepsilon$ & 3.76 & 4.65 & 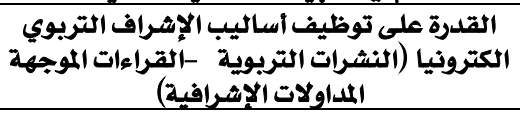 & in & 。 \\
\hline 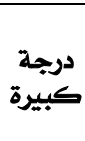 & $\cdot 9 \cdot 0$ & $r, w$ & 3.74 & 4.06 & 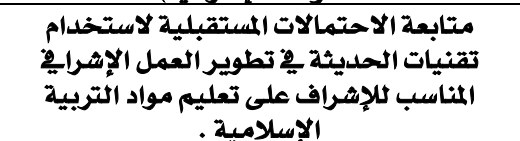 & 17 & T \\
\hline كبيرة & 1,IrY & r.vo & 3.71 & 4.24 & استخدام الإشراف الالكتروني كنموذج إشراي2. & 19 & v \\
\hline كبيرة & $1,1 \& 1$ & $r, v \varepsilon$ & 3.70 & 4.23 & القدرة على تكوين مجتمي معكية الانترنت لمعلمي التربية & $r$ & 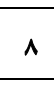 \\
\hline 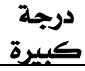 & $1, \cdot 1 r$ & ז'ו r r & 3.82 & 4.36 & المتوسط العام & & \\
\hline
\end{tabular}

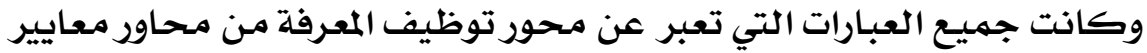

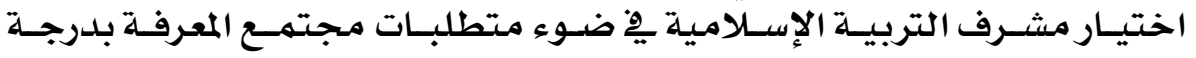

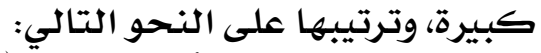

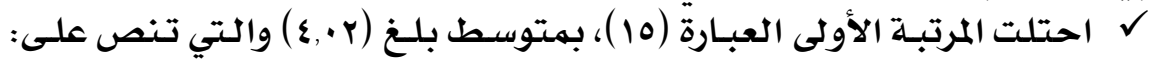

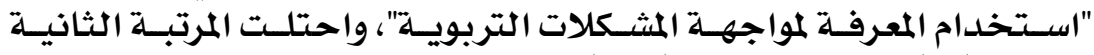

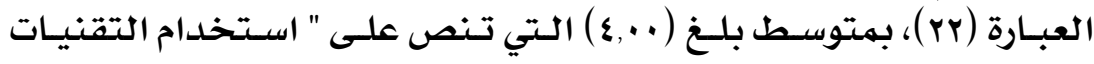

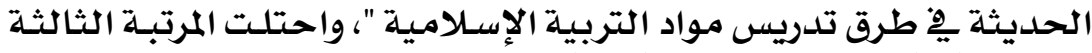

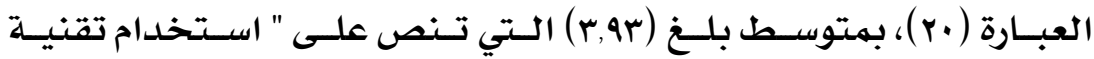

\section{$\varepsilon \vee 7$}




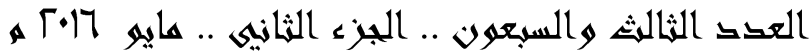

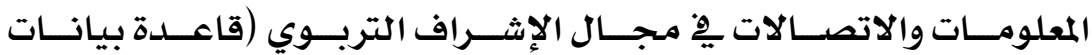

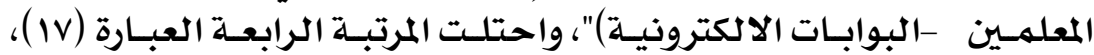

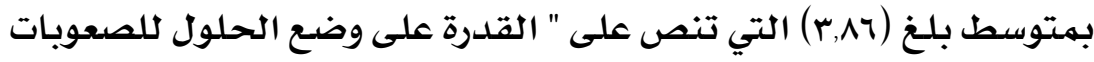

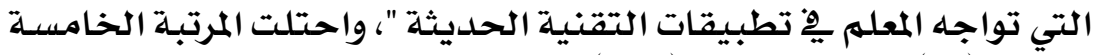

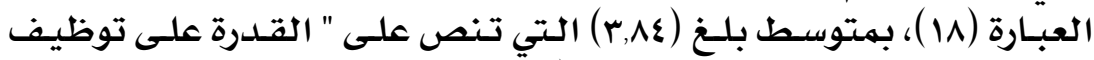

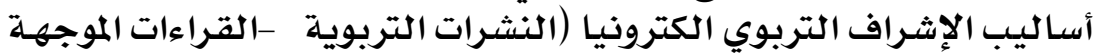

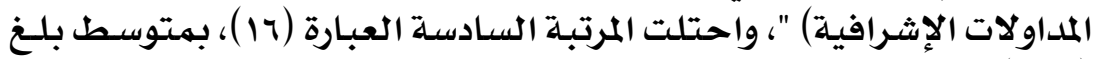
(r,VV)

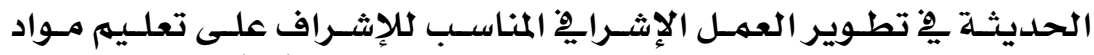

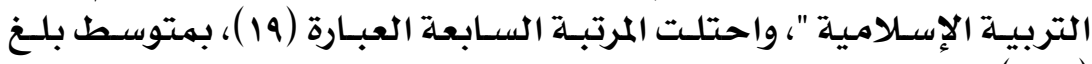
(r,Vo)

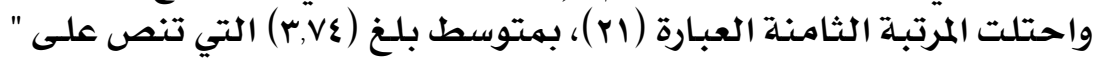

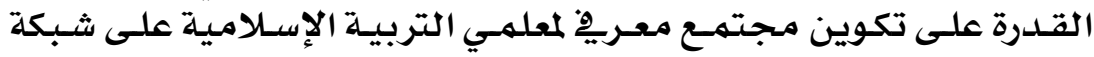
الانترنت ".

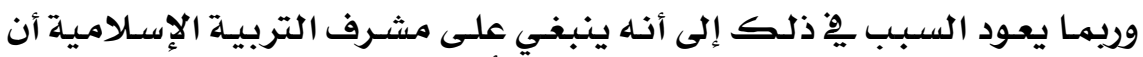

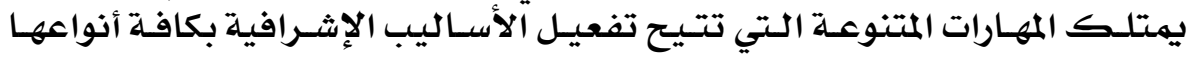

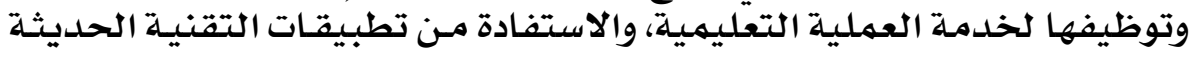

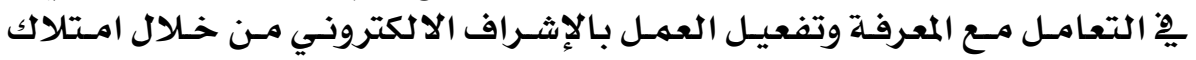

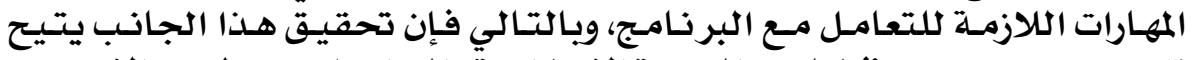

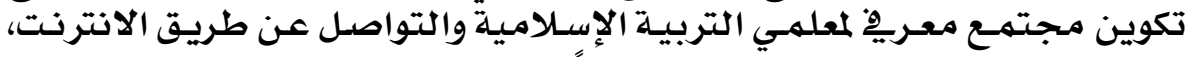

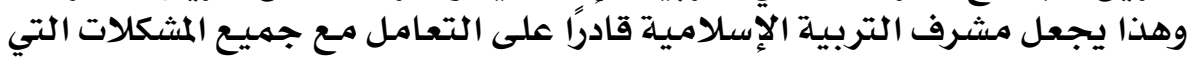

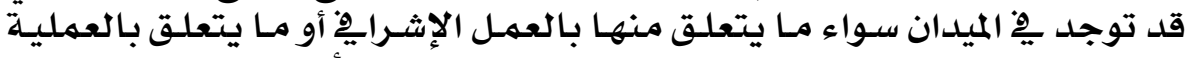

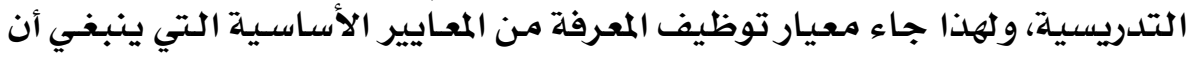

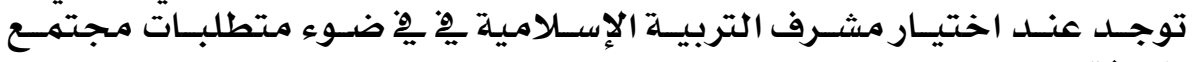
المعرفة.

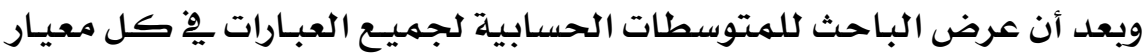

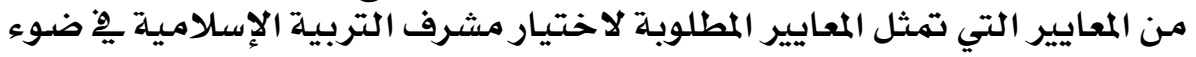

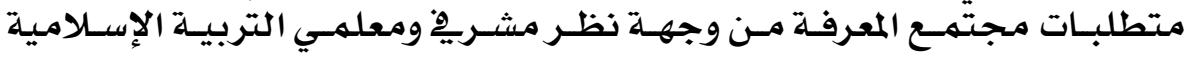

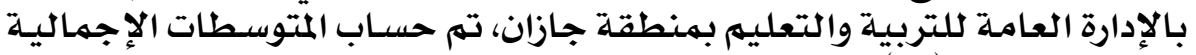

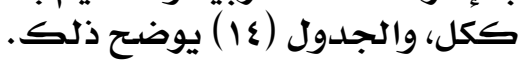

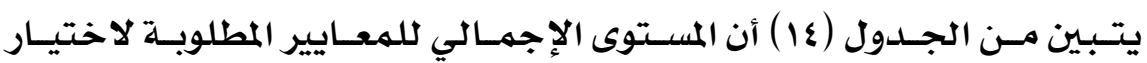

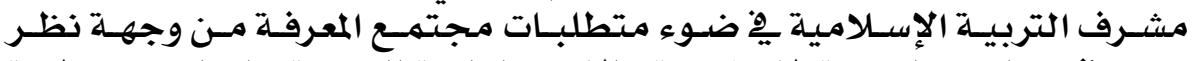

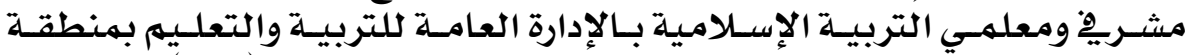

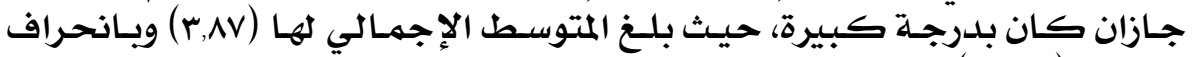

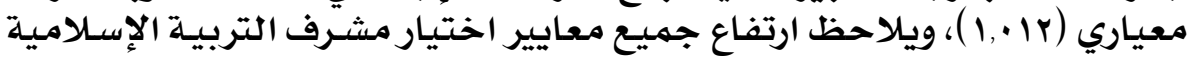

\section{$\varepsilon \vee V$}




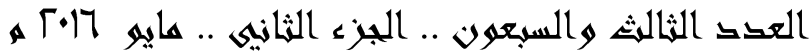

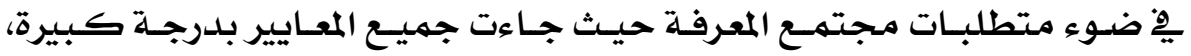

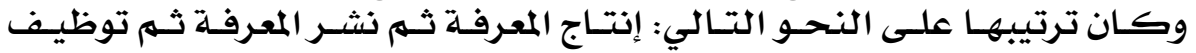
المعرفة.

جدول (ع) : المتوستطات الحسابية الإجمالية والانحرافات المعيارية للمعايير المطلوبة لاختيار مشرف

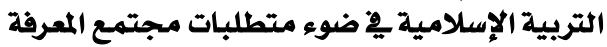

\begin{tabular}{|c|c|c|c|c|c|c|}
\hline \multicolumn{3}{|c|}{ الإجمالى } & \multirow{2}{*}{ المتوسطين } & \multirow{2}{*}{ المتوسطين } & \multirow[b]{2}{*}{ تنازليًا حسب المتوسيرطات } & \multirow[b]{2}{*}{ p } \\
\hline التقدير & الانحياري & المتوسطى & & & & \\
\hline درجة كبيرة & $1 . \cdots 7$ & r.M & 3.84 & 4.28 & إنتاج المعرفة & 1 \\
\hline درجة كبيرة & $1 .+Y V$ & r.AV & 3.83 & 4.29 & نشر المعرفة & $r$ \\
\hline درجة كبيرة & $1 . \cdot 1 r$ & r.AT & 3.82 & 4.36 & توظيف المعرفة & $r$ \\
\hline درجة كبيرة &. $.9 \varepsilon r$ & r.AV & 3.83 & 4.31 & المتوسط الإجمالى & \\
\hline
\end{tabular}

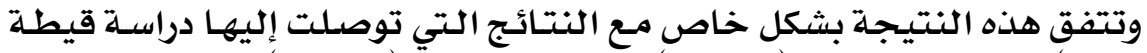

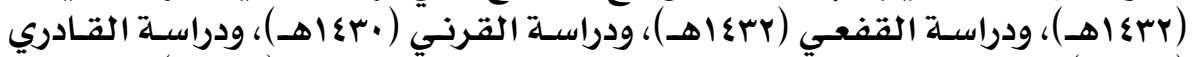

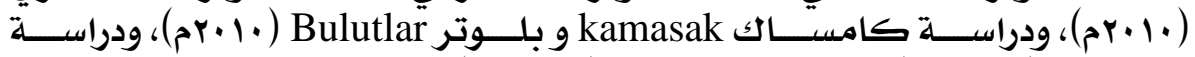

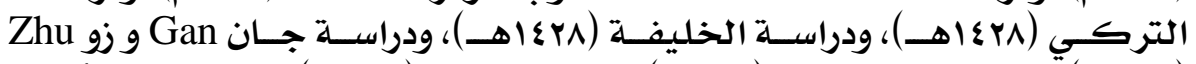

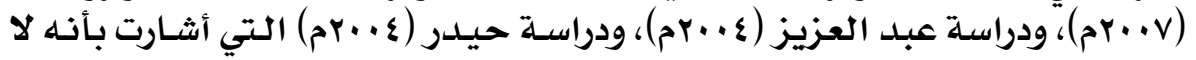

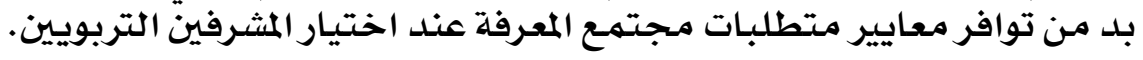

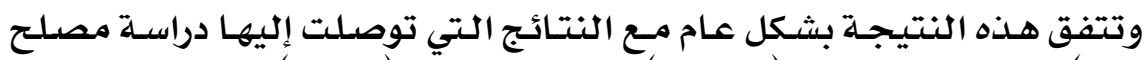

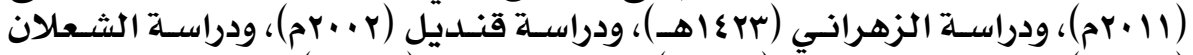

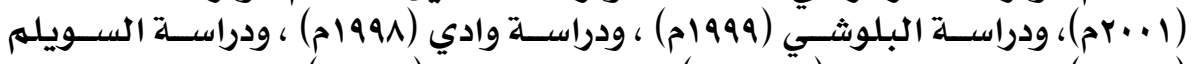

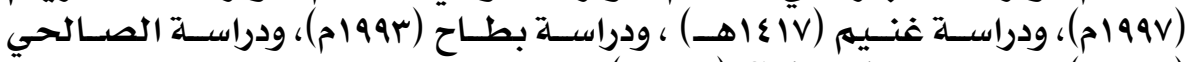

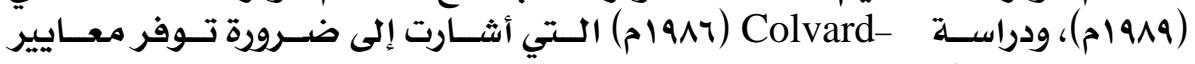
محددة ودقيقة لاختيار المشرفين التربويين.

\section{• إجابة السؤال الثالث وتفسيره وهناقشته:}

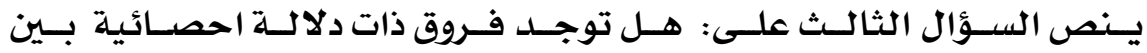

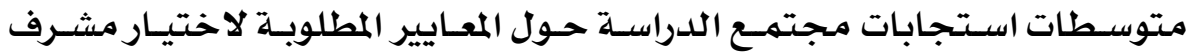

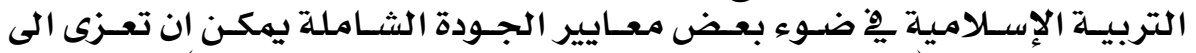

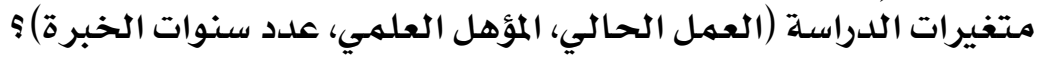

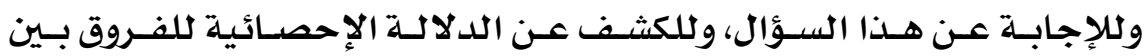

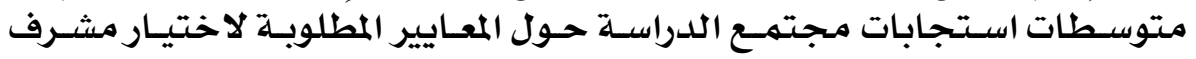

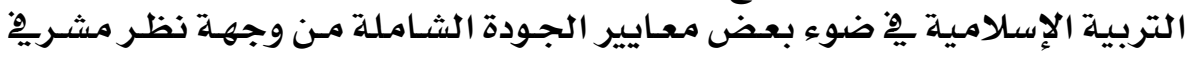

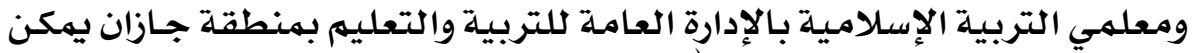

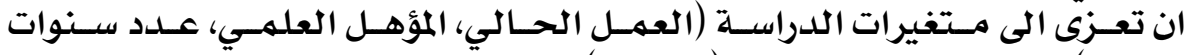

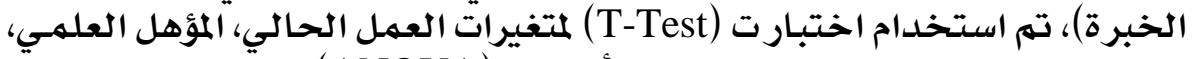

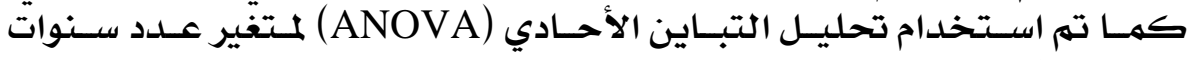
الخبرة، وفيما يلي نتائج هذا السئل السوال.

\section{$\varepsilon \vee \wedge$}




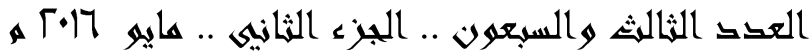

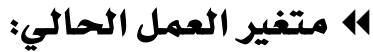

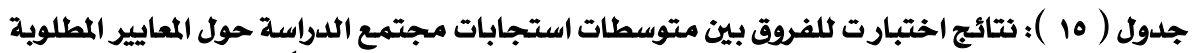

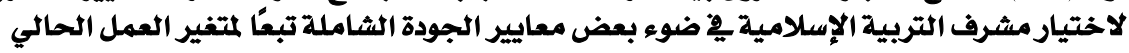

\begin{tabular}{|c|c|c|c|c|c|c|}
\hline مستوى الدلالة & قيمة (ت) & الحرية & المعياري & الانحياري & الحسوسطى & العمل الحالي \\
\hline \multirow{2}{*}{$\bullet \cdot, \cdot 1$} & \multirow{2}{*}{ r,Yo\& } & \multirow{2}{*}{$r \cdot r$} & $r, V \cdot r r r$ & 11,EYrrV & $17 Y, Y 9$ & مشرف تربية إسلامية \\
\hline & & & 1,TAVY. & $r r, \cdot V r+q$ & $1 \varepsilon r, \wedge 0$ & معلم تربية إسلامية \\
\hline
\end{tabular}

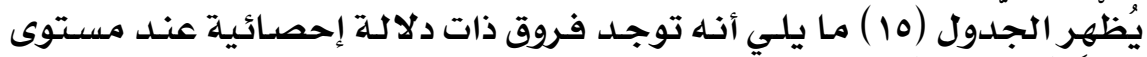

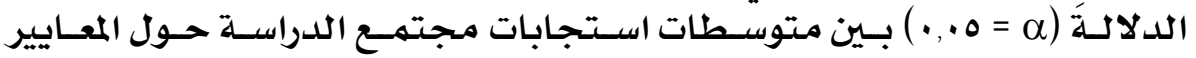

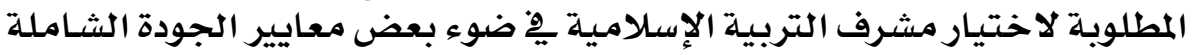

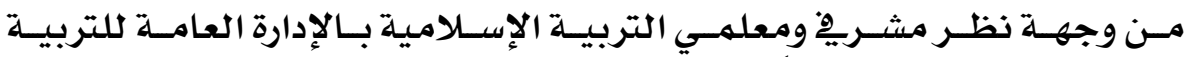

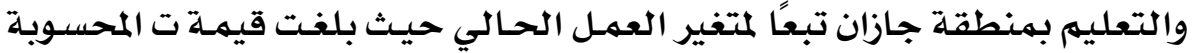

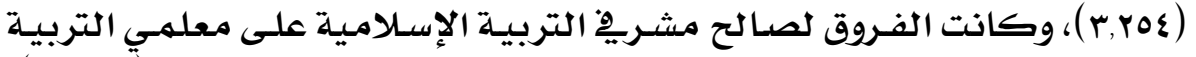

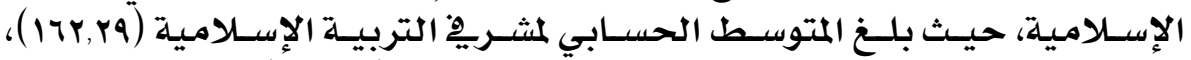

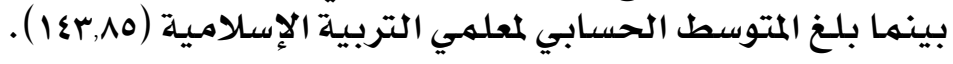

وربها يعود السبب يِّ ذلك إلى أن الذين عملهم الحالي مشرف تربيـة إسـلاميـة

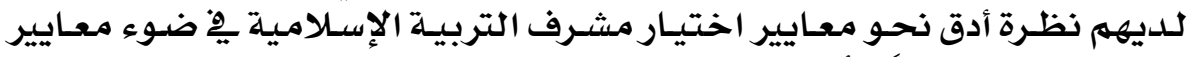

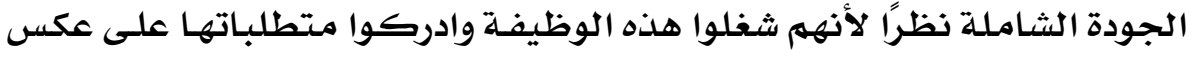

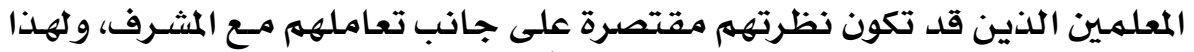

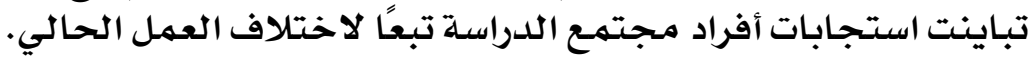

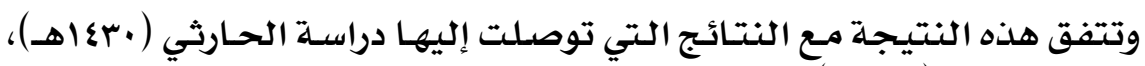

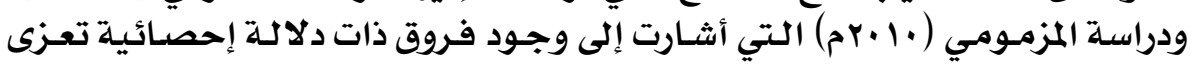
لمتغير العمل الحالي.

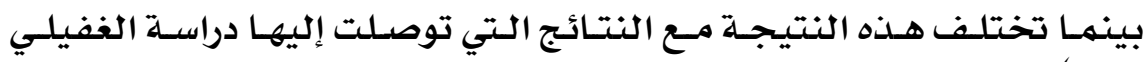

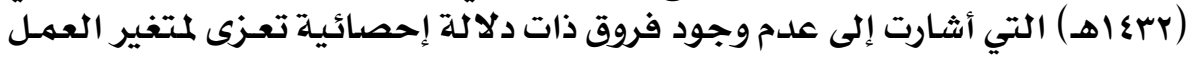

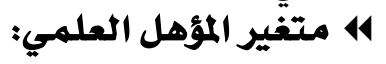

جدول (17) نتائج اختبارت للفروق بين متوسطات استجابات مجتمبح الدراسة حول المعايير المطلوبة

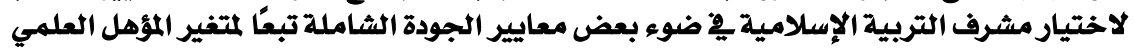

\begin{tabular}{|c|c|c|c|c|c|c|}
\hline مستوى الدلالة & قيمة (ت) & دالحرية & المعياري & الانحراف & المستوسطى & المؤهل العلمي \\
\hline \multirow{2}{*}{$\bullet \cdot, \cdot 1$} & \multirow{2}{*}{ r.\&9V } & \multirow{2}{*}{$r \cdot r$} & $r, r v \cdot r q$ & $|7,01 \cdot 1|$ & $|07, Y|$ & فوق جامعى \\
\hline & & & $1, \operatorname{Vr\varepsilon q1}$ & rr,Yrrra & 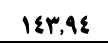 & جامعى \\
\hline
\end{tabular}

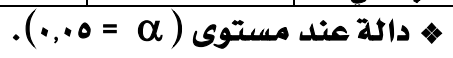

\section{$\varepsilon \vee q$}




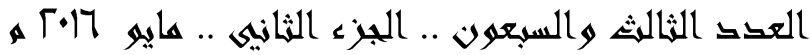

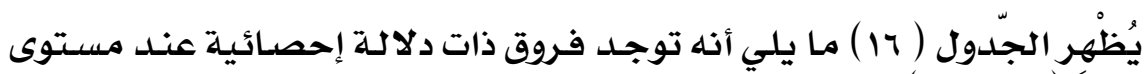

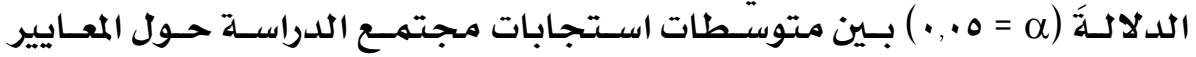

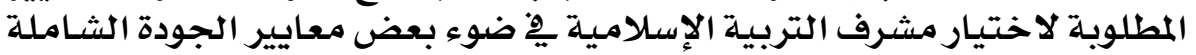

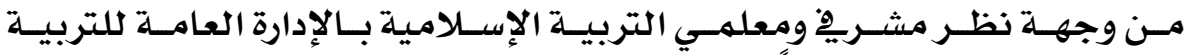

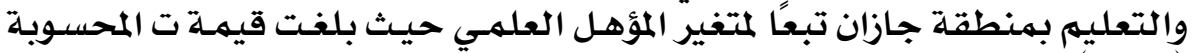

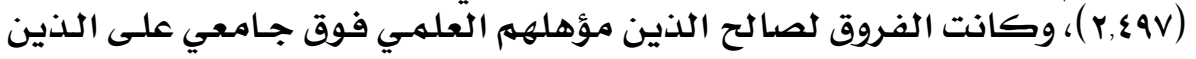

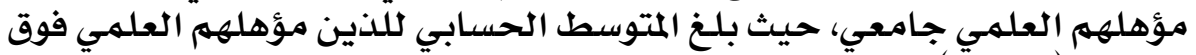

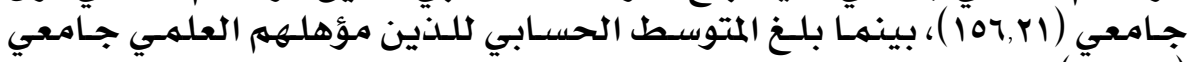

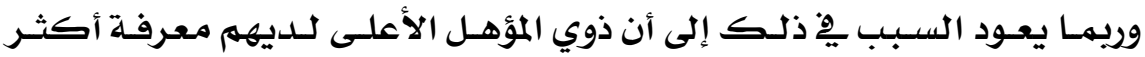

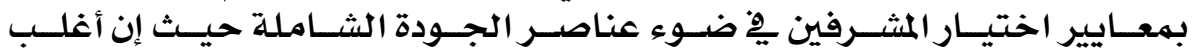

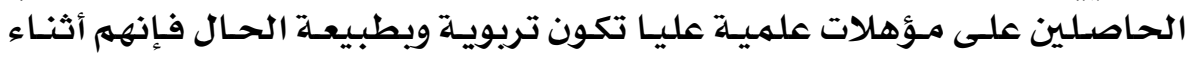

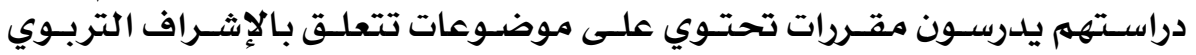

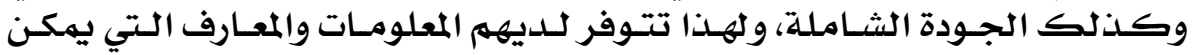

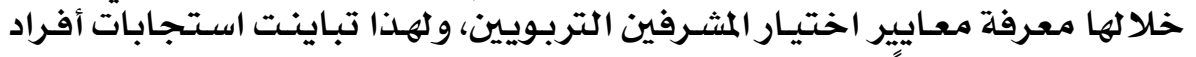

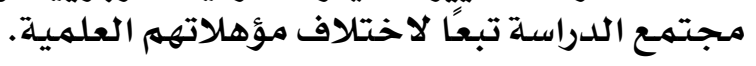

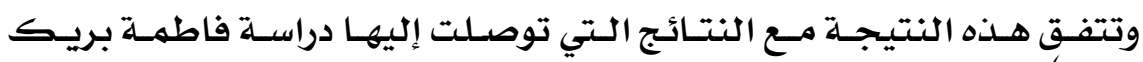

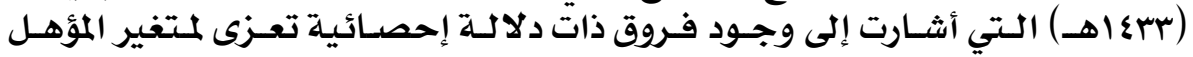
العلهي.

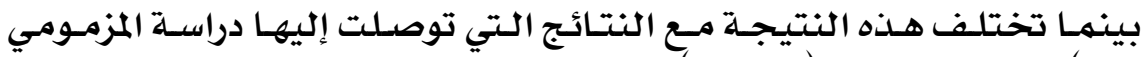

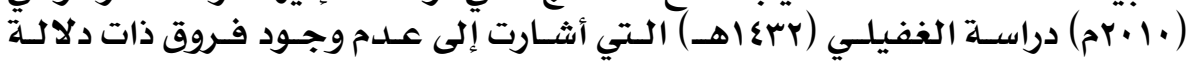

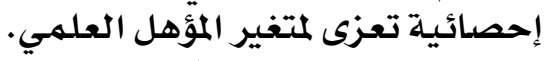

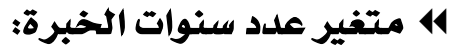

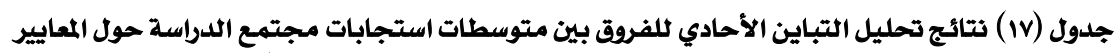

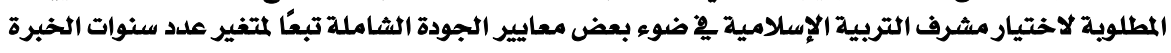

\begin{tabular}{|c|c|c|c|c|c|}
\hline مستوى الدلالة & قيمة & متروسطات & درجة الحرية & مجموع المربعات & مصلدر التباين \\
\hline \multirow{3}{*}{$\bullet \cdot, \cdots+$} & \multirow{3}{*}{$7, \cdot r r$} & $r \cdot \mid r, 701$ & $r$ & $Y \cdot Y O, r \cdot Y$ & بين المحموعات \\
\hline & & \&৭१, rVq & $r+1$ & $1 \ldots r v 0,1 . \varepsilon$ & داخل المحموعات \\
\hline & & & $r \cdot r$ & $1 \cdot 7 \varepsilon \cdot \cdot, \varepsilon \cdot V$ & المجموع الكلى \\
\hline
\end{tabular}

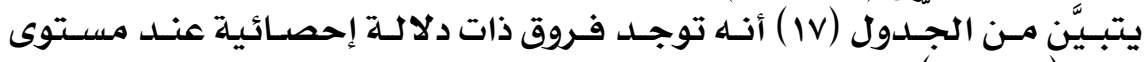

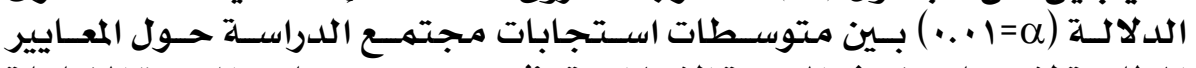

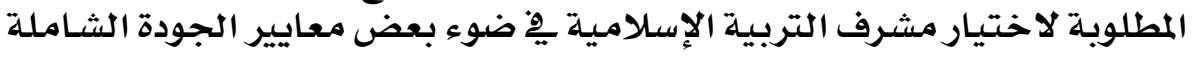

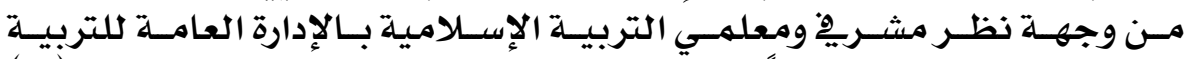

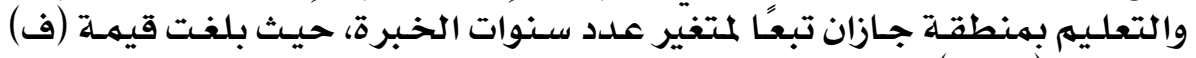
المحسوبية (بس •. ( ).

\section{$\varepsilon \wedge$}




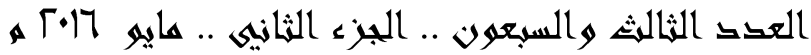

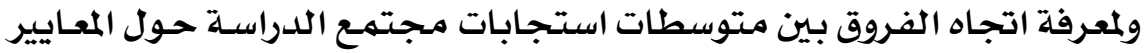

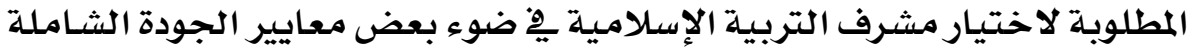

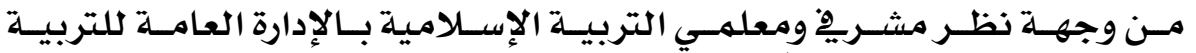

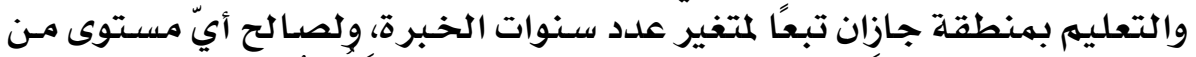

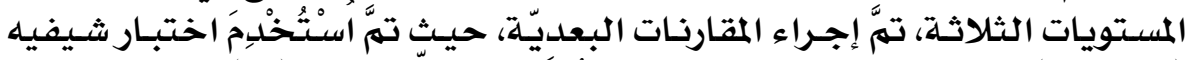

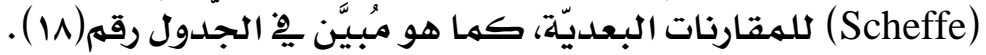

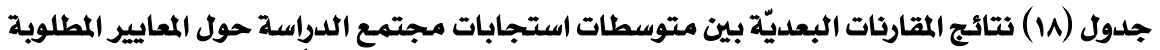

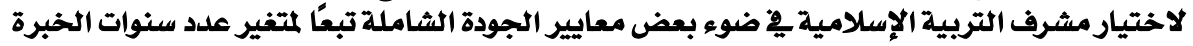

\begin{tabular}{|c|c|c|c|c|}
\hline . & من 0- 1. & آل من • & المتوسط & مدد سنوات الخبرة \\
\hline- & - & - & 187.19 & آل من ه سنوات \\
\hline- & - & $\diamond 11,19$ & IEV.rA & من • إلى أقل من · ا سنوات \\
\hline - & \& I,AT & $\Delta \mid r, \cdot 0$ & IE१.Y₹ & من +1 سنوات فأكثر \\
\hline
\end{tabular}

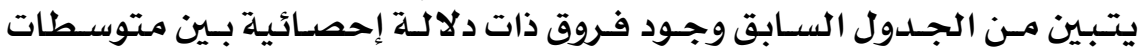

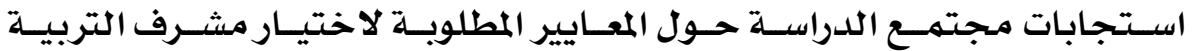

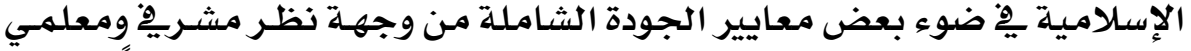

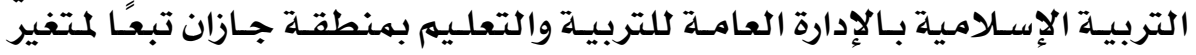

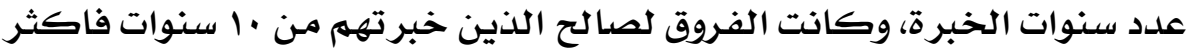

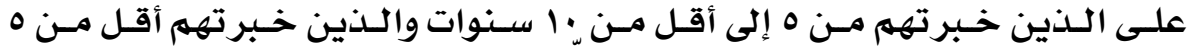

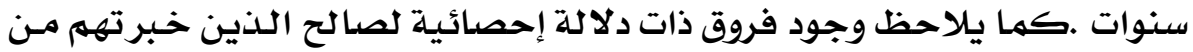

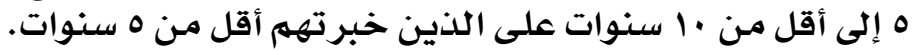

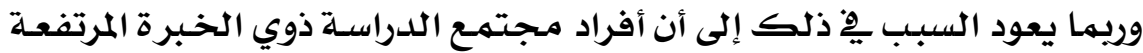

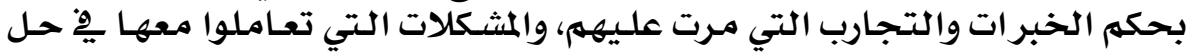

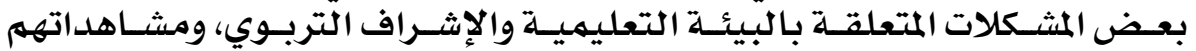

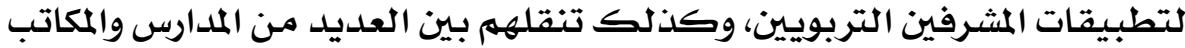

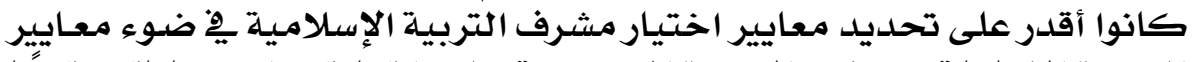

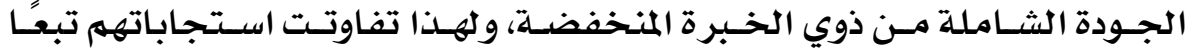
لاختلاف خبر اتهم.

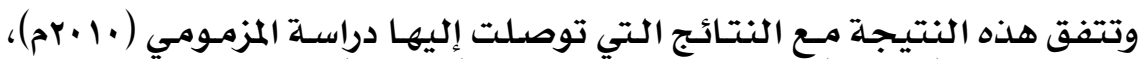

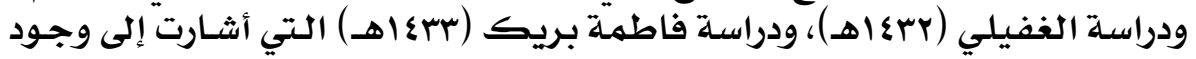

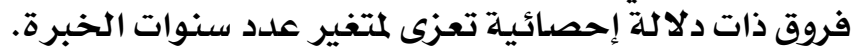

• إجابة السؤال الرابع وتفسيره وهناقشته:

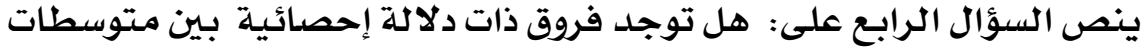

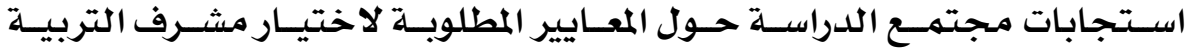

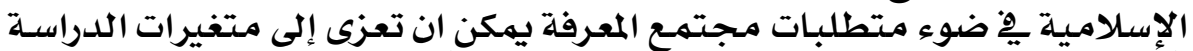

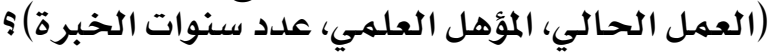

\section{$\varepsilon \wedge 1$}




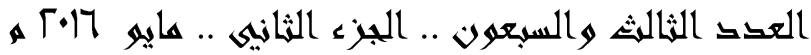

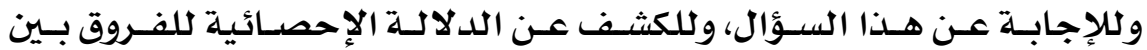

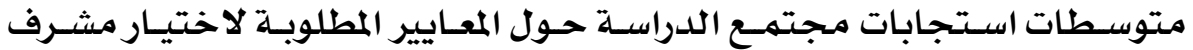

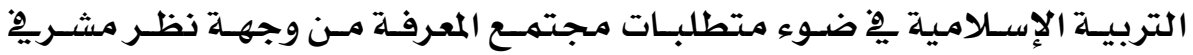

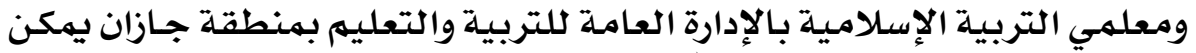

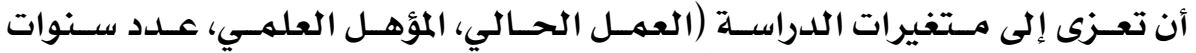

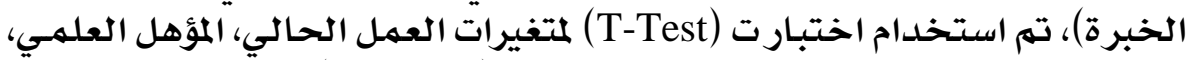

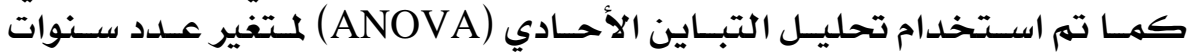

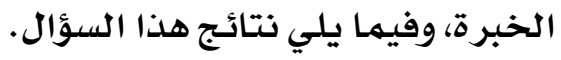

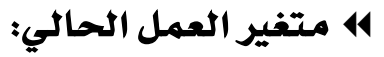

جلدول (19): نتائج اختبارت للفروق بين متوسطات استجابات مجتمع الدراسة حول المعايير المطلوبة

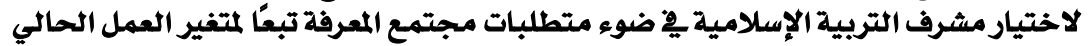

\begin{tabular}{|c|c|c|c|c|c|c|}
\hline مستوى & قيمة & الحرجية & المخياريا & الالنحراف & الحتوسطيى & العمل الحالي \\
\hline \multirow{2}{*}{$\bullet \cdot, \cdot 1$} & \multirow{2}{*}{ r,YOI } & \multirow{2}{*}{$r \cdot r$} & Y.VYIEY & $11 . r Y \cdot V 1$ & 9\&.Arro & مشرف تربية إسلامية \\
\hline & & & 1.rYotr & 17.V7.rr & As.r100L & ـامعلم تربية إسلامية \\
\hline
\end{tabular}

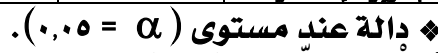

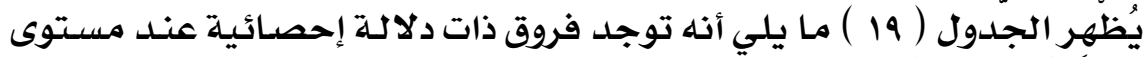

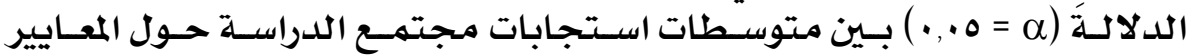

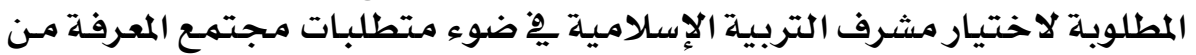

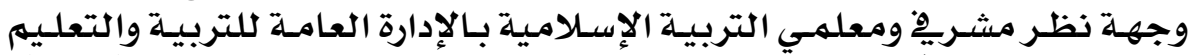

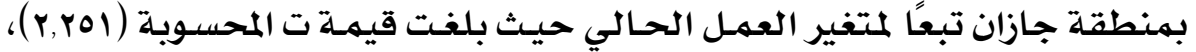

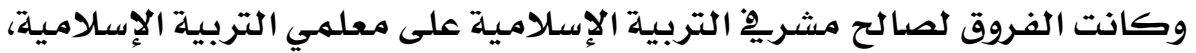

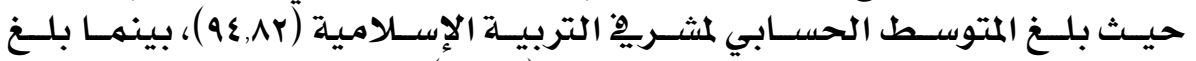

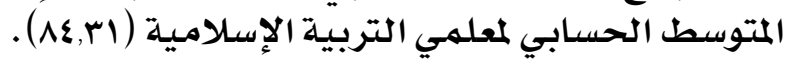

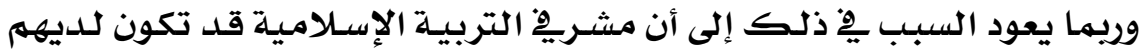

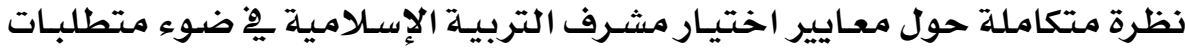

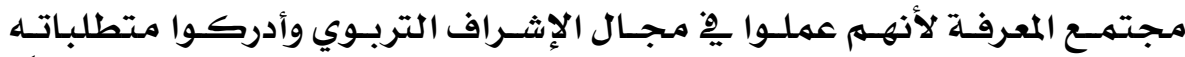

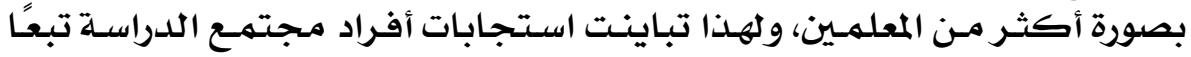
لاختالاف العمل الحمالي.

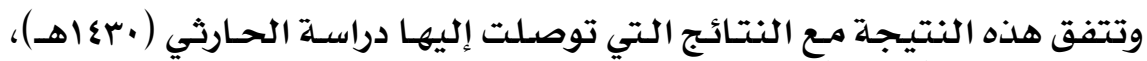

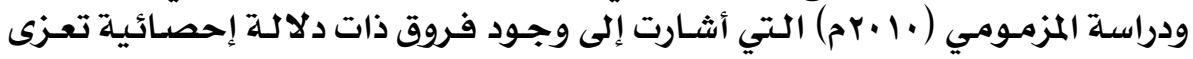

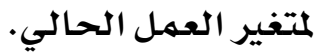

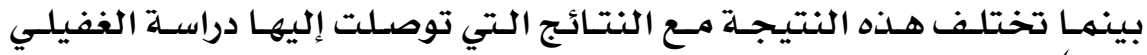

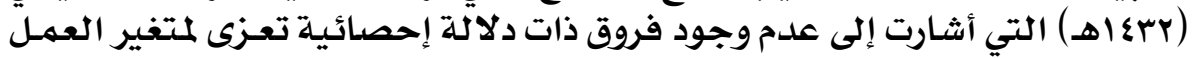
الحالي.

\section{$\varepsilon \wedge Y$}




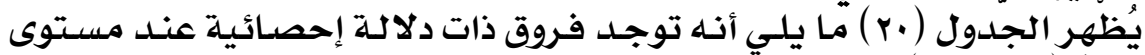

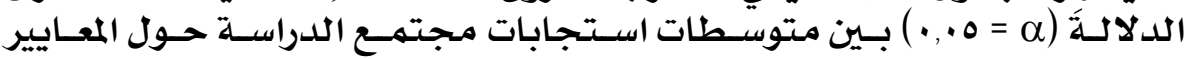

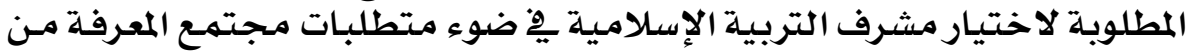

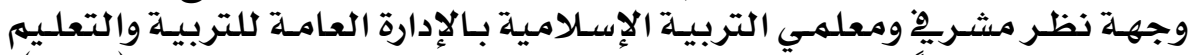

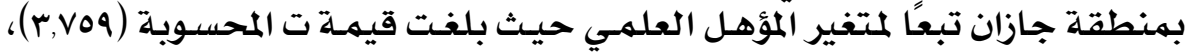

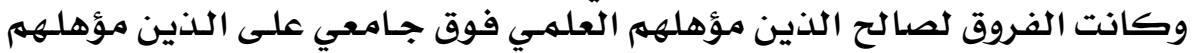

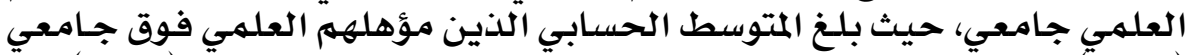

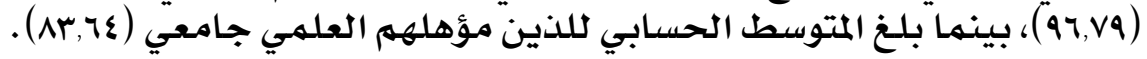

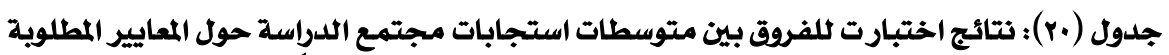

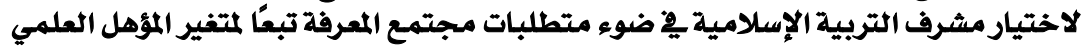

\begin{tabular}{|c|c|c|c|c|c|c|}
\hline مستوى & قيمة (ت) & الحرية & المعياريا & الانحياري & الحستوسطي & المؤهل العلمي \\
\hline \multirow{2}{*}{$\bullet \cdot, \cdot 1$} & \multirow{2}{*}{ r,voq } & \multirow{2}{*}{$r+r$} & Y,YTYTR & $11, \bullet \wedge \varepsilon$ OV & $97, \mathrm{Vq} / \mathrm{V}$ & فوق جامعى \\
\hline & & & 1, rma६o & 17,7Y^9Y & Ar,T $\mathbf{R} \varepsilon \varepsilon$ & جامعي \\
\hline
\end{tabular}

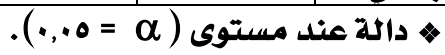

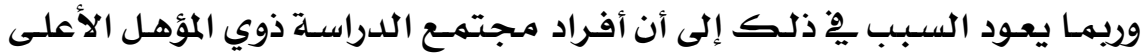

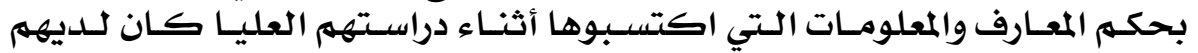

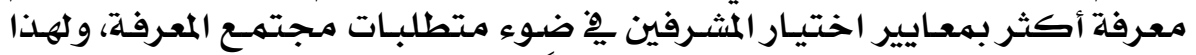

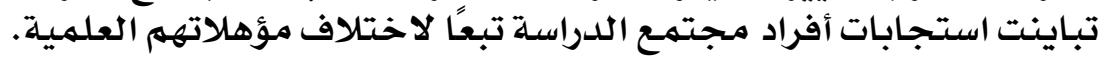

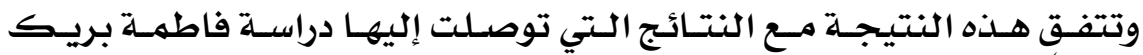

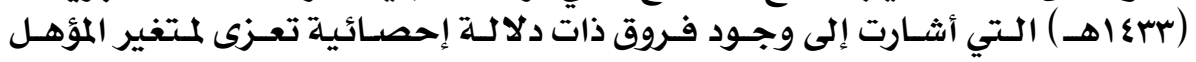

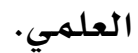

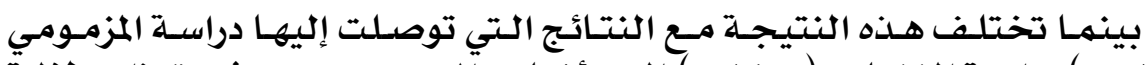

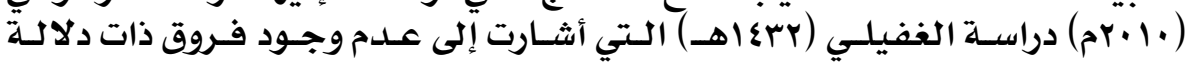

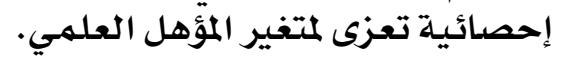

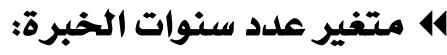

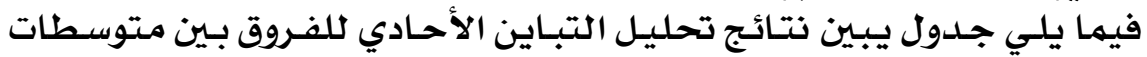

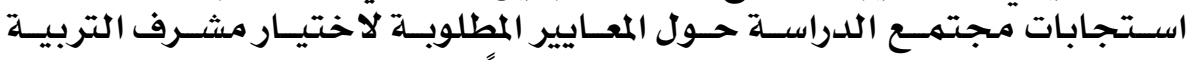

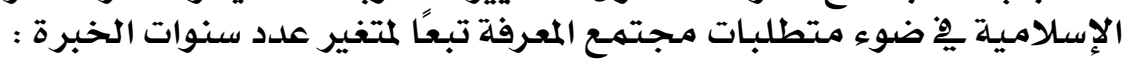

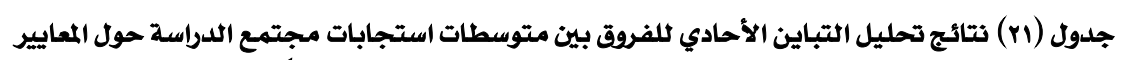

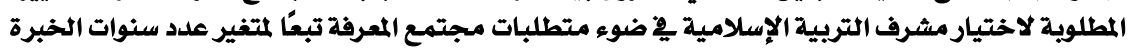

\begin{tabular}{|c|c|c|c|c|c|}
\hline مستوى الدلالد & قيمة (ف) & متوسط المريعات & درجة الحرية & مجموع المريعات & مصدر التباين \\
\hline \multirow{3}{*}{$\bullet, \cdot, \cdot 1$} & \multirow{3}{*}{$1 r, 709$} & rr\&a,rmq & $r$ & $7794, \varepsilon V Y$ & بين المجموعات \\
\hline & & $r £ 0,199$ & $r+1$ & $\sum q Y \wedge 0, \cdot V Y$ & داخل المجموعات \\
\hline & & & $r \cdot r$ & 009 or,o\&\& & المجموع الكلى \\
\hline
\end{tabular}

\section{$\varepsilon \wedge \boldsymbol{Y}$}




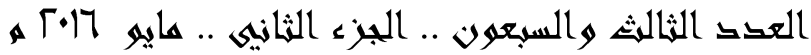

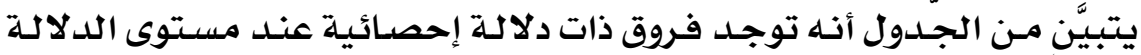

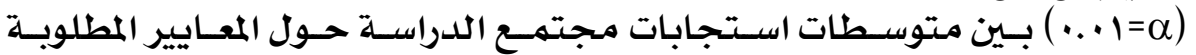

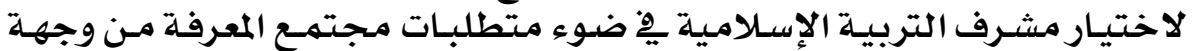

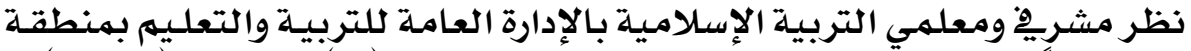

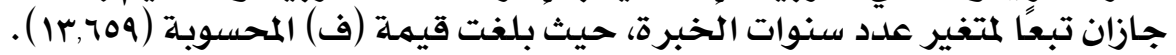

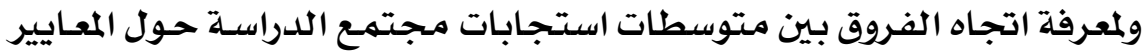

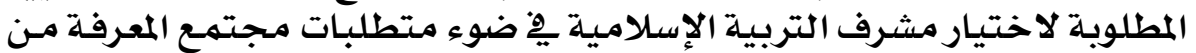

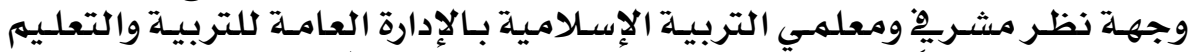

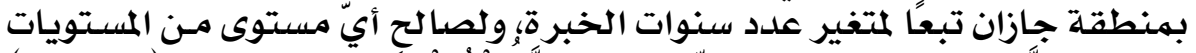

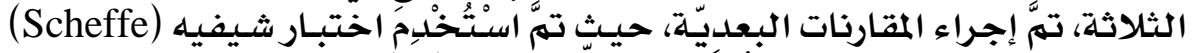

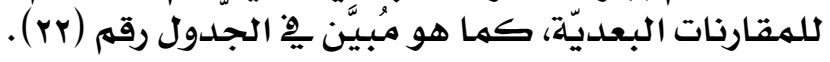

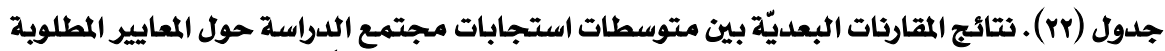

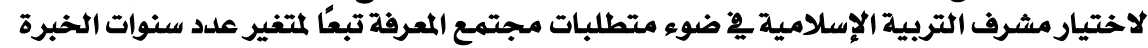

\begin{tabular}{|c|c|c|c|c|}
\hline . أ فاكثر & من 0- -1 & أقل من 0 & المتوسط & عدد سنوات الخبرة \\
\hline- & - & - & Vo.vA & أقل من ه سنوات \\
\hline - & - & $1 \cdot, y_{0}$ & AT..r & من ه إلى أقل من + 1 سنوات \\
\hline - & $\bullet r, \wedge \varepsilon$ & $\bullet 1 \varepsilon, \cdot 9$ & A9.AV & من · ا سنوات فاكثر \\
\hline
\end{tabular}

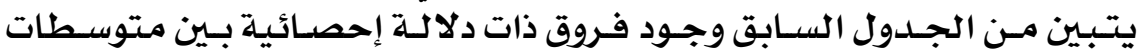

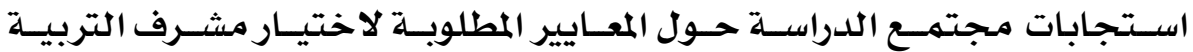

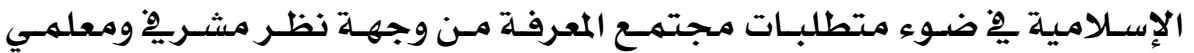

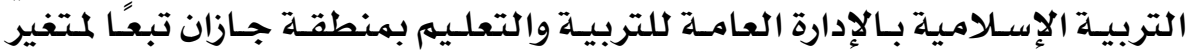

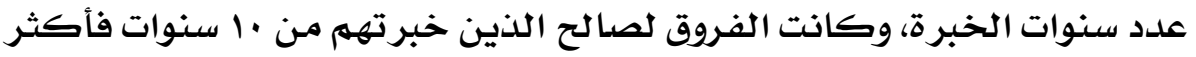

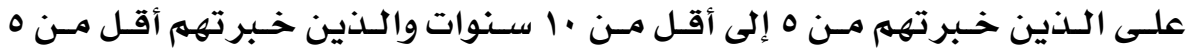
سنوات.

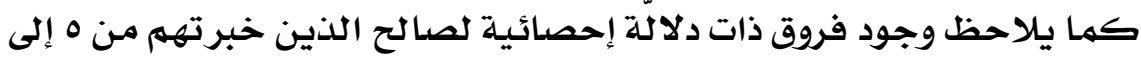

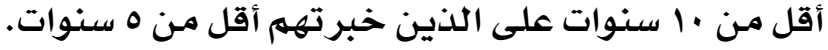

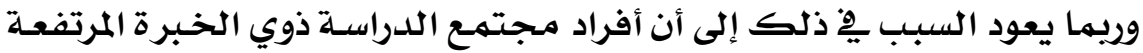

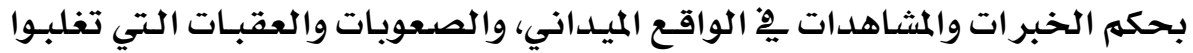

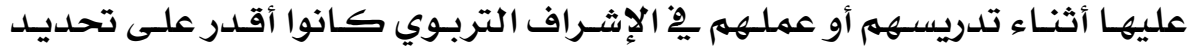

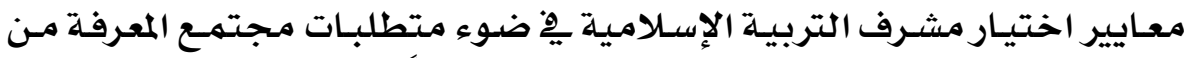

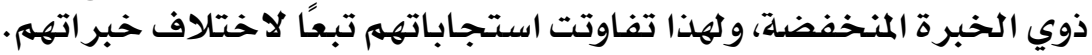

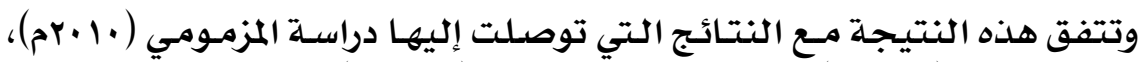

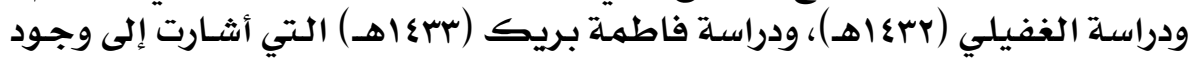

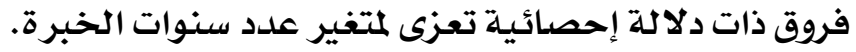

\section{$\varepsilon \wedge \varepsilon$}




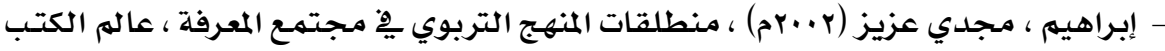

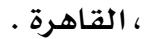

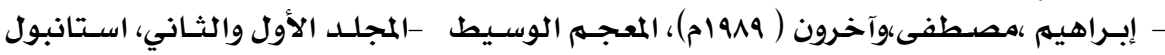

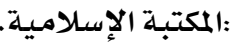

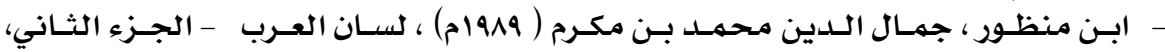

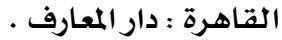

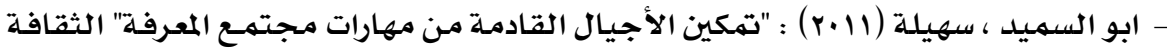

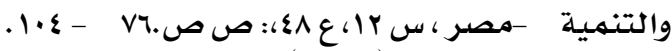

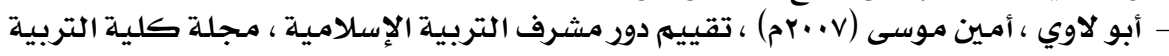

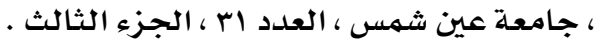

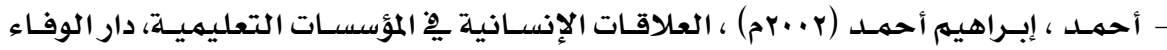

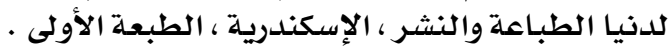

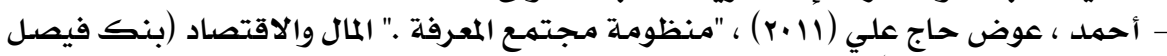

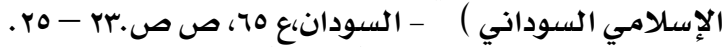

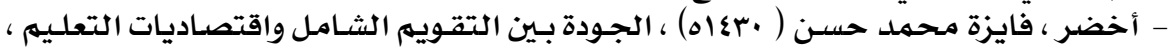

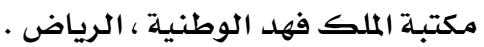

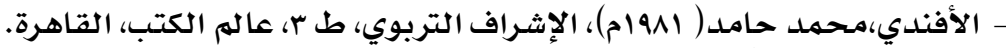

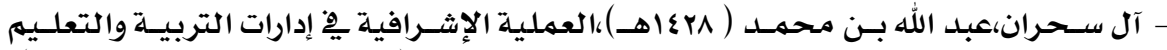

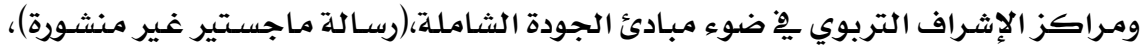

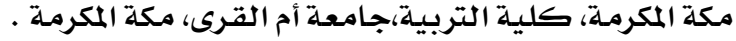

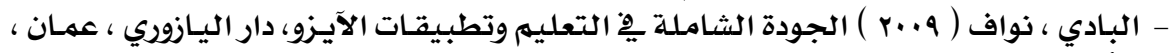

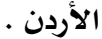

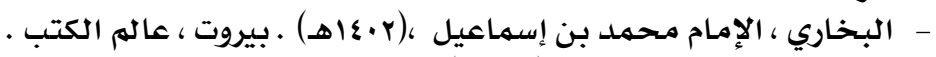

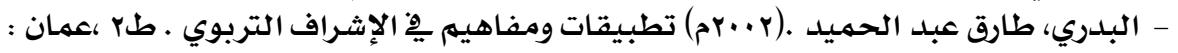

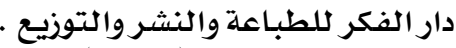

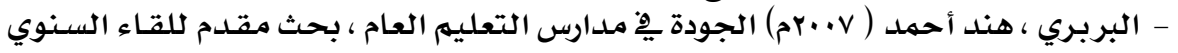

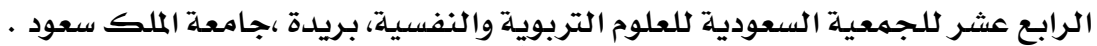

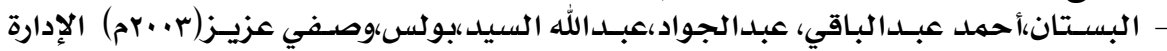
والإثـراف التربوي .مكتبـة الفلاح ، الكويت الكويت .

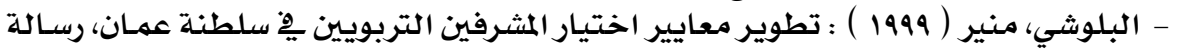

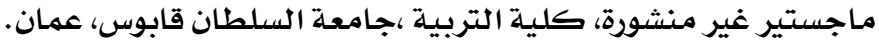

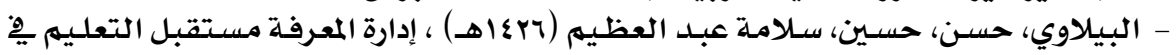

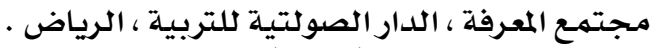

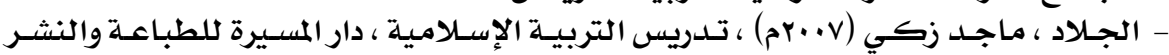

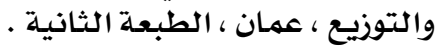

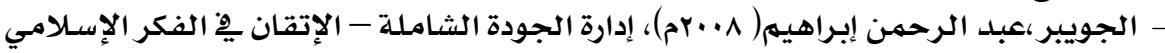

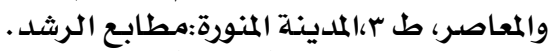

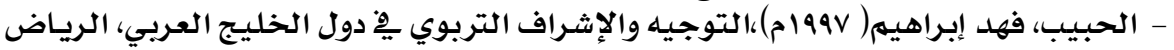
، مكتب التربية العربي لدول الدير الخليج.

\section{$\varepsilon \wedge \odot$}




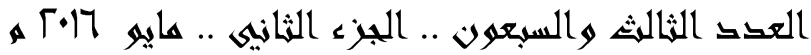

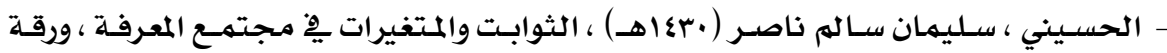

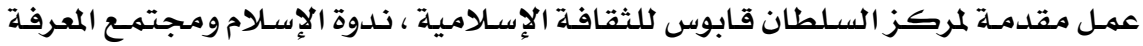

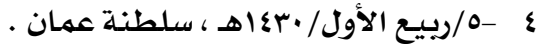

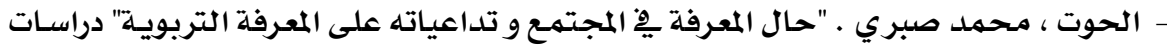

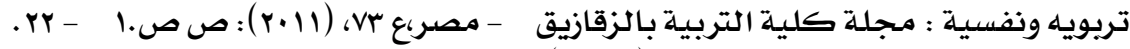

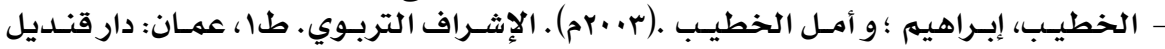

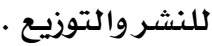

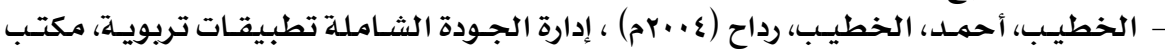

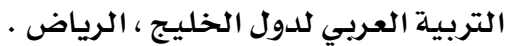

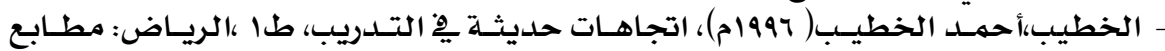
الفرزدق.

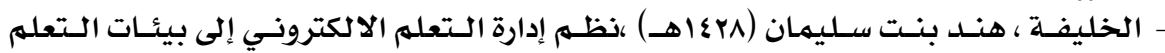

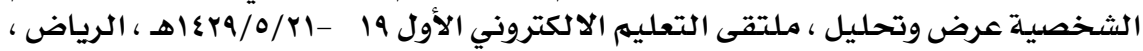

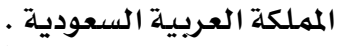

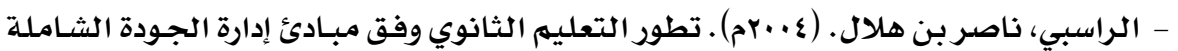

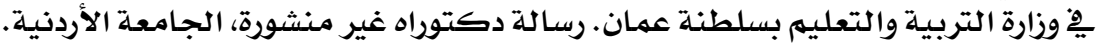

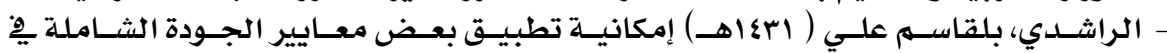

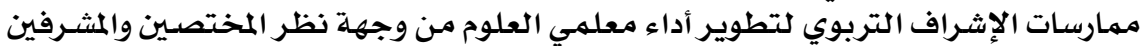

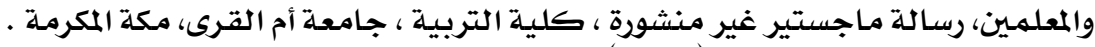

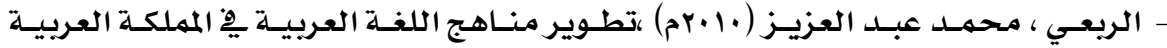

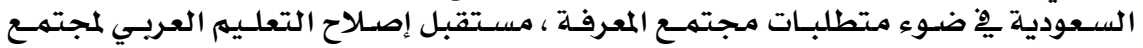

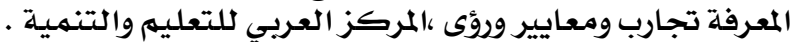

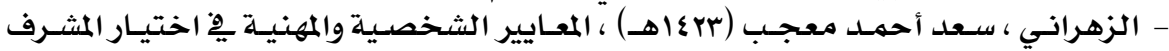

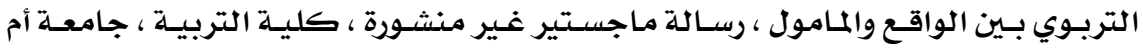

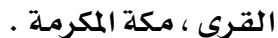

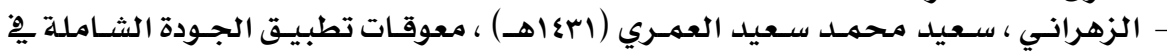

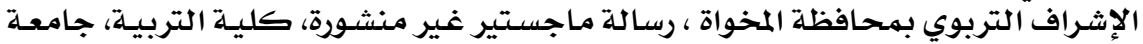

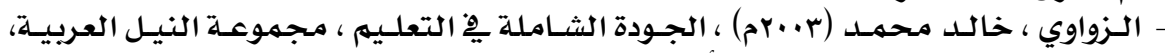

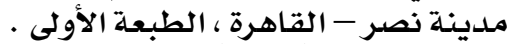

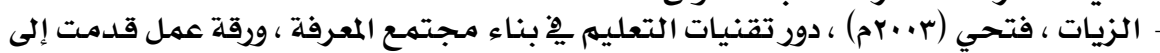

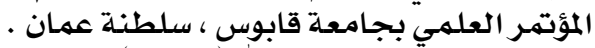

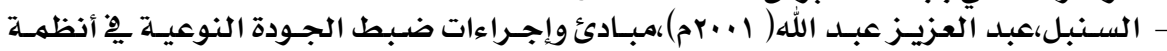

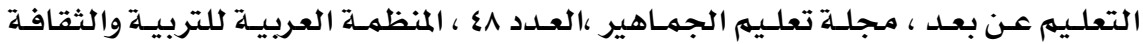

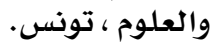

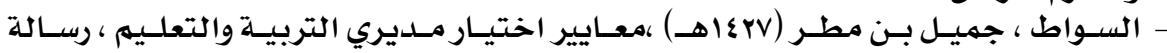

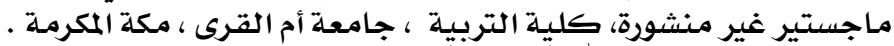

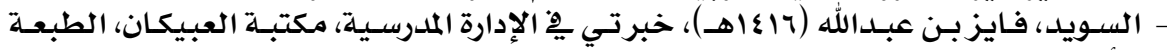

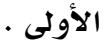

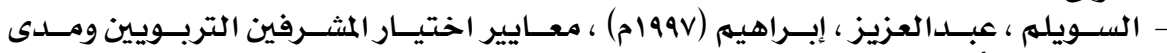

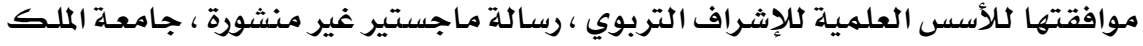

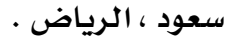

\section{$\varepsilon \wedge \neg$}




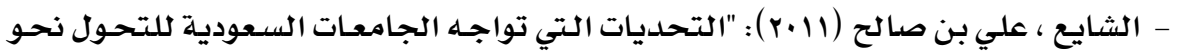

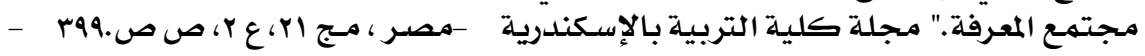

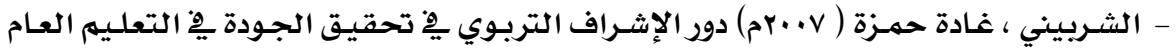

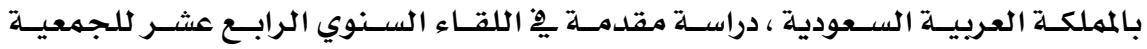

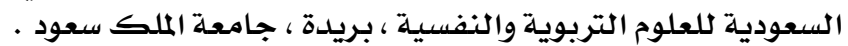

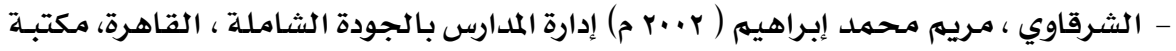

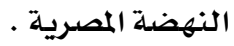

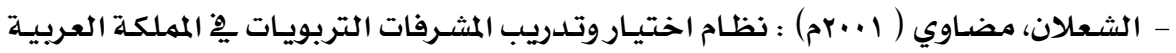

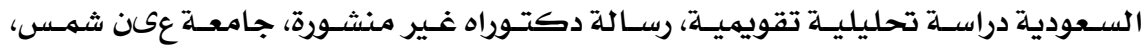

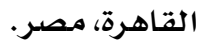

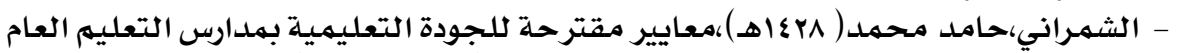

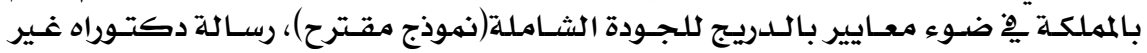

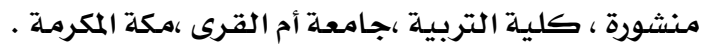

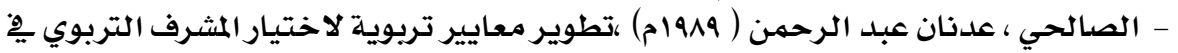

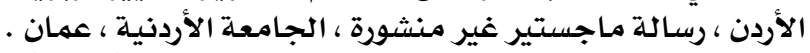

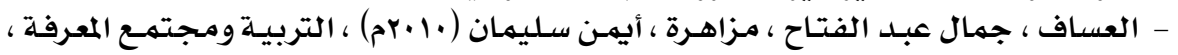
عمان

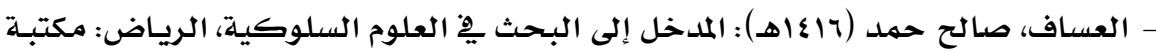
العبيكان.

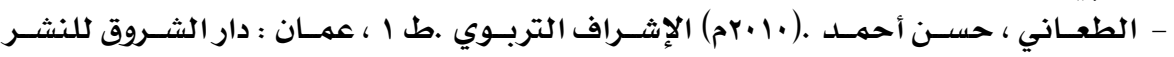

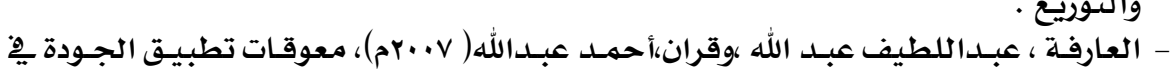

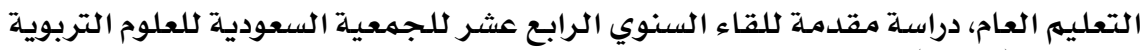

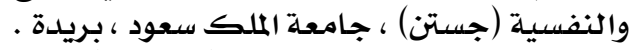

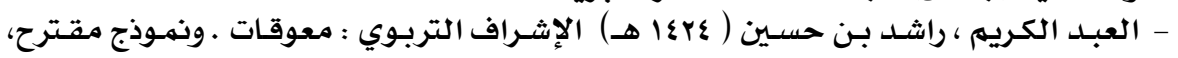

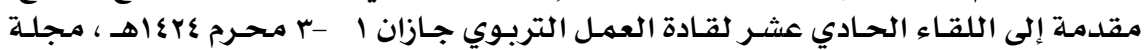

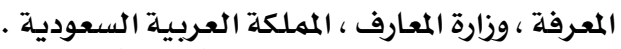

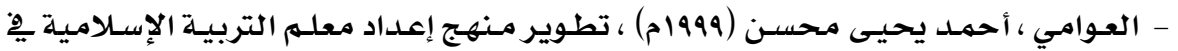

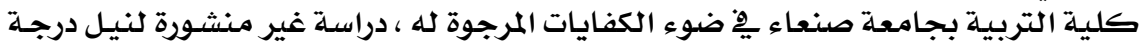

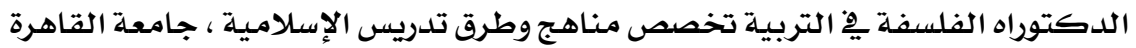

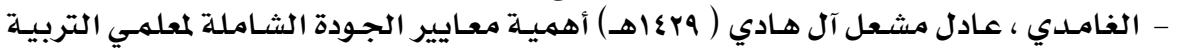

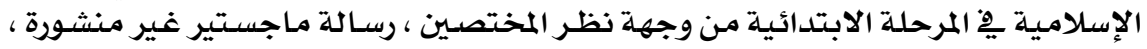

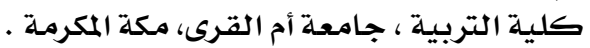

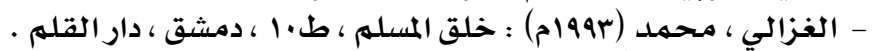

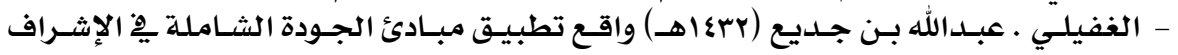

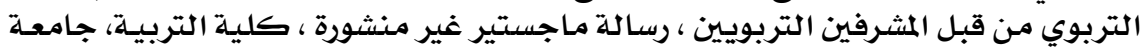

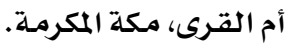

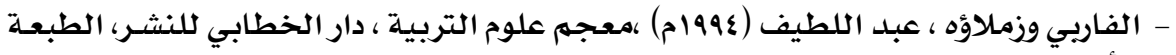
الأولى .

\section{$\varepsilon \wedge \vee$}




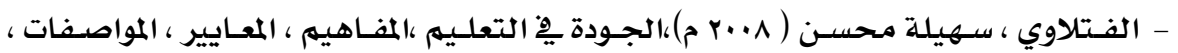

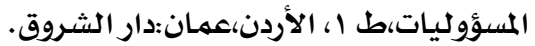

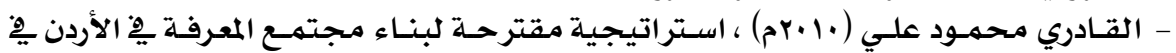

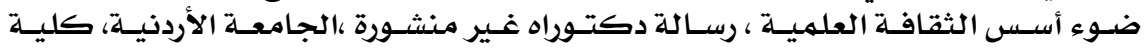

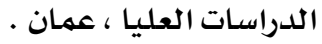

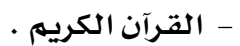

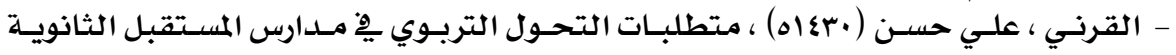

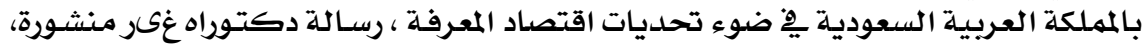

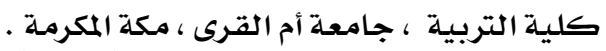

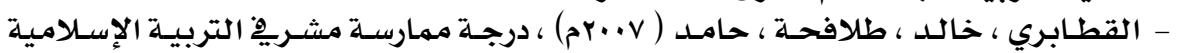

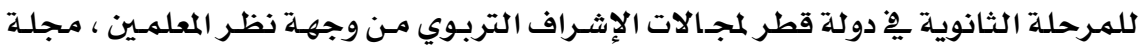

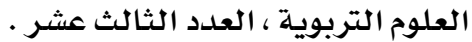

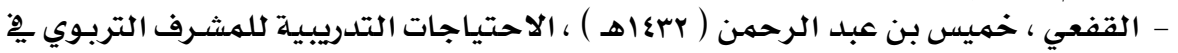

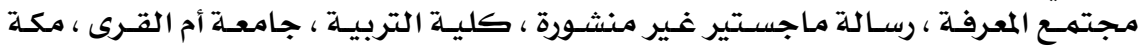
المكرمهة . مجتهـ المع

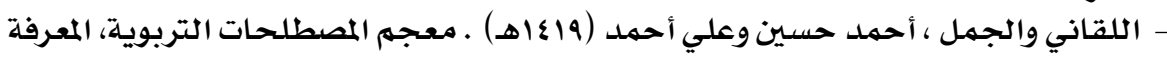

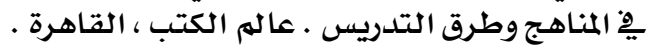

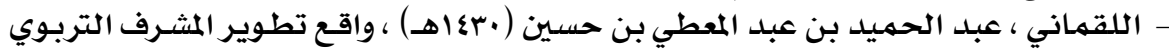

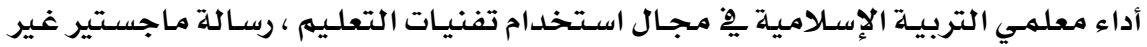

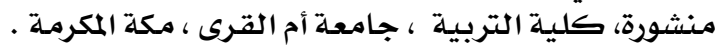

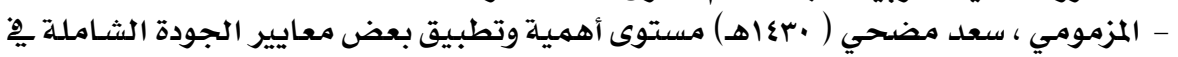

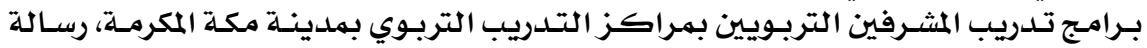

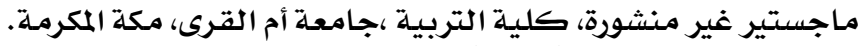

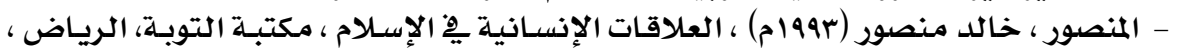

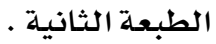

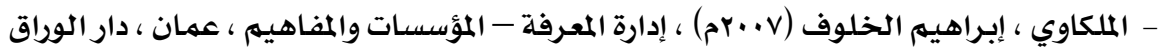

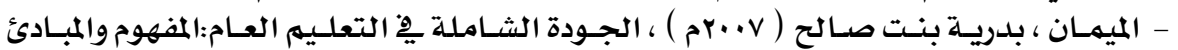

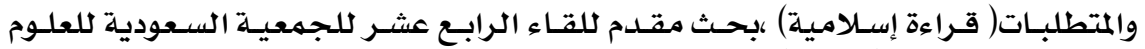

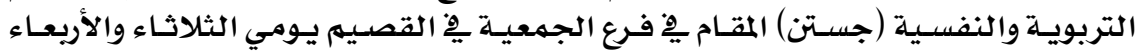

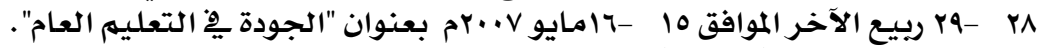

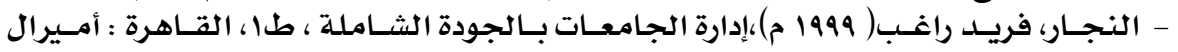

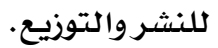

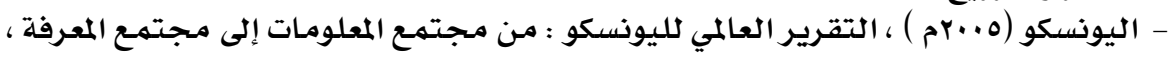

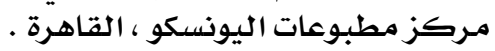

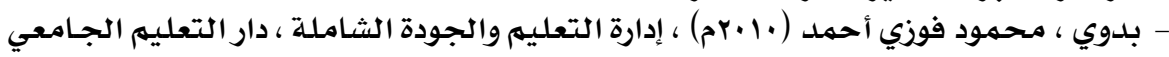

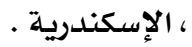

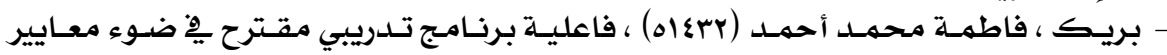

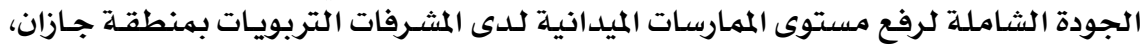

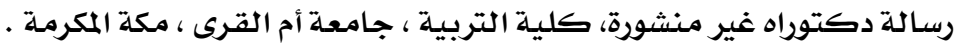

\section{$\varepsilon \wedge \wedge$}




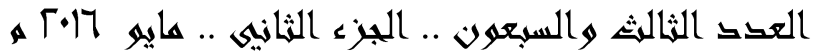

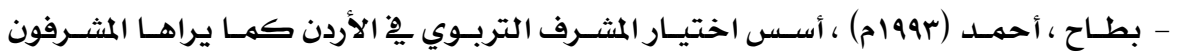

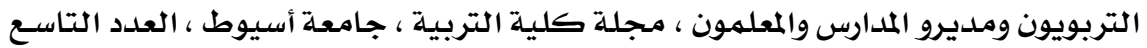

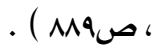

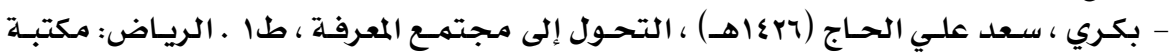

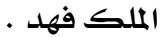

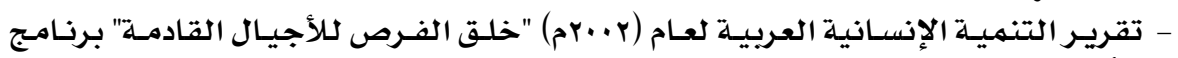

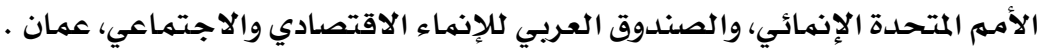

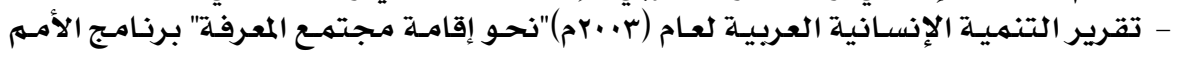

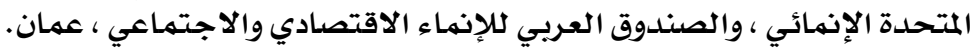

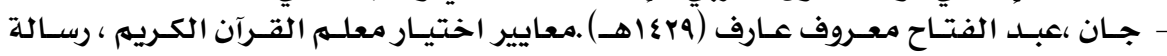

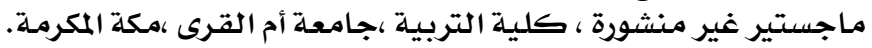

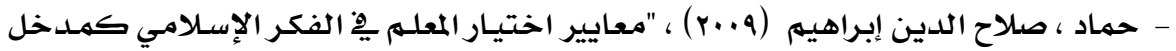

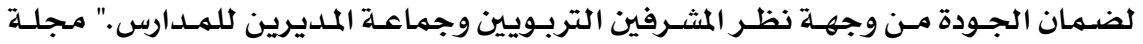

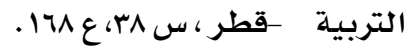

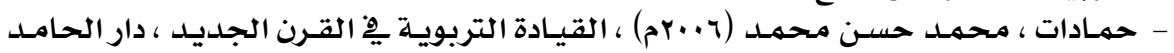

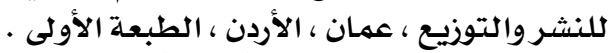

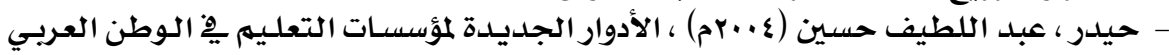

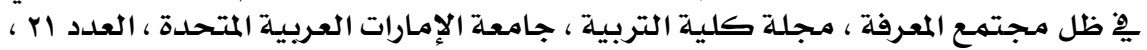

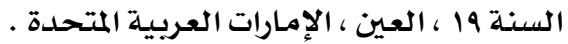

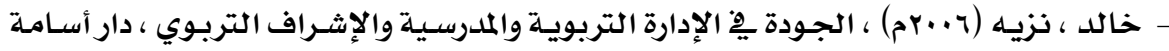

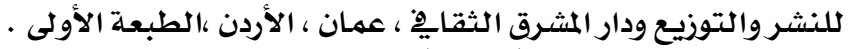

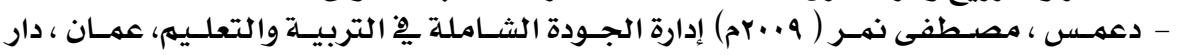

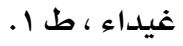

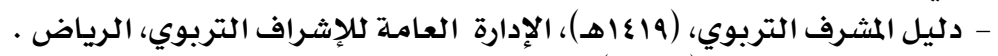

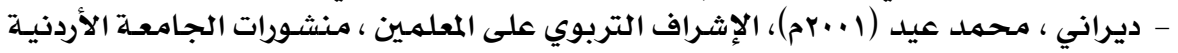

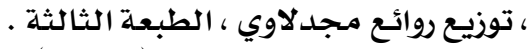

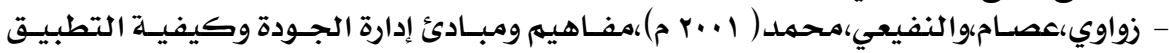

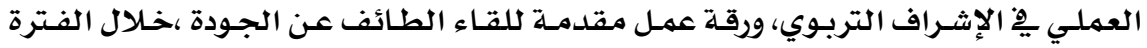

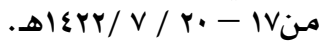

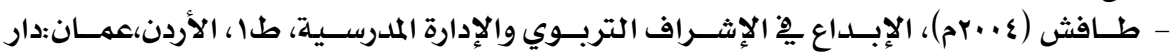

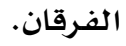

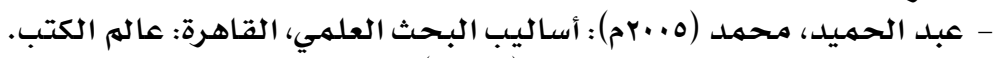

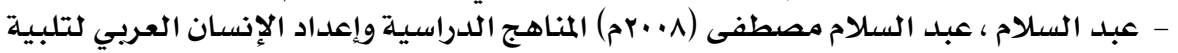

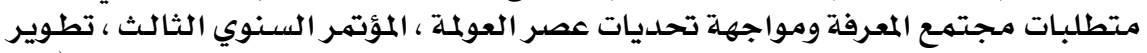

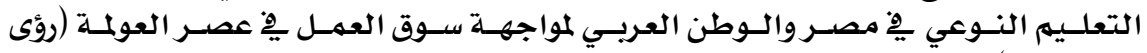

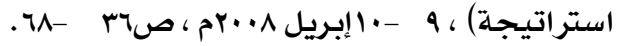

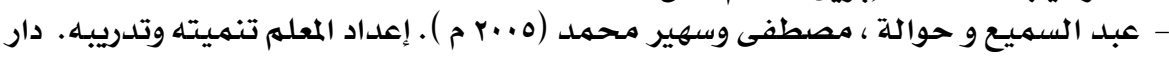

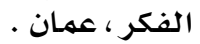

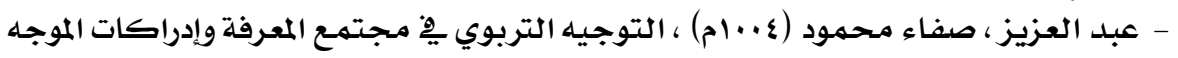

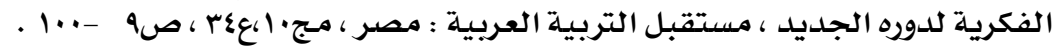

\section{$\varepsilon \wedge 9$}




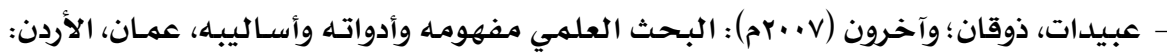
دار الفكر.

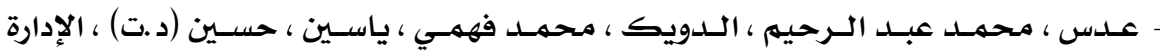

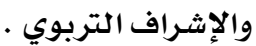

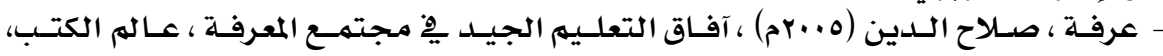

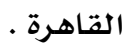

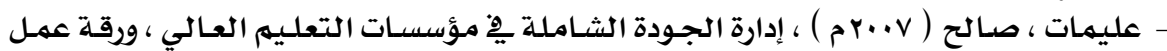

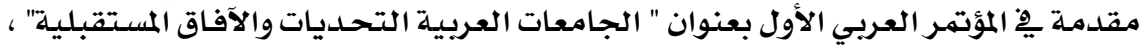

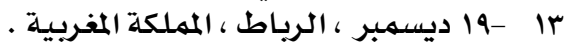

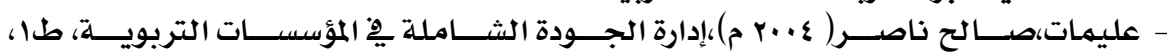
الأردن،عمان :دار الشرق.

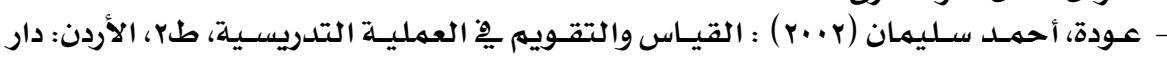

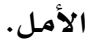

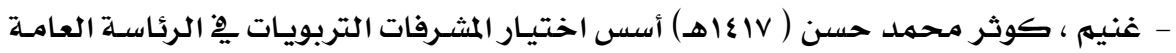

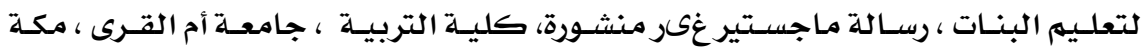

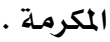

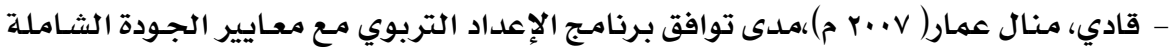

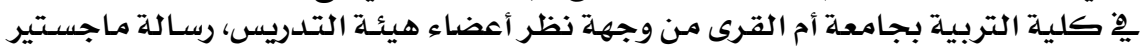

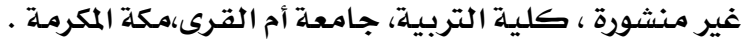

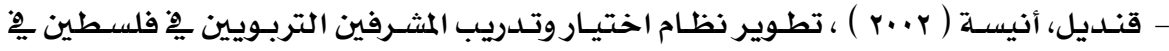

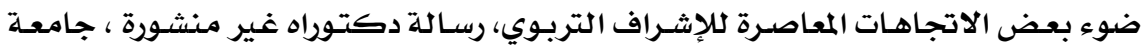

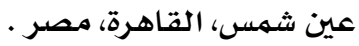

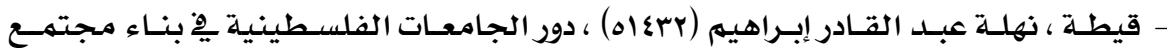

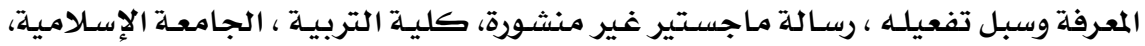
غزة .

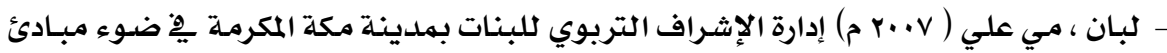

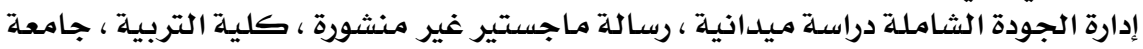

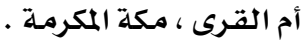

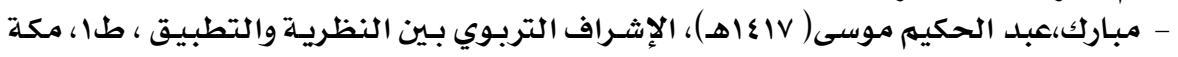
المكرمـة:مطابـع العمـرانيـة.

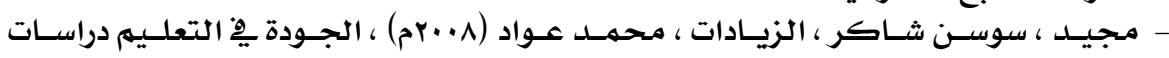

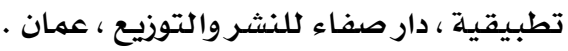

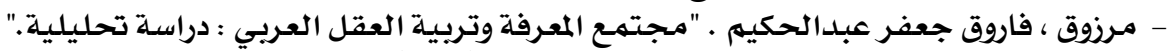

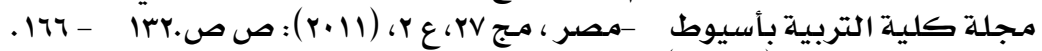

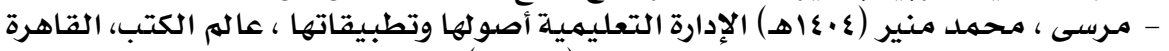

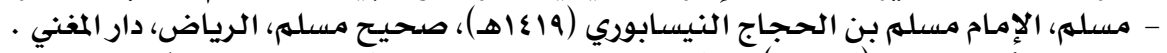

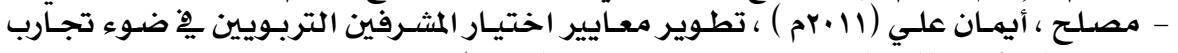

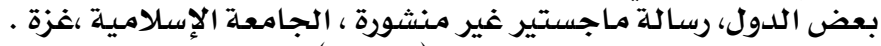

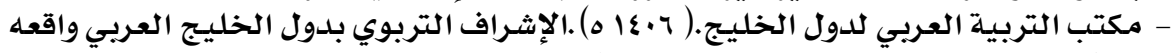

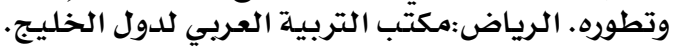

\section{$\varepsilon 9$.}




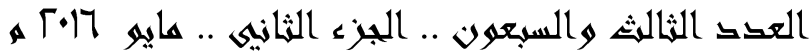

- منسي، محمد عبد الحليم (د.ت) : التقويم التربوي ومبـادئ الإحصاء، الإسكندرية، مركز

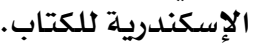

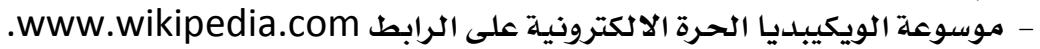

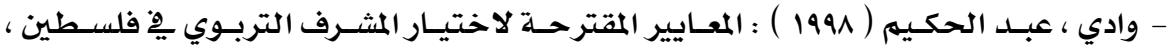

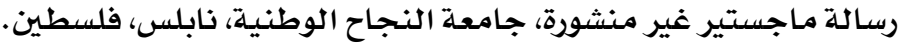

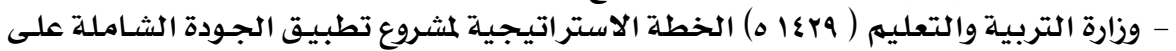

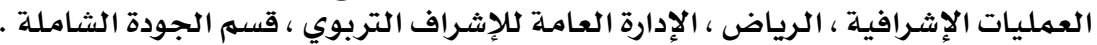

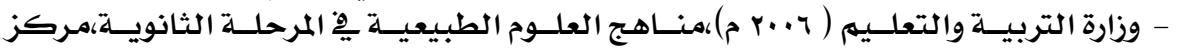

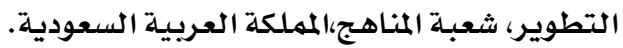

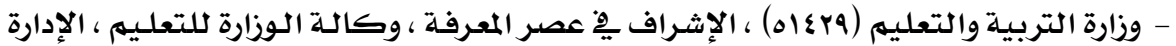

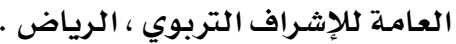

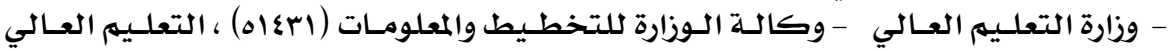

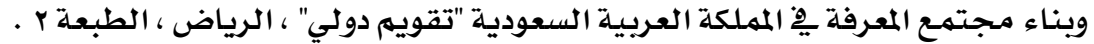

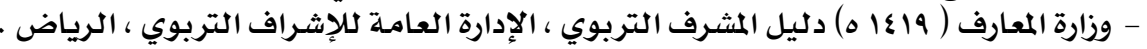

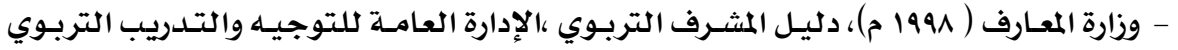

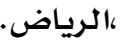

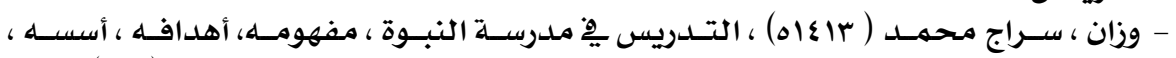

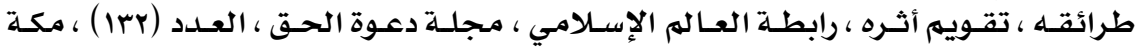

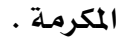

- Colvard, Fredrick Lee, (1986) Most Important Criteria For Public School Super Intendent Selecting As Perceived By School Presidents In Six Selected North Centeral Plains. State Dissertation Abstracts International , 47,143A.

- Detret , J . \& Others (2001) : Quality Management In Usa High School Evidence From The Field 1,2, School Leadership, Vol (10) P: 158-187.

- Gen, Y \& zhu, Z.(2007),(A learning framework for knowledge Building and collective Wisdom Advancement in Virtual Learning Communities" , educational technology and Society, v10,n 1, pp 206-266.

- Trap pen, William (2006) "A review of quality education concepts to improve teaching " (Dissertation, California state university , Dominguez hills) AAT 1427249.

\section{潾潾潾潾}

\section{\&q।}


